\title{
Social participation and health-related quality of life in adolescents with chronic musculoskeletal pain or chronic fatigue
}

Citation for published version (APA):

Westendorp, T. (2017). Social participation and health-related quality of life in adolescents with chronic musculoskeletal pain or chronic fatigue. [Doctoral Thesis, Maastricht University]. Ridderprint. https://doi.org/10.26481/dis.20171221tw

Document status and date:

Published: 01/01/2017

DOI:

10.26481/dis.20171221tw

Document Version:

Publisher's PDF, also known as Version of record

\section{Please check the document version of this publication:}

- A submitted manuscript is the version of the article upon submission and before peer-review. There can be important differences between the submitted version and the official published version of record.

People interested in the research are advised to contact the author for the final version of the publication, or visit the DOI to the publisher's website.

- The final author version and the galley proof are versions of the publication after peer review.

- The final published version features the final layout of the paper including the volume, issue and page numbers.

Link to publication

\footnotetext{
General rights rights.

- You may freely distribute the URL identifying the publication in the public portal. please follow below link for the End User Agreement:

www.umlib.nl/taverne-license

Take down policy

If you believe that this document breaches copyright please contact us at:

repository@maastrichtuniversity.nl

providing details and we will investigate your claim.
}

Copyright and moral rights for the publications made accessible in the public portal are retained by the authors and/or other copyright owners and it is a condition of accessing publications that users recognise and abide by the legal requirements associated with these

- Users may download and print one copy of any publication from the public portal for the purpose of private study or research.

- You may not further distribute the material or use it for any profit-making activity or commercial gain

If the publication is distributed under the terms of Article $25 \mathrm{fa}$ of the Dutch Copyright Act, indicated by the "Taverne" license above, 


\section{Social Participation and Health-Related Quality of Life in Adolescents with \\ Chronic Musculoskeletal Pain or Chronic Fatigue}

Tessa Westendorp 



\section{Social Participation and Health-Related Quality of Life in Adolescents with Chronic Musculoskeletal Pain or Chronic Fatigue}

Tessa Westendorp 
Cover design: Lieke Koster, Luuk Koster en Mark de Niet

Lay-out: $\quad$ Mark de Niet

Drukker: Ridderprint, Ridderkerk

ISBN: 978-94-6299-795-0

\section{(C) 2017 Tessa Westendorp}

All rights reserved. No part of this publication may be reproduced, stored in a retrieval system or transmitted in any form or by any means, without written permission of the author or, when appropriate, of the publishers of the publications. 


\title{
Social Participation and Health-Related Quality of Life in Adolescents with Chronic Musculoskeletal Pain or Chronic Fatigue
}

\author{
Proefschrift \\ ter verkrijging van de graad van doctor aan de Universiteit Maastricht, \\ op gezag van de Rector Magnificus, Prof. dr. Rianne M. Letschert \\ volgens het besluit van het College van Decanen, \\ in het openbaar te verdedigen \\ op donderdag 21 december 2017 om 16.00 uur
}

door

Tessa Westendorp 


\section{Promotores}

Prof. dr. Jeanine A. Verbunt

Prof. dr. Rob J. E. M. Smeets

\section{Copromotor}

Dr. Sylvia C. Remerie

\section{Beoordelingscommissie}

Prof. dr. A.J.H.M. Beurskens (voorzitter)

Dr. M.E.J.B. Goossens

Prof. dr. J. Passchier, VU University Amsterdam

Prof. dr. M.F. Reneman, UMCG Groningen

This thesis is supported by Kinderrevalidatie Fonds Adriaanstichting (KFA) and Stichting Erasmus Fonds Pijnbestrijding.

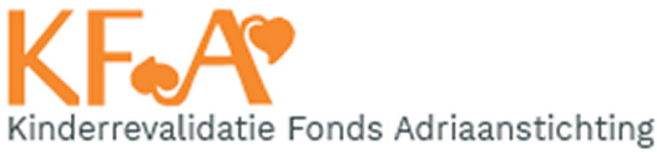

Their support is gratefully acknowledged. 
Voor mezelf 



\section{Inhoudsopgave}

Chapter 1 General Introduction 9

Chapter 2 Responsiveness of the Child Health Questionnaire - Parent 21

Form in adolescents with nonspecific chronic pain or fatigue

Chapter 3 Factors associated with school participation and healthrelated quality of life in adolescents with chronic musculoskeletal pain or chronic fatigue

Chapter 4 Multidisciplinary treatment for adolescents with chronic pain/fatigue. Who will benefit?

Chapter 5 Social functioning in adulthood: Understanding long-term outcomes of adolescents with chronic pain/fatigue treated at inpatient rehabilitation programs

Chapter 6 General Discussion

Chapter 7 Valorisation

Summary

Samenvatting

Dankwoord

About the author

List of publications 



\section{Chapter 1}

General Introduction 
Chronic pain and fatigue are both common complaints in childhood and adolescence. Prevalence rates vary from $4-40 \%$ for chronic pain, ${ }^{1-4}$ and $2-21 \%$ for chronic fatigue..$^{5-7}$ Both complaints can persist over time during childhood and adolescence. Even in $30 \%$ of the adolescents chronic pain was still present after two years, ${ }^{8}$ whereas almost $40 \%$ of adolescents with severe fatigue still reported complaints of fatigue after one year. ${ }^{9}$ Although only limited information on risk factors for persistence of complaints in adulthood is available, some studies indicate that pain or fatigue reported in childhood and adolescence are associated with pain or fatigue in adulthood. ${ }^{10,11}$ Chronic pain and fatigue can both have a considerable impact on an adolescent's daily functioning. ${ }^{1,5}$

In the Netherlands around the year 2000 healthcare providers in care for adolescents with chronic pain/fatigue made a shift in focus. They shifted from focussing on chronic pain/fatigue as a main focus towards focussing on the consequences for daily life and the potency to change the ability to live with these complaints. At that same time the Dutch Ministry of Health, Welfare and Sport (VWS) and the Netherlands Organisation for Health Research and Development (ZonMW) started to financially support several initiatives to gain further knowledge on pain, impairment in daily life and social functioning of people with chronic pain. Some of these initiatives were: The research network Low Back Pain and Disability (LoBaDis), the Pijn Kenniscentra (Pain Expertise Centers) and the Ontwikkelcentra Pijnrevalidatie (Expertise Development for Pain Rehabilitation Centers - OPR-en). Since 2004 Rijndam Rehabilitation and Health-care Group hosted both one of the four OPRen. Rijndam focussed on expertise development in children and adolescents with pain. The main reason was the increasing number of children and adolescents with chronic pain and fatigue who were referred for multidisciplinary rehabilitation treatment. The most important aim of the Rijndam OPR was to develop and provide knowledge regarding the characteristics of these adolescents with chronic pain/ fatigue and the consequences of their complaints. And, last but not least to increase the insight in the successfulness of multidisciplinary treatment.

In 2001, the Dutch Rehabilitation Expert Group of Children and Adolescents in Pain and Fatigue (werkgroep voor chronische pijn en vermoeidheid binnen de kinderrevalidatie) started a prospective cohort study to gain insight in the characteristics of the target population. Additionally, this expert group was interested in outcomes after treatment and related changes in health-related quality of life after clinical treatment. Data collection lasted till 2005. In 2010 the collaboration between Maastricht University and Rijndam Rehabilitation was officially established by starting a PhD trajectory, resulting in this thesis. For the purpose of the studies included in this thesis, data collected between 2001 and 2005 were used. Datacollection that started in 2001 was based on a set of measurements as selected by 
this Dutch expert group. This immediately implies that only those variables selected to be part of this dataset, were eventually available as potentially important factors.

\section{Aim of this thesis}

The main aim of this thesis is to gain more knowledge on social participation and health-related quality of life in adolescents with chronic musculoskeletal pain or chronic fatigue in relation to complaints, personal and environmental factors. In addition, successful rehabilitation treatment and long-term functioning of these adolescents in adulthood is studied.

Before describing the existing knowledge concerning the impact on the adolescent's life with pain/fatigue complaints, in this paragraph we will first introduce definitions for important variables as used in this thesis:

First, the focus of this thesis is on adolescent patients. Adolescence is the transition in development between youth and full adulthood, which represents a period in which a person organically, but not emotionally becomes mature. This thesis intends to give some insight into this specific period of a person's life who experiences pain or fatigue. The World Health Organisation (WHO) defines adolescence as the period of a person's life from 10 up to 20 years, ${ }^{12}$ which will also be used in this thesis.

Second, the definition of chronic musculoskeletal pain. This thesis focusses specifically on chronic pain related to the musculoskeletal system, since this type of pain - contrary to for example abdominal pain and headache - is the focus of multidisciplinary rehabilitation treatment in the Netherlands. Most common complaints are: low back pain, neck pain (including whiplash associated disorder), pain in limbs, fibromyalgia and pain related to complex regional pain syndrome. The pain is labelled to be chronic pain when it is present for more than six months, recurrently or continuously. ${ }^{13}$

And third, defining chronic fatigue. This thesis also concentrates on patients with chronic fatigue who are severely disabled in activities in daily living and therefore apply for multidisciplinary rehabilitation treatment. According to the Fukuda criteria, chronic fatigue syndrome (CFS) is characterized as severe and disabling new-onset fatigue that lasts for at least 6 months and is accompanied by 4 or more of the following symptoms: impaired memory or concentration, sore throat, tender cervical or axillary lymph nodes, muscle pain, multiple joint pain, new headaches, unrefreshing sleep, and post exertional malaise. Somatic and psychiatric illnesses should be excluded..$^{14}$ 


\section{Impact on the adolescent's life}

Chronic pain and fatigue can both have a considerable impact on the adolescent's life, especially on important domains of functioning, like school attendance, sports and leisure time activities..$^{13,15}$ Several studies illustrate different aspects of the impact on the adolescent's life. Crawley \& Sterne (2009) found poor physical functioning and low mood. ${ }^{15}$ Perquin et al. (2001) showed high use of health care services $(43 \%)^{16}$ and Hunfeld et al. (2001) reported a negative impact on quality of life. ${ }^{17}$ The influence of chronic pain and fatigue in adolescents is often not only limited to the individual person. Missen et al. (2012) concluded marked impact on maternal psychological health. ${ }^{18}$ Also the impact of these chronic conditions on society has been studied and appears to be enormous, ${ }^{19}$ for instance due to reduced or absent (future) workability. Adolescents with pain/fatigue are often not able to function at the same level as their peers and as a consequence, their future perspective regarding school and work career is at stake. The financial burden for the family that occurs when one of their members is an adolescent with chronic fatigue syndrome (CFS), is high. ${ }^{18}$

Pain and fatigue can also have a considerable impact on quality of life. The WHO defines quality of life as an individual's perception of his position in life in the context of the culture and value systems in which the individual lives and in relation to his goals, expectations, standards and concerns. ${ }^{20}$ Health-related quality of life (HRQoL) is considered to be an important aspect of an individual's health status. To assess HRQoL, information is required about subjective aspects of health, wellbeing and behaviour. ${ }^{21} \mathrm{HRQOL}$ is therefore an important outcome variable in clinical studies on interventions aiming to increase quality of life. ${ }^{22}$ There are however, only a few instruments that specifically can measure HRQoL in adolescents with chronic pain or fatigue. Of the measures available in the Dutch language complete information on the psychometric properties is not available.

Currently only limited information is available on the long-term consequences regarding functioning and social participation. Social participation refers to the person-in-society, also described as 'involvement in a life situation' ${ }^{23}$ Results of two 13-year-follow-up surveys indicate that pain and fatigue reported in adolescence are both associated with pain or fatigue in early adulthood..$^{10,11}$ However the impact of pain/fatigue on the level of participation is still unidentified.

A framework often used in rehabilitation to express the impact of complaints on a person's life is the International Classification of Functioning, Disability and Health (ICF) developed by the WHO. ${ }^{24}$ The ICF describes three levels of functioning: body function and structure, activity and participation. ${ }^{24}$ These levels of functioning might have consequences for HRQoL. Therefore, HRQoL can be considered as an 
overall component. In addition, personal and environmental factors can interact with the different levels of functioning. An overview of the ICF-model integrated with HRQoL as an overall additional aspect, for the specific conditions chronic musculoskeletal pain and chronic fatigue is shown in figure 1.

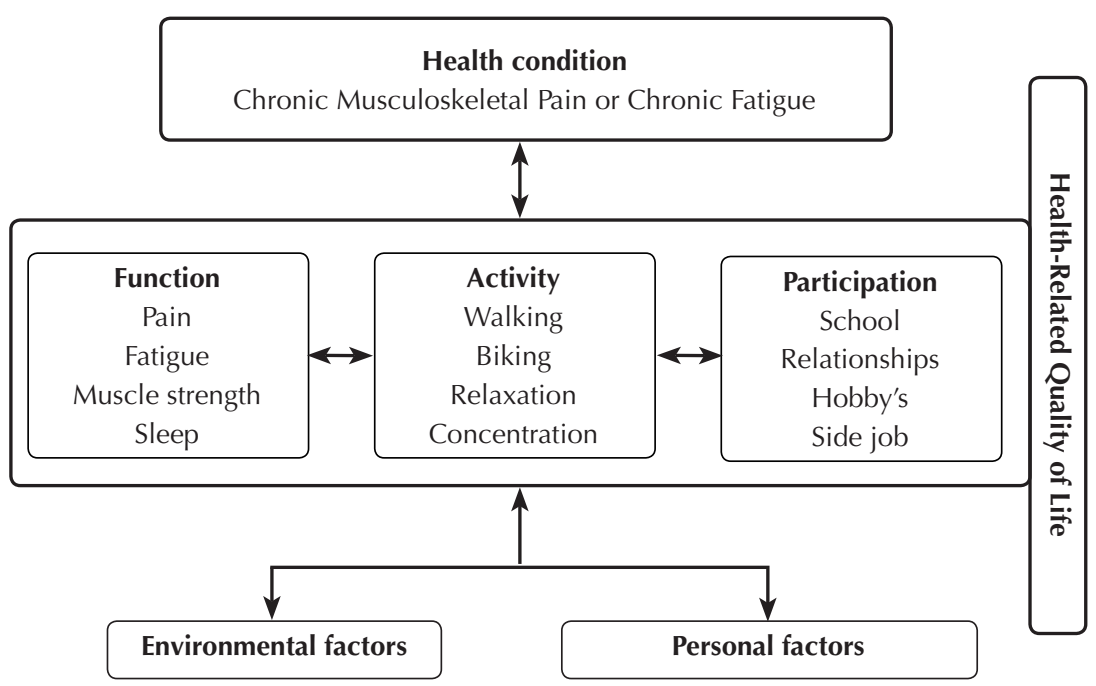

Figure 1: ICF-model, in which HRQoL is integrated, as a framework of an adolescent with chronic musculoskeletal pain or chronic fatigue in relation to this thesis

Despite the sparsely available literature on the impact of chronic pain and fatigue in adolescents, it is recognised by clinicians as well as patients and their families that chronic pain and fatigue affect social participation and HRQoL of an adolescent. But it is not known what factors indeed do influence the level of participation and HRQoL of adolescents being chronically in pain or fatigued. Using the ICFmodel as a starting point, it can be hypothesized that the chronic pain/fatigue related functions, activity limitations, environmental factors, and personal factors can be influencing factors for the adolescent's social participation and HRQoL. At present time, we have not identified these factors adequately, let alone properly studied their exact role in participation and HRQoL. Identifying these factors and subsequently trying to influence them, might result in a positive effect on social participation and HRQoL. 


\section{Rehabilitation treatment}

In the Netherlands during the period between 2001-2005, the period of this cohort study, highly disabled adolescents due to chronic musculoskeletal pain or chronic fatigue were mostly treated in a clinical rehabilitation setting. Currently these treatment programs are also offered in outpatient clinics. The main aim of rehabilitation treatment is to increase the level of participation, despite pain and/ or fatigue. The impact of pain and fatigue on functioning can differ considerably between persons. The inpatient rehabilitation treatment provided to the adolescents who were part of the cohort study was based on cognitive behavioural treatment principles, using elements such as cognitive behavioural therapy including graded activity, relaxation, education and involvement of and counselling for parents. A multidisciplinary approach was used to optimise the important domains of social functioning, like school participation, sports and leisure time. Most of the treatment provided was individual treatment, whereas the relaxation and education modules were sometimes provided in groups. During treatment, the weekend leaves were progressively extended to facilitate school reintegration. ${ }^{25}$

\section{Study cohorts}

This thesis contains results gained from data of two cohorts of adolescents. Participants in both cohorts received the inpatient rehabilitation treatment as described for chronic musculoskeletal pain or chronic fatigue. The first cohort is the National cohort, initiated in 2001 by the Dutch Rehabilitation Expert Group for Children and Adolescents in Pain and Fatigue. These adolescents participated in inpatient rehabilitation treatment between 2001 and 2005 in five different rehabilitation centers; Rijndam Rehabilitation, De Trappenberg rehabilitation (nowadays Merem Rehabilitation), Rehabilitation Friesland, Roessingh rehabilitation center and De Hoogstraat rehabilitation center (chapter 2, 3, 4 and 5). The second cohort is the so called Friesland cohort consisting of adolescents provided with inpatient rehabilitation treatment for chronic pain at Rehabilitation Friesland between 1992 and $2000^{26}$ and were involved in the study described in chapter 5 . The content of the treatments provided in the five participating centers was based on the consensus report for treatment in Dutch rehabilitation centers for children with pain and fatigue. $^{25}$

\section{Outline of this thesis}

In this part the further outline of this thesis is described. As pain and fatigue can have a tremendous impact on quality of life, it is important to assess quality of life accurately. The Child Health Questionnaire $(\mathrm{CHQ})$ is a frequently used instrument for measuring the important outcome variable HRQoL and has a separate child and 
parent form. Evidence on the validity and reliability is available, but information regarding the responsiveness of the Dutch $\mathrm{CHQ}$ was lacking. Therefore, we will study the responsiveness of the $\mathrm{CHQ}$ in chapter 2, specifically the parent form. Clinicians could benefit from insight into the responsiveness of this measurement to interpret the clinical relevance of changes in scores on the $\mathrm{CHQ}$ after an intervention.

In chapter 3 we will identify associating factors for social participation (assessed as school absence) and HRQoL (assessed with CHQ) before the start of treatment. In chapter 3 data of the National cohort are used to gain insight into these factors.

In chapter 4 the successfulness of multidisciplinary rehabilitation treatment for adolescents with chronic pain/fatigue will be investigated. We will first define treatment success and the assessment of this variable. Data from the National cohort will be used in this study. Furthermore, potentially influencing factors for successful treatment will be studied, with a specific focus on factors that can possibly be influenced by treatment as provided in multidisciplinary rehabilitation teams.

In chapter 5 the focus is on long term functioning of adolescents with chronic pain or fatigue who had inpatient rehabilitation during puberty. How do adolescents confronted with chronic pain and fatigue in adolescence function as young adults (10 year follow-up)? In this chapter predictors for long-term social participation are subject of study. In addition, we will focus on the current life situation of young adults still dealing with pain/fatigue complaints. Participants from the National cohort and the Friesland cohort will be included.

In figure 2 the schematic outline of this thesis is presented.

The general discussion (chapter 6) will provide a critical appraisal on the overall findings of the different studies. Furthermore, methodological considerations and clinical implications will be presented. In this chapter also directions for future research will be recommended and final conclusions will be made.

Finally, in chapter 7 valorisation opportunities of our findings will be described. 


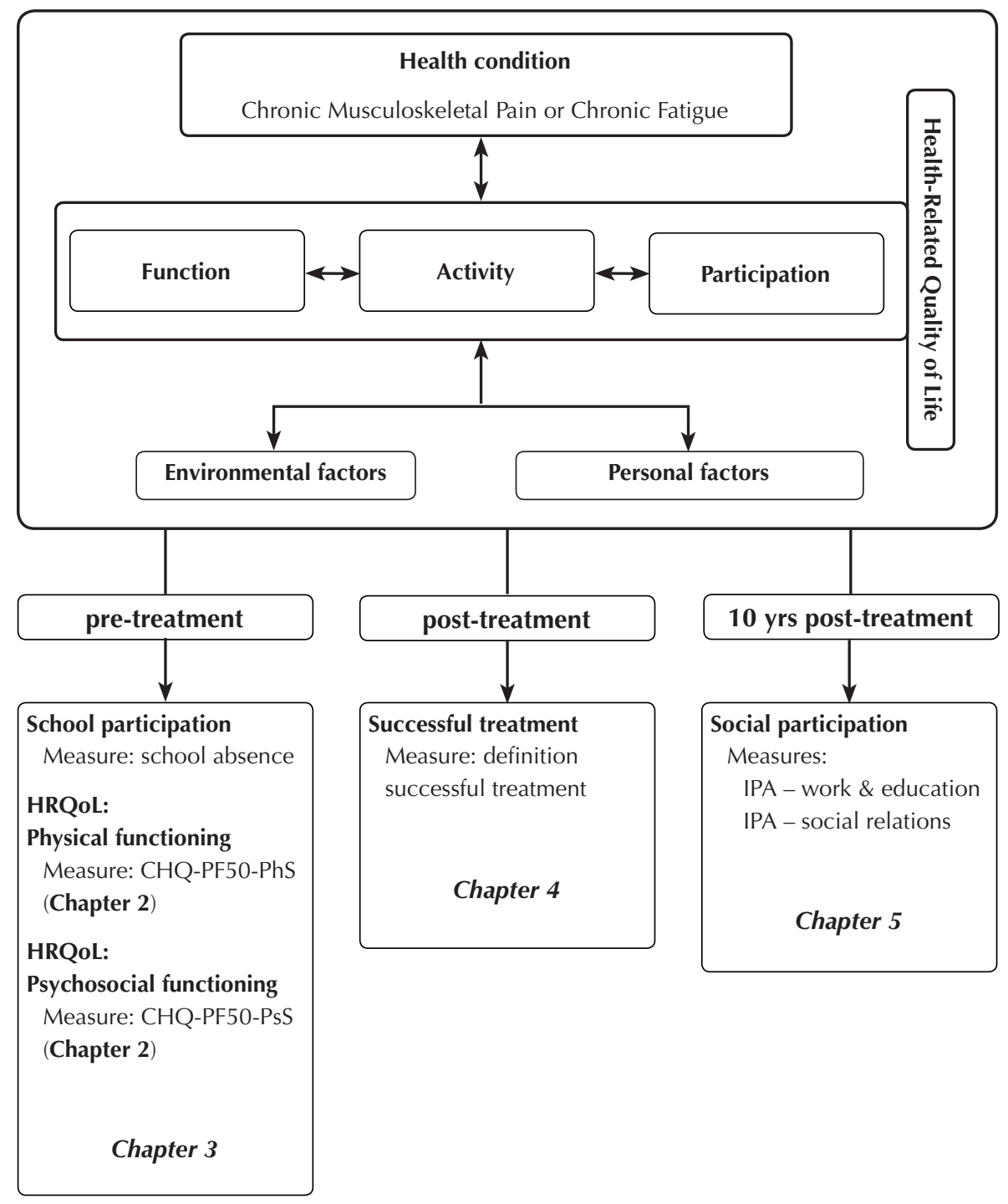

Figure 2: Schematic outline of this thesis 


\section{References}

1. Haraldstad, K., et al., Pain in children and adolescents: prevalence, impact on daily life, and parents' perception, a school survey. Scand J Caring Sci, 2011. 25(1): p. 27-36.

2. King, S., et al., The epidemiology of chronic pain in children and adolescents revisited: a systematic review. Pain, 2011. 152(12): p. 2729-38.

3. Konijnenberg, A.Y., et al., Children with unexplained chronic pain: substantial impairment in everyday life. Arch Dis Child, 2005. 90(7): p. 680-6.

4. Perquin, C.W., et al., Pain in children and adolescents: a common experience. Pain, 2000. 87(1): p. 51-8.

5. Crawley, E., The epidemiology of chronic fatigue syndrome/myalgic encephalitis in children. Arch Dis Child, 2014. 99(2): p. 171-4.

6. Farmer, A., et al., Prevalence of chronic disabling fatigue in children and adolescents. $\mathrm{Br}$ J Psychiatry, 2004. 184: p. 477-81.

7. ter Wolbeek, M., et al., Severe fatigue in adolescents: a common phenomenon? Pediatrics, 2006. 117(6): p. e1078-86.

8. Perquin, C.W., et al., The natural course of chronic benign pain in childhood and adolescence: a two-year population-based follow-up study. Eur J Pain, 2003. 7(6): p. 551-9.

9. ter Wolbeek, M., et al., Predictors of persistent and new-onset fatigue in adolescent girls. Pediatrics, 2008. 121(3): p. e449-57.

10. Bell, D.S., K. Jordan, and M. Robinson, Thirteen-year follow-up of children and adolescents with chronic fatigue syndrome. Pediatrics, 2001. 107(5): p. 994-8.

11. Brattberg, G., Do pain problems in young school children persist into early adulthood? A 13-year follow-up. Eur J Pain, 2004. 8(3): p. 187-99.

12. WHO, Health for the World's Adolescents. A second chance in the second decade., ed. W.H. Organization. 2014, Geneva: WHO-press.

13. Merskey, H. and N. Bogduk, IASP Task Force on Taxonomy Classification of Chronic Pain. 1994, IASP.

14. Fukuda, K., et al., The chronic fatigue syndrome: a comprehensive approach to its definition and study. International Chronic Fatigue Syndrome Study Group. Ann Intern Med, 1994. 121(12): p. 953-9.

15. Crawley, E. and J.A. Sterne, Association between school absence and physical function in paediatric chronic fatigue syndrome/myalgic encephalopathy. Arch Dis Child, 2009. 94(10): p. 752-6.

16. Perquin, C.W., et al., Insights in the use of health care services in chronic benign pain in childhood and adolescence. Pain, 2001. 94(2): p. 205-13.

17. Hunfeld, J.A., et al., Chronic pain and its impact on quality of life in adolescents and their families. J Pediatr Psychol, 2001. 26(3): p. 145-53.

18. Missen, A., et al., The financial and psychological impacts on mothers of children with chronic fatigue syndrome (CFS/ME). Child Care Health Dev, 2012. 38(4): p. 505-12.

19. Sleed, M., et al., The economic impact of chronic pain in adolescence: methodological considerations and a preliminary costs-of-illness study. Pain, 2005. 119(1-3): p. 183-90

20. WHO, WHOQOL-100, the 100 questions with response scales, D.o.M.H. The WHOQOL group, Editor. 1995, World Health Organisation, Division of Mental Health: Geneva. 
21. Cantrell, M.A. and M.M. Kelly, Health-related quality of life for chronically ill children. MCN Am J Matern Child Nurs, 2015. 40(1): p. 24-31.

22. Terwee, C.B., et al., On assessing responsiveness of health-related quality of life instruments: guidelines for instrument evaluation. Qual Life Res, 2003. 12(4): p. 349-62.

23. Piskur, B., et al., Participation and social participation: are they distinct concepts? Clin Rehabil, 2014. 28(3): p. 211-20.

24. WHO, ICF, Nederlandse vertaling van de 'International classification of functioning, disability and health'. ed. W.-F.C. Centre. 2002, Houten: Bohn Stafleu van Loghum.

25. Dutch Rehabilitation Expert Group for Children and Adolescents in Pain and Fatigue, Elements of treatment for chidren and adolescents with chronic musculoskeletal pain consensus report. 2008, Rotterdam: Rijndam Rehabilitation.

26. de Blecourt, A.C., et al., Preliminary evaluation of a multidisciplinary pain management program for children and adolescents with chronic musculoskeletal pain. Disabil Rehabil, 2008. 30(1): p. 13-20. 




\section{Chapter 2}

\section{Responsiveness of the Child Health Questionnaire - Parent Form in adolescents with nonspecific chronic pain or fatigue}

Tessa Westendorp, Jeanine A. Verbunt, Sylvia C. Remerie, Rob J.E.M. Smeets European Journal of Pain 2014;18;540-547. 


\begin{abstract}
Background: The Child Health Questionnaire is a widely used instrument for measuring health-related quality of life covering both the physical and psychosocial domain. This study examined the responsiveness of the Dutch CHQ 50-item Parent Form (PF50) in a sample of adolescents with chronic nonspecific pain and/or fatigue.
\end{abstract}

Method: Five different methods were used to calculate the responsiveness for the physical (PhS) and psychosocial (PsS) subscale of the CHQ-50: Standardized response mean (SRM), pooled effect sizes (ES), standard error of measurement of agreement (SEMagreement), minimal detectable change (MDC) and the area under the receiver operating characteristics (ROC) curve. For data analysis the population was divided into two groups based on the parent's global perceived effect of treatment, a changed group (A) and an unchanged group (B).

Results: The responsiveness analyses were performed including 92 adolescents (88.0\% girls; mean age 16.4 years). The SRM are 2.89 and 1.01 for the PhS and PsS, respectively. Large ES are found for Group A (PhS=3.30; PsS=1.16). The method used for calculating SEMagreement results in a score of $\mathrm{PhS}=18.92$ and $\mathrm{PsS}=11.39$. The MDC of PhS and PsS are 52.45 and 31.57, respectively. The area under the ROC curve $(\mathrm{AUC}$ ) for $\mathrm{PhS}=0.79$ and for $\mathrm{PsS}=0.64$, and the corresponding optimal cut-off points are 21.1 and 7.0.

Conclusion: Using the methods SRM, ES and AUC, the responsiveness of the CHQ-PF50 in adolescents with nonspecific chronic pain or fatigue treated in a rehabilitation clinic is adequate for the physical scale and moderate for the psychosocial scale. 


\section{Introduction}

An important outcome measure in clinical studies is health-related quality of life (HRQOL). ${ }^{1}$ The Child Health Questionnaire (CHQ) is an instrument developed for measuring health-related quality of life covering both the physical and psychosocial domain. ${ }^{2,3}$ The $\mathrm{CHQ}$ has been translated, and applied in general populations as well as in populations of chronically ill children. ${ }^{4-6}$ Two forms of the $\mathrm{CHQ}$ are available; a child and a parent form. The most frequently applied CHQ-version is the 50-item Parent Form (CHQ-PF50), designed to be filled out by parents of children 5 to 18 years of age. ${ }^{3}$ The $\mathrm{CHQ}$ has been translated and its psychometric properties were tested for application in various countries. Its validity and reliability have been evaluated for Germany, the UK, the French-speaking part of Canada, ${ }^{2}$ Australia, ${ }^{7}$ Norway, ${ }^{8}$ Italy, ${ }^{9}$ and the Netherlands. ${ }^{10}$ Although evidence on its validity and reliability in various language versions is available, information regarding the responsiveness of the $\mathrm{CHQ}$ is rather limited.

Responsiveness can be defined as the ability to detect clinically important changes over time (even if these changes are small), and to differentiate these from measurement errors. ${ }^{11}$ Responsiveness as measurement property enables clinicians to interpret the clinical relevance of score changes after an intervention period. ${ }^{11}$ So far, the $\mathrm{CHQ}$ responsiveness has been studied in children with acute asthma ${ }^{12}$ and juvenile idiopathic arthritis. ${ }^{13}$ Gorelick et al. (2003) reported moderate responsive scores to acute changes in functional status on the physical and psychosocial subscales of the CHQ-PF28 in children with acute asthma. Selvaag et al. (2003) demonstrated that the CHQ-PF50 is sensitive to clinically relevant changes in children with juvenile idiopathic arthritis. In adolescents with chronic nonspecific pain and/or fatigue the responsiveness and clinical relevance of score changes have never been investigated. Chronic pain and chronic fatigue share a considerable impact on the child's or adolescent's life. ${ }^{14,15}$

The aim of our study is to determine the responsiveness of the Dutch 50-item parent version of the $\mathrm{CHQ}$ in a sample of adolescents with chronic nonspecific pain and/ or fatigue. Based on existing literature, our hypothesis is that the CHQ-PF50 is responsive and feasible as a measure for $\mathrm{HRQ}$ oL in various populations.

\section{Methods}

\section{Study population}

The study population consists of 172 adolescents $(85.7 \%$ girls, mean age: 16.2 years) with chronic pain or fatigue and their parents who participated in a prognostic cohort study during the period between 2001 and 2005. Patients entered the study 
in a chronological order. A rehabilitation physician decided whether the patient should be provided an inpatient treatment on the basis of the following aspects; the severity of chronic pain and/or fatigue and its associated disability, school absence and psychological and/or social factors influencing the persistence of the chronic pain/fatigue. Patients were eligible for the study when they followed an inpatient clinical rehabilitation treatment for chronic pain/fatigue (with one of the following ICD-diagnoses; 723.9 nonspecific neck complaints, 724.2 nonspecific back complaints, 729.1 fibromyalgia, 729.9 other nonspecific complaints, 733.7 complex regional pain syndrome or 780.7 chronic fatigue syndrome) in one of 5 participating Dutch rehabilitation centers. From the treatment perspective that the primary goal of rehabilitation treatment is to improve the level of functioning and participation despite the chronic pain and/or fatigue, we combined the data of adolescents with pain and fatigue for this study. The adolescents with chronic pain and chronic fatigue received the same treatment in all participating centers. This inpatient treatment is based on cognitive behavioral treatment including elements as graded activity, cognitive behavioral therapy, relaxation, education and involvement and counseling of the parents. During treatment the weekend leaves are progressively extended to facilitate patients in partly resuming school participation. The outline of the treatment was the same in all participating centers. The average treatment time was 14.6 weeks ( $\mathrm{SD}=9.5)$.

\section{Procedure}

Before the start and directly after the end of the clinical treatment both the adolescent and one of the parents filled out a booklet with several questionnaires. In the booklet the adolescent scored his/her pain/fatigue on a VAS (0-100), and his/ her parent filled out the CHQ 50 item form. The same parent, who had filled out the CHQ before treatment, was asked to fill out the CHQ after treatment. In addition, immediately after treatment, both the adolescent and the parent rated the global perceived effect of treatment. Besides, the physician had to answer the question about global perceived effect. This question will be described in more detail in the paragraph of the external criterion. Only the data of the parent's global perceived effect will be used as external criterion.

The questionnaires that were filled out by the adolescents and parents were part of the clinical assessment procedure as part of the clinical rehabilitation treatment. Therefore, and the fact that this is a study on an anonymous database, no approval of the Medical Ethical Committee (MEC) is required in the Netherlands. 


\section{Outcome instrument: The Child Health Questionnaire-Parent Form}

The CHQ-PF50 consists of 50 items divided in 11 multi-item scales ( 3 to 6 items) and 2 single-item scales. Examples of items in the Parent Form are: 'What is your child's general health?', 'How often in the past four weeks did your child lie or cheat?' and 'How satisfied do you think your child was in the past four weeks in his/ her relation with family members?' Each CHQ-item has 4, 5 or 6 response options. Following the $\mathrm{CHQ}$ standard procedure, the scale item scores are summed and transformed into a score ranging from 0 (worst possible health state) to 100 (best possible health state). ${ }^{16}$ Higher scores indicate a better-perceived health.

For the CHQ-PF50 a "Physical" (PhS) and "Psychosocial" (PsS) CHQ summary score the mean norm score for cross-cultural general populations is $50(\mathrm{SD} \pm 10) .{ }^{16}$ According to the method of Landgraf et al. (1996) PhS and PsS summary scale scores are calculated by aggregating and transforming the 11 multi-item scale scores using a linear T-score transformation method. ${ }^{16}$ We used the PhS and PsS CHQ-PF50 summary scores for data analysis in this study.

\section{External criterion: Global perceived effect of treatment}

The primary external criterion used in this study is the parent's judgment about the result of treatment. At the end of treatment the parent was asked to fill out a 1-item questionnaire to score the perceived effect of treatment, which was operationalized as the perceived change in complaints and limitations of his/her child. The parent rated the treatment effect using the following scale; (1) no complaints and restrictions, (2) complaints but no restrictions, (3) complaints and less restrictions, (4) unchanged, (5) the problem worsened.

Consecutively, three groups were formed based on the leading principle of treatment to focus on reducing the child's restrictions in daily life functioning. Group (A) contained subjects whose parent reported that he/she was free of restrictions post-treatment. This group, labeled as 'changed' included the original scores (1) en (2), indicating that the child had no restrictions, which is the main aim of rehabilitation treatment, compared to the situation before treatment. Group (B), called 'unchanged' contained subjects whose parent reported that he/she was still restricted post-treatment and included the original scores (3) and (4). Group (C) contained subjects whose parent reported that he/she deteriorated and included the score (5). As described in other studies, for the responsiveness analyses the changed group (Group A) and the unchanged group (Group B) are used. ${ }^{17,18}$

Also in other studies the same 1-item questionnaire construction, with categorizing the answers in 'changed' and 'unchanged', to determine the responsiveness has been used..$^{17,18}$ 


\section{Data analysis}

A paired t-test was used to compare pre- and post-treatment CHQ-PF50 scores for subjects in groups A, B and C based on the parent's perceived effect of treatment.

The following five methods for the evaluation of responsiveness with the PhS and PsS CHQ summary scores were used:

Standardized response means (SRM) were calculated by dividing the mean change score of Group A by the standard deviation of this change score. ${ }^{19}$ The higher the standardized response mean, the better the responsiveness.

Pooled effect sizes (ES) were calculated by dividing the mean change score of Group $\mathrm{A}$ by the pooled standard deviation this group $\left(\mathrm{SD}_{\text {pooled improved }}\right)$, in which $\mathrm{SD}_{\text {pooled improved }}=\sqrt{ }\left[\left(\mathrm{SD}_{\text {before treatment }}^{2}+\mathrm{SD}_{\text {after treatment }}^{2}\right) / 2\right] \cdot{ }^{19}$ Effect sizes are labeled as large when exceeding $0.80 .{ }^{20}$

Standard error of measurement of agreement (SEM $M_{\text {agreement }}$ ) equals the square root of the within variance minus the subject variance, including systematic differences. The within variance is based on variance between measures (pre and post-treatment), to account for systematic error between measurements. The subject variance is the residual variance of Group B subjects corresponding to the interaction between subjects and measurements. ${ }^{11}$

Smallest detectable change or minimal detectable change (MDC) is the minimal amount of change above the measurement error with a given level of confidence, usually $95 \%$ confidence level. MDC was calculated as follows: $1.96 \times \sqrt{ } 2 \times$ standard error of the measurement. ${ }^{21}$ In this equation 2 equals the number of measurements of the group that reported to be unchanged (group B).

The area under the receiver operating characteristics (ROC) curve (AUC) is the last measure of responsiveness. In this analysis, group A and B are both involved, because it is a measure of the ability of a questionnaire to distinguish subjects who have and have not changed. ${ }^{11}$ The AUC of an ROC curve represents the probability that scores will correctly discriminate between Group A and B. An area of 0.7 to 0.8 is defined as acceptable and an area of 0.8 to 0.9 as excellent. ${ }^{22}$ The best discrimination between groups of patients can be expressed in scores of the greatest sensitivity and/or specificity. A sensitivity of 1 indicates that all true positives are identified, whereas a specificity of 1 indicates that all true negatives are identified. ${ }^{22}$ The optimal cutoff point, which is the closest point to the left upper corner of the graph, was estimated by choosing the point for which sensitivity and specificity jointly minimize the total error in misclassification. In case two or more cutoff points lead to an identical error in misclassification, the point with the highest sensitivity was considered as the optimal cutoff point. ${ }^{17}$ 
Independent t-tests were performed to verify for differences in the pre-treatment characteristics; age, gender, duration of complaint and VAS-score for pain or fatigue between the patients not included in this study and those whose data were used for determining responsiveness. Also independent t-tests were applied, in case of a normal distribution of data, to check for differences between parent, child and rehabilitation physician global perceived effect scores.

\section{Results}

Of the 172 patients included in the cohort study, 14 parents did not fill out the CHQPF50 at the start of treatment and 63 parents did not complete this questionnaire at the end of treatment. Ninety-two out of 95 parents gave a judgment about the result of treatment. Table 1 provides the characteristics of the remaining 92 adolescents used for the responsiveness analyses, also subdivided into a chronic pain and chronic fatigue group. Patients with all data available $(n=92)$ did not differ regarding age, gender, duration of complaint, VAS-score for pain/fatigue and summary scores of the CHQ-PF50 before treatment from patients with no complete dataset $(n=80)$.

Table 2 shows the number of parents per category of global perceived effect of treatment. Only one parent reported that his/her child was deteriorated, and this number is far too low to compare to groups A and B. No significant differences were seen between the ratings on the global perceived effect regarding the treatment given by the parent, child or rehabilitation physician (data not presented).

Table 3 shows mean CHQ-PF50 PhS and PsS summary scores and their standard deviation at the start and the end of treatment of each global perceived effect score of the parent $(n=92)$. Also the changed group $A$ and unchanged group B is shown. Further, for every global perceived effect score and group the change score and the occurrence of significant differences are presented. Group A and B both show a significant increase in CHQ-PF50 PhS and PsS scores between start and end of treatment $(\mathrm{p}<0.001)$. We found a significant difference between group $\mathrm{A}(\mathrm{PhS}=49.5)$ and group $\mathrm{B}(\mathrm{PhS}=33.3)$ on the mean post test score of the physical summary scale of the CHQ-PF50. Other significant differences between group A and B were not found. 
Table 1: Characteristics of adolescents with nonspecific chronic pain or fatigue for the whole study sample $(n=92)$, the chronic pain group $(n=52)$ and the chronic fatigue group $(n=40)$

\begin{tabular}{lccc}
\hline Variable & $\begin{array}{c}\text { Study sample } \\
(\mathbf{n = 9 2})\end{array}$ & $\begin{array}{c}\text { Chronic pain group } \\
(\mathbf{n = 5 2 )}\end{array}$ & $\begin{array}{c}\text { Chronic fatigue } \\
\text { group (n=40) }\end{array}$ \\
\hline Age (in years) & $16.4(2.5)$ & $16.2(2.8)$ & $16.7(1.9)$ \\
Gender: \% female & 88.0 & 86.5 & 90.0 \\
Duration of complaint (in months) & $34.9(27.9)$ & $35.2(30.8)$ & $34.5(24.2)$ \\
ICD-9 diagnoses (n(\%)) & & $6(6.5)$ & \\
723.9 nonspecific neck complaints & & $11(12.0)$ & \\
724.2 nonspecific back complaints & & $4(4.3)$ & \\
729.1 fibromyalgia & & $11(12.0)$ & \\
729.9 other nonspecific complaints & & & $40(43.5)$ \\
733.7 complex regional pain syndrome & & $61.3(21.8)$ & $77.5(15.7)$ \\
780.7 chronic fatigue syndrome & $68.2(20.9)$ & $18.7(10.8)$ & $20.2(10.1)$ \\
Pre-treatment VAS-score pain or fatigue & $19.4(10.5)$ & & $41.0(10.2)$ \\
Pre-treatment PhS summary score on & & $42.6(9.3)$ & \\
CHQ-PF50 & & & \\
Pre-treatment PsS summary score on & $41.9(9.7)$ & & \\
CHQ-PF50 & & & \\
\hline
\end{tabular}

Mean scores (SD) or numbers of subjects ( $\mathrm{n}$ ) with percentages are provided. CHQ-PF50 $=$ Child Health Questionnaire 50-item Parent Form. PhS = Physical summary score of the CHQ-PF50. PsS = Psychosocial summary score of the CHQ-PF50

Table 2: Numbers of parent rating of global perceived effect of treatment per category $(n=92)$

\begin{tabular}{lcc}
\hline Categories of global perceived effect of treatment & Group A, B or C & Number (\%) \\
\hline No complaints and restrictions (1) & Group A & $19(20,7)$ \\
Complaints but no restrictions (2) & Group A & $14(15,2)$ \\
Complaints and less restrictions (3) & Group B & $51(55,4)$ \\
Unchanged (4) & Group B & $7(7,6)$ \\
The problem worsened (5) & Group C & $1(1,1)$ \\
\hline
\end{tabular}

Table 4 contains the results of the five methods used to test responsiveness of the CHQ-PF50. The SRM are 2.89 and 1.01 for the PhS and PsS, respectively. Large ES were found for Group $\mathrm{A}(\mathrm{PhS}=3.30$; $\mathrm{PsS}=1.16)$. Both the SRM and ES indicate adequate responsiveness. The method used for calculating SEM agreement gave the following results: $\mathrm{PhS}=18.92$ and $\mathrm{PsS}=11.39$. The MDC of $\mathrm{PhS}$ and $\mathrm{PsS}$ are 52.45 and 31.57, respectively, which means that a change of 52.45 points on the $\mathrm{PhS}$ and 31.57 points on the PSS indicates a clinical relevant change. The results show poor responsiveness for the SEM agreement $_{\text {and MDC. }}$. 
Table 3: CHQ-PF50 PhS and PsS summary scores pre and post-treatment and change scores for 5 categories of the parents perceived effect of treatment, group A and B and the total group

\begin{tabular}{|c|c|c|c|c|}
\hline \multirow[t]{2}{*}{ CHQ-PF50 score } & & \multirow{2}{*}{$\begin{array}{l}\text { Pre-test (start) } \\
\text { Mean (SD) }\end{array}$} & \multirow{2}{*}{$\begin{array}{l}\text { Post-test (end) } \\
\text { Mean (SD) }\end{array}$} & \multirow{2}{*}{$\begin{array}{l}\begin{array}{c}\text { Change } \\
\text { (end-start) }\end{array} \\
\text { Mean (SD) }\end{array}$} \\
\hline & & & & \\
\hline \multirow{2}{*}{$\begin{array}{l}1=\text { no complaints and restrictions } \\
(\mathrm{n}=19)\end{array}$} & $\mathrm{PhS}$ & $23.70(11.83)$ & $52.34(4.60)$ & $28.64(10.59)^{b}$ \\
\hline & PsS & $37.96(11.14)$ & $51.59(8.72)$ & $13.63(12.32)^{b}$ \\
\hline \multirow{2}{*}{$\begin{array}{l}2=\text { complaints but no restrictions } \\
(\mathrm{n}=14)\end{array}$} & $\mathrm{PhS}$ & $18.33(5.50)$ & $45.54(7.45)$ & $27.21(8.66)^{b}$ \\
\hline & PsS & $42.10(9.14)$ & 49.92 (8.94) & $7.83(8.28)^{a}$ \\
\hline \multirow{2}{*}{$\begin{array}{l}3=\text { complaints and less } \\
\text { restrictions }(n=51)\end{array}$} & $\mathrm{PhS}$ & $17.67(10.87)$ & $34.75(14.14)$ & $17.06(12.26)^{b}$ \\
\hline & PsS & $43.91(8.40)$ & $50.11(7.98)$ & $6.20(8.98)^{b}$ \\
\hline \multirow{2}{*}{$\begin{array}{l}\text { 4=unchanged } \\
(\mathrm{n}=7)\end{array}$} & $\mathrm{PhS}$ & 20.15 (10.00) & $22.50(10.12)$ & $2.34(10.31)$ \\
\hline & PsS & 39.54 (13.03) & $48.40(12.66)$ & $8.85(8.79)^{a}$ \\
\hline \multirow{2}{*}{$\begin{array}{l}5=\text { problem worsened } \\
(\mathrm{n}=1)\end{array}$} & $\mathrm{PhS}$ & $30.31(-)$ & $55.39(-)$ & $25.08(-)^{c}$ \\
\hline & PsS & $31.20(-)$ & $37.06(-)$ & $5.86(-)^{c}$ \\
\hline \multirow{2}{*}{$\begin{array}{l}\text { Total } \\
(\mathrm{n}=92)\end{array}$} & $\mathrm{PhS}$ & $19.35(10.51)$ & $39.32(14.37)$ & $19.96(13.24)^{b}$ \\
\hline & PsS & $41.94(9.67)$ & $50.11(8.63)$ & $8.18(9.89)^{b}$ \\
\hline \multirow{2}{*}{$\begin{array}{l}\text { Changed ( } 1 \text { and } 2-\text { Group } A) \\
(n=33)\end{array}$} & $\mathrm{PhS}$ & $21.42(9.91)$ & $49.46(6.79)^{d}$ & $28.03(9.70)^{b}$ \\
\hline & PsS & $39.72(10.39)$ & $50.88(8.72)$ & $11.17(11.03)^{b}$ \\
\hline \multirow{2}{*}{$\begin{array}{l}\text { Unchanged ( } 3 \text { and } 4-\text { Group B) } \\
(\mathrm{n}=58)\end{array}$} & $\mathrm{PhS}$ & $17.99(10.72)$ & $33.27(14.22)^{d}$ & $15.29(12.90)^{b}$ \\
\hline & PsS & $43.39(9.04)$ & $49.90(8.54)$ & $6.52(8.93)^{b}$ \\
\hline
\end{tabular}

$\mathrm{n}=$ number of subjects, CHQ-PF50 $=$ Child Health Questionnaire 50-item Parent Form. PhS $=$ Physical summary score of the CHQ-PF50. PsS $=$ Psychosocial summary score of the CHQ-PF50. ${ }^{a} \mathrm{p}<0.01$ ${ }^{b} p<0.001 .{ }^{c}$ the $p$-value cannot be computed because the sum of case weights is equal to $1 .{ }^{d}$ significant difference $(p<0.001)$ post-treatment between Group A and B on the CHQ-PF50 PhS summary score

Table 4: Results of different methods of responsiveness for the CHQ-PF5- PhS and PsS summary scores

\begin{tabular}{lcc}
\hline Method of responsiveness & Physical scale (PhS) & Psychosocial scale (PsS) \\
\hline Standardized response mean (Group A) & 2.89 & 1.01 \\
Pooled effect sizes (Group A) & 3.30 & 1.16 \\
Standard error of measurement - agreement (Group B) & 18.92 & 11.39 \\
Smallest detectable change (Group B) & 52.45 & 31.57 \\
ROC curve - AUCa (Group A and B) & $0.79[0.70-0.89]$ & $0.64[0.52-0.76]$ \\
Optimal cut-off change score & 21.08 & 6.98 \\
\hline
\end{tabular}

a ROC = Receiver operating characteristics curve - AUC = Area under the curve [95\% confidence interval] 
The ROC curves of both CHQ-PF50 scales are displayed in Figure 1. The AUC for $\mathrm{PhS}$ is 0.79 , indicating adequate responsiveness, whereas the AUC of PsS is 0.64, meaning that for this measure the responsiveness is moderate. With a combination of sensitivity $(73 \%)$ and specificity (67\%), the optimal cut-off value for the physical scale of the CHQ-PF50 that minimizes the overall classification error is 21.1. For the psychosocial scale two cut-off points were obtained with different sensitivity and specificity (option 1: sensitivity $=0.606$, specificity $=0.672$, cut-off point $=9.350$; option 2: sensitivity $=0.727$, specificity $=0.534$, cut-off point $=6.984$ ). As stated in the method section, the change score with the highest sensitivity (option 2) was chosen as the optimal cut-off point for the psychosocial scale of the CHQ-PF50.

\section{ROC Curve}

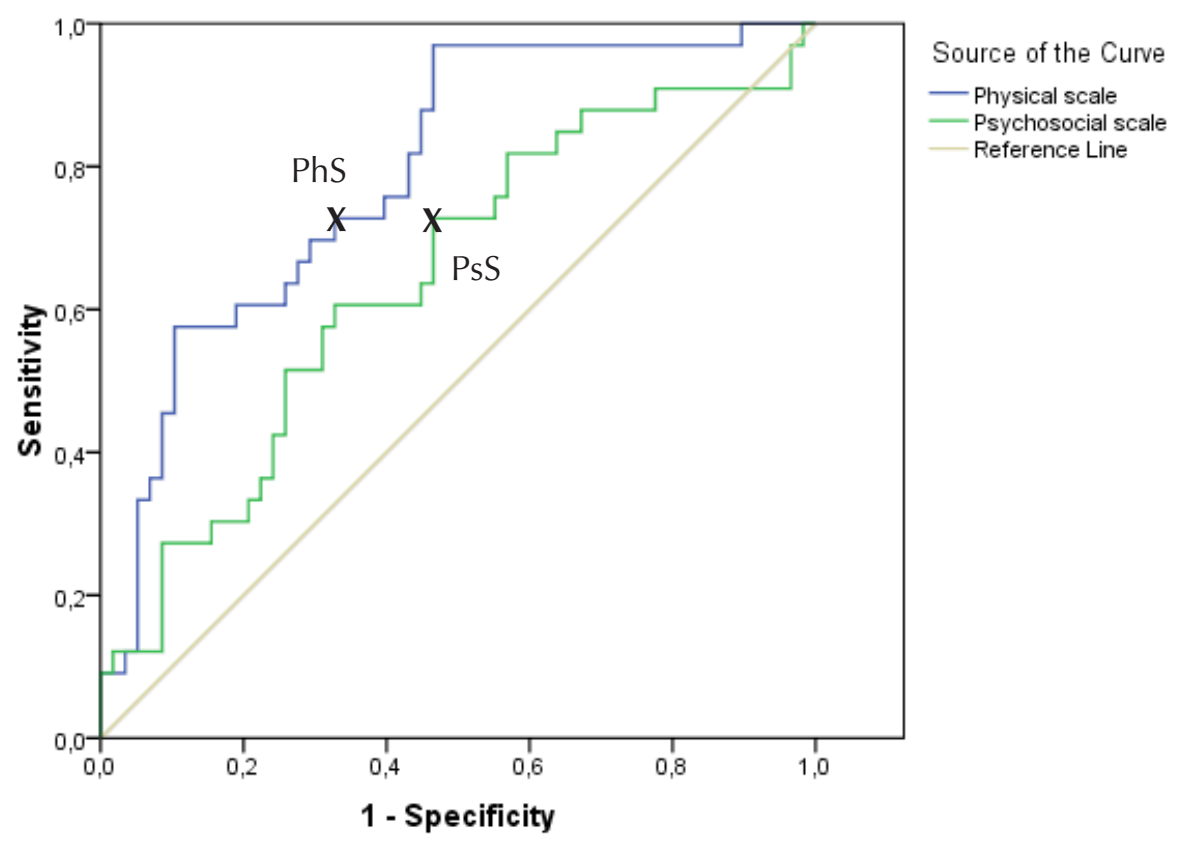

Figure 1: Receiver operating characteristics analysis of the physical and psychosocial scale of the CHQ 50-item parent form with optimal cut-off point for each summary scale.

PhS: Optimal cut-off point: $=21.1$, Sensitivity $=73 \%$, Specificity $=63 \%$

PsS: Optimal cut-off point: $=7.0$, Sensitivity $=73 \%$, Specificity $=53 \%$ 


\section{Discussion}

In this study we examined the responsiveness of the CHQ 50-item parent form in adolescents with nonspecific chronic pain or fatigue in five different ways. Our results show a moderate to adequate responsiveness for three methods, and rather high values of SEM agreement and MDC indicating a poor responsiveness. Differences in these quality evaluations can be explained to the methods used in this study. The SRM and ES were calculated using only patients of Group A (no restrictions after treatment) and can identify clinically important change. Otherwise, the $S E M_{\text {agreement }}$ and MDC distinguish change in general and were computed with data of Group B (less restrictions or unchanged). And finally, relevant changes in the CHQ-PF50 are defined with the ROC curves and optimal cut-off points, while using data of both groups (A and B). ${ }^{1}$

For clinical practice the assessment of clinically important change seems best applicable. ${ }^{1}$ And since both SRM and ES show adequate responsiveness, it can be concluded that the CHQ-PF50 can be used as an evaluative instrument to show changes after treatment.

However, rather large $\mathrm{SEM}_{\text {agreement }}(\mathrm{PhS}=18.92 ; \mathrm{PsS}=11.39)$ and MDC $(\mathrm{PhS}=52.45$; PsS $=31.57$ ) values were found. It is reasonable that both methods show these results, whereas the minimal detectable change is based on the SEM agreement ${ }^{22}$ The $S E M_{\text {agreement }}$ and MDC are based on the parents' global perceived effect score of patients of the 'unchanged' group B. In our analyses group B consists of categories 3 (complaints and less restrictions) and 4 (unchanged). The reason for adding category 3 in the 'unchanged' group B is that to our opinion, the change of patients in category 3 is too limited to be regarded as a clinically relevant change after inpatient rehabilitation treatment. However, the parents in category $3(n=51)$ do report a change on the CHQ-PF50 (table 3) and this is probable the main reason for the relative high values of the $\mathrm{SEM}_{\text {agreement }}$ and MDC. This way of reasoning is congruent with Demoulin et al. (2010), who describe the influence of different ways of clustering global perceived effect scores; the more patients with an improvement on the outcome measurement are included in the 'unchanged' category, the higher the responsiveness parameters and the worse the accuracy of distinguishing changed from unchanged patients by using SEM agreement and MDC become. ${ }^{17}$

Due to the fact that the method used to determine responsiveness based on the area under the ROC curve involves both groups A and B and an optimal cutoff point can be calculated, this method seems to be advocated for clinical purposes. In addition, relevant changes (21.1 for the PhS, and 7.0 for the PsS) are more straightforward to interpret for clinicians after treatment. In this study, the results of the ROC-curve method show adequate responsiveness for the PhS summary scale and moderate 
responsiveness for the PsS, respectively.

The findings regarding CHQ responsiveness in the study of Selvaag et al. (2003) were comparable to ours. ${ }^{13}$ Selvaag et al. (2003) used the SRM for defining responsiveness in a JIA population and found a large SRM (0.96) for the CHQ-PF50 PhS scale and a moderate SRM (0.67) for the psychosocial summary scale. ${ }^{13}$ Gorelick et al. (2003) calculated the responsiveness with effect sizes in an asthma study sample and found rather small effects for both summary scales $(0.18$ and 0.19$)$. In this study the PF28-version of the CHQ was used instead of the PF50. ${ }^{12}$ Selvaag et al. (2003) and Gorelick et al. (2003) used no other methods to assess responsiveness, therefore no comparison with regard to the results of the area under the ROC, SEM $M_{\text {agreement }}$ and MDC is possible. ${ }^{12,13}$

The use of different methods for studying the responsiveness shows the same pattern regarding the CHQ-PF50 PhS and PsS summary scales, although for all five statistical techniques, change scores of the PhS appeared to be consistently higher than the change scores of the PsS. The same differences in change scores of the summary scales are seen in the studies of Gorelick et al. (2003) and Selvaag et al. (2003). ${ }^{12,13}$ This discrepancy between changes in scores might be explained by differences in pre-treatment scores $\left(\mathrm{PhS}_{\text {pre-treatment }}=19.23(10.44) ; \mathrm{PsS}_{\text {pre-treatment }}=41.9\right.$ (9.7)).

The pre-treatment CHQ-PF50 scores of the physical scale in our sample of adolescents are remarkable. The reported mean level of physical health related quality of life $\left(\mathrm{PhS}_{\text {pre-treatment }}=19.23(10.44) ; \mathrm{n}=92\right)$ is low as compared to the scores of Dutch schoolchildren ( $\mathrm{PhS}=56.4(5.7) ; \mathrm{n}=353)$, and more striking to children with asthma ( $\mathrm{PhS}=45.7$ (8.4); $\mathrm{n}=178)$, and attention deficit hyperactivity disorder $(\mathrm{ADHD})(\mathrm{PhS}=57.6(6.2) ; \mathrm{n}=83) .{ }^{10}$ The finding that patients with pain perceive their health-related quality of life low as compared to patients with other chronic diseases (e.g. migraine and cancer pain), has also been reported by Lame et al. (2005) in a study in adult patients with chronic pain, visiting a specialized pain clinic. ${ }^{23}$ An explanation for these low CHQ-PF50 PhS scores might be that participating patients in our study sample were specifically selected on their level of disability to receive a clinical rehabilitation treatment for their chronic musculoskeletal pain and/ or fatigue. Adolescents with nonspecific chronic pain report many restrictions in daily life activities, ${ }^{24}$ which could be reflected in the low CHQ-PF50 PhS summary scores. Even after completion of the clinical rehabilitation treatment, PhS CHQPF50 scores $\left(\mathrm{PhS}_{\text {post-treatment }}=39.68\right.$ (14.28); $\mathrm{n}=92$ ) did not reach values seen in healthy individuals. This indicates that post-treatment, adolescents with pain or fatigue still have a reduced quality of life, even though $49.5 \%$ of them showed a clinically important improvement of the quality of life as a result of treatment. 
A remarkable finding is the relatively higher PSS summary score (41.9) before treatment compared to the PhS summary score (19.4). As a result, the possibility to change on the physical scale is much higher than on the psychosocial scale. Pre-treatment scores of the PsS seem in line with scores of Dutch schoolchildren (53.2 (6.4), $\mathrm{n}=353),{ }^{10}$ whereas the post-treatment PsS score (50.2 (8.6), $\mathrm{n}=92$ ) reaches scores of the normal population and even outlines scores of an ADHD population ( $\mathrm{PsS}=36.9$ (10.9); $\mathrm{n}=83$ ) in the study of Raat et al. (2002). According to the AUC method a lower cut-off score on the psychosocial scale (7.0) as compared to the physical scale (21.1) has been found to distinguish patients with or without a clinical relevant change. Furthermore, since the main goal of rehabilitation treatment is specially designed to increase physical functioning; the change on the physical scale can be expected to be higher than the score on the psychosocial functioning scale. This could imply two things; the psychosocial functioning scale is less responsive than the physical functioning scale or that the psychosocial aspects in the rehabilitation program should be more accentuated.

Our study has limitations. First, although 172 adolescents participated in the study, only 92 parents filled out a CHQ at pre and post-treatment and scored the global perceived effect of treatment, and could thus be used for the responsiveness analysis of the CHQ-PF50. The reason for this incompletion rate could be partly non-response and partly practical reasons, whereas this study was performed in a clinical setting. Unfortunately, there are no data available to confirm this. However, since pre-treatment characteristics of those with and without a complete dataset did not differ, it can be assumed that our results can be generalized to the population adolescents with nonspecific chronic pain or fatigue who receive an inpatient clinical rehabilitation treatment. Second, although a child version of the $\mathrm{CHQ}$ (CHQ-CF50) was available, we decided not to use this since it has not been tested for validity and reliability. In addition, no PhS and PsS summary scales are available for any $\mathrm{CHQ}$-child version. A confirmatory factor analysis of the 50-item CHQchild form and additional testing of its psychometric properties seems a topic for further research.

Based on this study, the following implications for clinical practice concerning the use of the CHQ-PF50 can be given. The CHQ-PF50 can be used as a clinical measurement for adolescents with nonspecific chronic pain or fatigue. In comparison to other health-related quality of life scales, such as PedsQL $4.0^{25}$ and QL-Y, ${ }^{26}$ the $\mathrm{CHQ}$ has the advantage to provide a wide spectrum of questions on physical functioning as well as psychosocial functioning. In addition, the $\mathrm{CHQ}$ seems in favor of the QL-Y, since a CHQ parent and concept child version are available. For clinical practice we recommend to use the optimal cut-off point of the PhS and PsS to assess whether a relevant change after treatment has occurred. 
Chapter 2

Summarizing, the responsiveness of the Child Health Questionnaire - Parent Form in adolescents with nonspecific chronic pain or fatigue treated in a rehabilitation clinic is adequate for the physical scale and moderate for the psychosocial scale when using the SRM, ES and AUC as methods. 


\section{References}

1. Terwee CB, Dekker FW, Wiersinga WM, Prummel MF, Bossuyt PM. On assessing responsiveness of health-related quality of life instruments: guidelines for instrument evaluation. Qual Life Res. 2003;12(4):349-62.

2. Landgraf JM, Maunsell E, Speechley KN, Bullinger M, Campbell S, Abetz L, et al. CanadianFrench, German and UK versions of the Child Health Questionnaire: methodology and preliminary item scaling results. Qual Life Res. 1998;7(5):433-45.

3. Raat H, Mohangoo AD, Grootenhuis MA. Pediatric health-related quality of life questionnaires in clinical trials. Curr Opin Allergy Clin Immunol. 2006;6(3):180-5.

4. Asmussen L, Olson LM, Grant EN, Landgraf JM, Fagan J, Weiss KB. Use of the child health questionnaire in a sample of moderate and low-income inner-city children with asthma. Am J Respir Crit Care Med. 2000;162(4 Pt 1):1215-21.

5. Dunbar-Masterson C, Wypij D, Bellinger DC, Rappaport LA, Baker AL, Jonas RA, et al. General health status of children with D-transposition of the great arteries after the arterial switch operation. Circulation. 2001;104(12 Suppl 1):1138-42.

6. Nixon Speechley K, Maunsell E, Desmeules M, Schanzer D, Landgraf JM, Feeny DH, et al. Mutual concurrent validity of the child health questionnaire and the health utilities index: an exploratory analysis using survivors of childhood cancer. Int J Cancer Suppl. 1999;12:95-105.

7. Waters E, Salmon L, Wake M. The parent-form Child Health Questionnaire in Australia: comparison of reliability, validity, structure, and norms. J Pediatr Psychol. 2000;25(6):38191.

8. Selvaag AM, Ruperto N, Asplin L, Rygg M, Landgraf JM, Forre O, et al. The Norwegian version of the Childhood Health Assessment Questionnaire (CHAQ) and the Child Health Questionnaire (CHQ). Clin Exp Rheumatol. 2001;19(4 Suppl 23):S116-20.

9. Ruperto N, Ravelli A, Pistorio A, Malattia C, Viola S, Cavuto S, et al. The Italian version of the Childhood Health Assessment Questionnaire (CHAQ) and the Child Health Questionnaire (CHQ). Clin Exp Rheumatol. 2001;19(4 Suppl 23):S91-5.

10. Raat H, Bonsel GJ, Essink-Bot ML, Landgraf JM, Gemke RJ. Reliability and validity of comprehensive health status measures in children: The Child Health Questionnaire in relation to the Health Utilities Index. J Clin Epidemiol. 2002;55(1):67-76.

11. Terwee CB, Bot SD, de Boer MR, van der Windt DA, Knol DL, Dekker J, et al. Quality criteria were proposed for measurement properties of health status questionnaires. J Clin Epidemiol. 2007;60(1):34-42.

12. Gorelick MH, Scribano PV, Stevens MW, SchultzTR. Construct validity and responsiveness of the Child Health Questionnaire in children with acute asthma. Ann Allergy Asthma Immunol. 2003;90(6):622-8.

13. Selvaag AM, Flato B, Lien G, Sorskaar D, Vinje O, Forre O. Measuring health status in early juvenile idiopathic arthritis: determinants and responsiveness of the child health questionnaire. J Rheumatol. 2003;30(7):1602-10.

14. Crawley E, Sterne JA. Association between school absence and physical function in paediatric chronic fatigue syndrome/myalgic encephalopathy. Arch Dis Child. 
2009;94(10):752-6.

15. King S, Chambers CT, Huguet A, MacNevin RC, McGrath PJ, Parker L, et al. The epidemiology of chronic pain in children and adolescents revisited: a systematic review. Pain. 2011;152(12):2729-38.

16. Landgraf JM, Abetz L, Ware JE. Child Health Questionnaire (CHQ): a user's manual. Boston, MA: The Health Institute, New England Medical Center.; 1996.

17. Demoulin C, Ostelo R, Knottnerus JA, Smeets RJ. Quebec Back Pain Disability Scale was responsive and showed reasonable interpretability after a multidisciplinary treatment. J Clin Epidemiol. 2010;63(11):1249-55.

18. Kuijer W, Brouwer S, Dijkstra PU, Jorritsma W, Groothoff JW, Geertzen JH. Responsiveness of the Roland-Morris Disability Questionnaire: consequences of using different external criteria. Clin Rehabil. 2005;19(5):488-95.

19. Cohen J. Statistical power analysis for the behavioral sciences. New York: Academic Press; 1988.

20. Angst F. The new COSMIN guidelines confront traditional concepts of responsiveness. BMC Med Res Methodol. 2011;11:152; author reply

21. de Vet HC, Terwee CB, Ostelo RW, Beckerman H, Knol DL, Bouter LM. Minimal changes in health status questionnaires: distinction between minimally detectable change and minimally important change. Health Qual Life Outcomes. 2006;4:54.

22. Copay AG, Subach BR, Glassman SD, Polly DW, Jr., Schuler TC. Understanding the minimum clinically important difference: a review of concepts and methods. Spine J. 2007;7(5):541-6.

23. Lame IE, Peters ML, Vlaeyen JW, Kleef M, Patijn J. Quality of life in chronic pain is more associated with beliefs about pain, than with pain intensity. Eur J Pain. 2005;9(1):15-24.

24. Roth-Isigkeit A, Thyen U, Stoven H, Schwarzenberger J, Schmucker P. Pain among children and adolescents: restrictions in daily living and triggering factors. Pediatrics. 2005; 115(2):e152-62.

25. Varni JW, Seid M, Kurtin PS. PedsQL 4.0: reliability and validity of the Pediatric Quality of Life Inventory version 4.0 generic core scales in healthy and patient populations. Med Care. 2001;39(8):800-12.

26. Merlijn VP, Hunfeld JA, van der Wouden JC, Hazebroek-Kampschreur AA, Passchier J. Shortening a quality of life questionnaire for adolescents with chronic pain and its psychometric qualities. Psychol Rep. 2002;90(3 Pt 1):753-9. 




\section{Chapter 3}

Factors associated with school participation and health-related quality of life in adolescents with chronic musculoskeletal pain or chronic fatigue

Tessa Westendorp, Sylvia C. Remerie, Marjolein de Craen, Rob J.E.M. Smeets, Jeanine A. Verbunt. 


\begin{abstract}
Purpose: Chronic pain and fatigue are common complaints in adolescents. Both have considerable impact on the adolescent's life. This study aims to identify factors associated with school participation and health-related quality of life (HRQoL) in adolescents with disabling chronic musculoskeletal pain or fatigue.
\end{abstract}

Materials and methods: Cross-sectional study of patients at the start of an inpatient rehabilitation treatment. Potential associated factors were identified from literature and clinical expert opinion, and assessed with questionnaires. Regression analyses were used to identify contributing factors for school participation and HRQoL, respectively.

Results: 172 adolescents (mean age 16.2 ( $\mathrm{SD}=2.5$ ); 85.5\% girls) with prolonged pain/ fatigue (mean duration 36.0 months $(S D=28.2)$ ) participated. Analyses identified age and chronic fatigue as significant contributing factors for school participation (Nagelkerke $R^{2}=0.151$ ); pain/fatigue severity was the only contributing factor for HRQoL-physical functioning $\left(\mathrm{R}^{2}=0.067 ; \Delta \mathrm{R}^{2}=0.060 ; \Delta \mathrm{F}=7.678(\mathrm{p}=0.006)\right)$; for HRQoL-psychosocial functioning, passive reaction coping was the only significant contributing factor $\left(\mathrm{R}^{2}=0.182 ; \Delta \mathrm{R}^{2}=0.152 ; \Delta \mathrm{F}=4.587(\mathrm{p}=0.005)\right)$.

Conclusions: Older adolescents and adolescents with chronic fatigue are more often absent from school. Increased pain/fatigue is related to lower HRQoL-physical functioning. Furthermore, a passive reaction coping style is related to lower HRQoLpsychosocial functioning and seems relevant to address during treatment. 


\section{Introduction}

Chronic pain and fatigue are common complaints in adolescence. Both have considerable impact on the adolescent's life in the domains of functioning, social participation and health-related quality of life. ${ }^{1-5}$

In the context of social participation, problems at school seem to have the highest impact on the adolescent's life. School-related problems for adolescents with pain mostly start with regular absence and reduced school functioning. ${ }^{6,7}$ Over time, school absence may lead to a delay in educational development and social deprivation. Pain and fatigue can also lead to a very unpleasant time at school. As the complaints are 'invisible', these can even lead to bullying and eventually, despite still being in school, contribute to social deprivation. ${ }^{8,9}$ Moreover, chronic pain and fatigue can also have an influence on extra-curricular activities, as sports and leisure activities might no longer be an option. This circumstance impedes an equal participation in society compared to peers. ${ }^{10}$ Non-participation may lead to repeating a class or transferring to a lower school degree, which can have a negative impact on future work possibilities. For society, this situation leads to high socioeconomic costs and healthcare use. ${ }^{11,12}$ In addition, the impact of financial and psychological aspects on families should not be underestimated. ${ }^{13}$ Therefore, pain and fatigue seem to have considerable impact on quality of life.

Earlier research has shown that chronic pain has also a negative impact on the quality of life in adolescents. ${ }^{4}$ Moreover, a higher rate of pain leads to lower levels of health-related quality of life (HRQoL) compared to the population norm and to children with other chronic diseases. ${ }^{14} \mathrm{HRQoL}$ is considered to be an important aspect of an individual's health status. To assess HRQoL, information is required about subjective aspects of health, well-being and behaviour. ${ }^{15,16}$ The International Classification of Functioning, Disability and Health (ICF) is a theoretical framework often used in a rehabilitation setting, to describe an individual's level of functioning. ${ }^{17}$ The main goal of rehabilitation treatment is to increase the level of participation. Within the ICF framework, school participation is a component of participation, whereas HRQoL is an overall component. As a consequence, both school participation and HRQoL are the topic of this study.

Because of the considerable impact that pain and fatigue have on participation and HRQoL of adolescents in daily life, the identification of the factors associated with restrictions on participation and HRQoL seem of great interest. Especially when these factors can indeed be influenced by treatment, this identification might lead to a more individual treatment approach and hence to more effective treatment. Unfortunately, little evidence is currently available on associated factors for HRQoL and school participation in this population. 
A number of previous studies in children and adolescents with chronic pain or fatigue have identified factors related to functioning and quality of life.

Lynch et al. (2006) found that catastrophizing and familial pain history were both significantly associated with impaired functioning (a higher level of disability) in children with chronic back pain. ${ }^{18}$ Similarly, Merlijn et al. (2006) found that emotionfocused avoidance coping strategies (i.e. catastrophizing) seem to strengthen the negative relation between pain intensity and psychological functioning in adolescents with various chronic pain conditions. ${ }^{19}$

In a clinical sample of adolescents with chronic pain conditions, it was shown that higher levels of depressive symptoms predicted increased school impairment. ${ }^{20}$ Furthermore, from a group of children diagnosed with chronic fatigue syndrome (CFS), reduced school attendance was more strongly associated with poor physical functioning than with anxiety. ${ }^{21}$

In previous research on adolescents with chronic pain, girls were linked to a lower quality of life, higher pain intensity and more frequent pain. ${ }^{4} \mathrm{~A}$ more recent study also associated higher pain intensity with a lower quality of life. ${ }^{19}$ In addition, the same research identified vulnerability as a psychosocial factor strongly related to several domains of quality of life in adolescents with chronic pain, such as 'satisfaction with life', 'psychology', 'physical functioning' and 'social functioning'.$^{19}$ Another study of children with chronic pain found that a higher level of anxiety sensitivity contributed independently to a lower level of a child's quality of life..$^{22}$

The aim of the present study is to identify factors associated with the level of school participation and HRQoL in adolescents with disabling chronic musculoskeletal pain or chronic fatigue.

\section{Materials and method}

\section{Design and population}

This cross-sectional study was performed in a population of adolescents with musculoskeletal chronic pain or fatigue referred for inpatient treatment in five rehabilitation centres in the Netherlands during the period between 2001 and 2005. All patients had chronic pain or chronic fatigue complaints and were disabled in performing activities of daily life.

\section{Assessment procedure}

Patients entered the study in chronological order. Before the start of inpatient treatment, both the adolescent and one of the parents filled in a booklet with a set of questionnaires. The questionnaires were part of the clinical assessment and 
treatment procedure. In addition, the rehabilitation physician assessed the diagnosis and demographic data - gender, age, living situation, life events, education level and school participation - by filling in a registration form before commencing treatment.

\section{Outcome measures}

In this study, both the level of school participation and health-related quality of life (HRQoL) are used as primary outcome measures.

\section{School participation}

The level of school participation was measured based on one question with three answer categories (normal school attendance, partial absence or complete absence of school) and was rated by the physician. This variable was dichotomized for use in the statistical analysis; normal school attendance and partial absence were combined into one category, whereas complete absence remained as a second, separate category.

\section{Health-related quality of life}

To quantify HRQoL the Child Health Questionnaire - Parent Form (CHQ-PF50) was used. This questionnaire represents the judgment of the patient's parents on the multidimensional aspects of HRQoL. In the CHQ-PF50 form a 'Physical' (PhS) and a 'Psychosocial' (PsS) summary score are calculated. The mean normative score for general cross-cultural populations is $50(\mathrm{SD} \pm 10) .23$ In this study, the same method of PhS and PsS CHQ-PF50 summary scores was used for data analysis. ${ }^{23}$ Regarding the psychometric properties of the Dutch CHQ-PF50, feasibility was excellent and validity good, while reliability varied for the different subscales/summary scales. ${ }^{24}$ The responsiveness using different methods was adequate for $\mathrm{PhS}$ and moderate for PsS. ${ }^{25}$

\section{Potential influencing factors}

Potential influencing factors were retrieved in two different ways, from literature and clinical expert opinion. The availability of these factors were checked within the database and those factors present were used for further analyses.

\section{Literature}

First, potential associated factors for school participation and HRQoL in adolescents with chronic pain or fatigue were retrieved from literature. Two potential associating factors for school functioning (depressive symptoms ${ }^{20}$ and physical functioning ${ }^{21}$ ) were identified. In addition, six factors were retrieved from literature as potential associated factors for quality of life: avoidance coping, ${ }^{19}$ catastrophizing, ${ }^{18,19}$ family 
member with pain/fatigue history, ${ }^{18}$ pain/fatigue intensity, ${ }^{4,19}$ vulnerability $^{19}$ and anxiety sensitivity. ${ }^{22}$

\section{Clinical expert opinion}

Second, five clinical experts (rehabilitation physicians and psychologists) with at least five years of experience in the field of adolescent pain rehabilitation were asked to add potential associating factors for school participation and HRQoL. The clinical experts, all member of the Dutch Rehabilitation Expert Group for Children and Adolescents in Pain and Fatigue, identified the following factors: duration of complaints, presence of life events, internalizing behaviour (i.e. social withdrawnness, depressive moods, anxiety feelings, difficulties in coping, psychosomatic complaints) and problems with peers.

\section{Data accessibility}

The clinical database included pre-treatment questionnaire assessment and psychological screening assessment. During this pre-treatment assessment procedure, each patient and a parent filled in the following single questions and questionnaires: pain/fatigue severity on a visual analogue scale (VAS), duration of complaints, presence of life events (with categories: none - family-related event - school-related event - other event), family member with chronic complaint history, education level, paternal work level, and marital status of parents. For the psychological screening assessment, the following questionnaires were filled in: the Utrecht Coping List (UCL), ${ }^{26}$ the Youth Self Report (YSR), ${ }^{27,28}$ the Achievement Motivation Test (PMT) ${ }^{29}$ and, the Dutch Personality Questionnaire for Youth (NPV-J). ${ }^{30}$ This dataset already existed before the present study was initiated.

Based on the literature search, the expert opinion and the presence of variables identified in the existing database, a definitive set of variables to be studied was established.

\section{ICF-blocks}

Each variable to be studied was assigned to different ICF-blocks in the ICF framework used, as presented in figure $1 .{ }^{17}$ The ICF blocks used are 'body functions and structures', 'activity', 'environmental factors' and 'personal factors'.

The following classification into ICF blocks is made regarding the potential associated factors:

- for 'body functions and structures': pain/fatigue severity pre-treatment (VAS 0-100) and duration of complaints pre-treatment (in months)

- for 'environmental factors': family member with pain/fatigue history (present - 
not present)

- for 'personal factors': life events (present - not present), withdrawn (subscale YSR), anxious/depressed (subscale YSR), passive coping (subscale UCL), avoidance (subscale UCL), positive anxiety (subscale PMT), negative anxiety (subscale PMT), social inadequacy (representing problems with peers; subscale NPV-J)

The ICF block 'activity' could not be used, as no potential associated factors were available which covered this item. Figure 1 shows the ICF model for an adolescent with chronic musculoskeletal pain or fatigue and the potential associated factors for school participation and HRQoL.

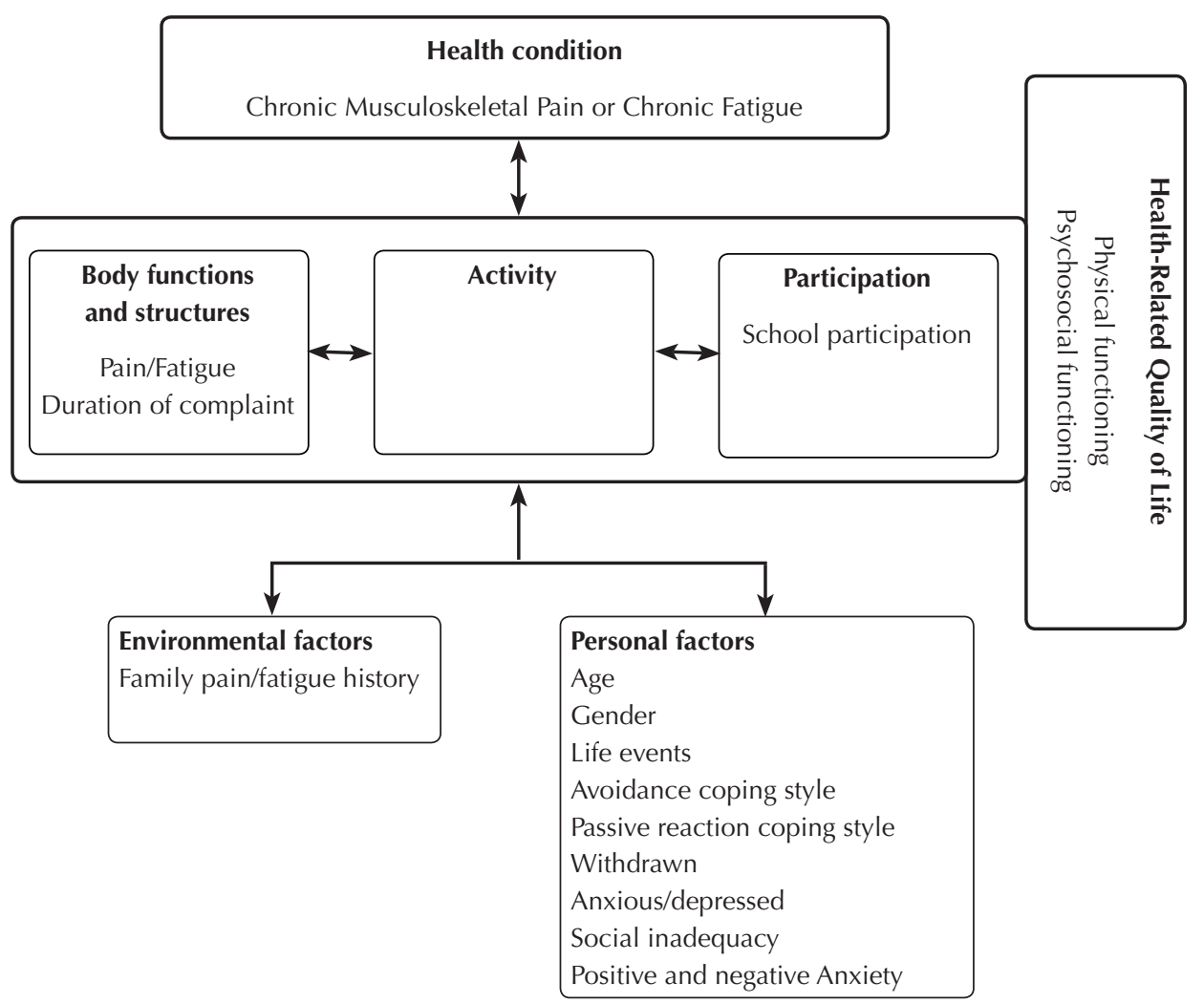

Figure 1: The ICF model for an adolescent with the chronic musculoskeletal pain or chronic fatigue health condition, the outcome measures for the level of participation and HRQoL, and the potential influencing factors. 


\section{Statistical analyses}

To gain insight into the research population, descriptive analyses were performed.

\section{Bivariate associations}

At the start, bivariate associations between the potential influencing factors and the dependent variables of school participation, HRQoL-physical functioning and HRQoL-psychosocial functioning were tested. In case of a dichotomous outcome variable (e.g. school participation) a $X^{2}$ test was used. In case of a continuous outcome variable with a normal distribution (e.g. HRQoL-PhS and HRQoL-PsS) Pearson correlation coefficients were calculated. For continuous variables with a non-normal distribution, Spearman correlation coefficients were used. For potential influencing factors with a dichotomous structure, differences in HRQoL between groups were computed using an independent t-test for normally distributed data and a Mann-Whitney $U$ test in case of a non-normal distribution of the data.

\section{Regression analyses}

To study contributing factors for participation and quality of life, three regression models were designed with school participation, HRQoL-PhS and HRQoL-PsS as the dependent factor, respectively. Only bivariate associations with a p-value below 0.05 were included in these regression analyses. Age and gender were added to the model as potential confounders, as these variables can affect the outcome variable and the potential associated factors. In case of significant difference between the 'diagnosis' pain and fatigue on one hand and school participation, HRQoLphysical functioning and/or HRQoL-psychosocial functioning on the other hand, the diagnosis was also added to the model as a confounding factor.

In order to identify associated factors for school participation, a stepwise forward logistic regression analysis was performed with school participation as the dependent factor, while controlling for age and gender. In the first step, gender and age were introduced into the model. Subsequently, the 'body functions and structures', 'environmental factors' and 'personal factors' blocks were introduced stepwise and the results expressed in odds ratios.

For analysing the contributing factors for health-related quality of life, two stepwise forward linear regression analyses were performed with CHQ-PF50, PhS and CHQ-PF50, PsS as the dependent factor, respectively. Again, age and gender were included in the model in the first step. Subsequently, potential contributing factors were introduced blockwise following the ICF-model. For both regression analyses, standardized beta coefficients and their significance were tested under the null hypothesis that the coefficient is not equal to zero. 
To control for multicollinearity in both the logistic regression and the linear regression analyses, it was verified whether variance inflation factors (VIF) were below $10 .{ }^{31}$ VIFs above 10 indicate that an independent variable has a strong linear relationship with other predictors. Furthermore, the average VIF in the regression model had to be below 1, otherwise multicollinearity might have biased the model. ${ }^{31}$ Any outliers, with a Cook distance above 1 were removed from the model..$^{32}$

All statistical analyses were performed using SPSS software version 24.0 (SPSS Inc., Chicago, IL).

\section{Hypotheses}

Based on the literature and expert opinion, as well as the availability of the relevant factors in the database, our hypothesis is that having depressive symptoms is significantly associated with non-school participation. Furthermore, we hypothesize that being a girl, having a family member with pain/fatigue history, and having a higher level of pain/fatigue are all significantly associated with a lower HRQoLphysical functioning. Last, we hypothesize that being a girl, having a higher level of pain/fatigue, and having a higher level of avoidance coping are all associated with a lower HRQoL-psychosocial functioning.

\section{Results}

\section{Descriptive}

The cohort consisted of 172 adolescents (mean age 16.2 ( $\mathrm{SD}=2.5$ ); $85.5 \%$ girls) with chronic pain $(55.8 \%)$ or fatigue $(44.2 \%)$ as their main complaint. Their average pre-treatment pain/fatigue level was $68.7(\mathrm{SD}=19.6)$ on the VAS $(0-100)$, while on average they have had complaints for three years (mean duration 36.0 months $(\mathrm{SD}=28.2)$ ) before starting their rehabilitation treatment. While $90.5 \%$ of the patients were mandatory school attenders, $9.5 \%$ had a paid job. Of all participants, $86.9 \%$ lived in a two-parent family. Almost one third (29.5\%) had a family member with pain/fatigue complaints. The use of medication for chronic pain/fatigue before treatment was $35.2 \%$, while $28.3 \%$ used aids, mostly for mobility, such as a wheelchair, a walking frame or a walking stick. Pre-treatment characteristics of this study population are presented in table 1 .

\section{Bivariate associations with school participation and HRQoL}

First, school participation was significantly related to diagnosis $\left(X^{2}=9.182 ; p=\right.$ 0.002) indicating that adolescents with fatigue more often dropped out of school completely. Since diagnosis (having pain/fatigue) appeared to be a differentiating factor for school participation, diagnosis was added as a confounding factor in the 
Table 1: Pre-treatment patient characteristics $(n=172)$

\begin{tabular}{|c|c|c|}
\hline Potential influencing factors (independent variables) & Scale range & $\begin{array}{l}\text { Baseline total sample } \\
\text { mean (SD) }\end{array}$ \\
\hline Age (years) & $9.3-22.5$ & $16.2(2.5)$ \\
\hline Gender (\% girls) & & $85.5 \%$ \\
\hline \multicolumn{3}{|l|}{ Diagnosis (n, \%) } \\
\hline Chronic pain & & $96(55.8 \%)$ \\
\hline Chronic fatigue & & $76(44.2 \%)$ \\
\hline Pain/fatigue severity $(\mathrm{VAS})^{*}$ & $0-100$ & $68.7(19.6)$ \\
\hline Duration of the complaint before treatment (months) & $4-120$ & $36.0(28.2)$ \\
\hline Family pain/fatigue history (\% present) & & $29.5 \%$ \\
\hline Life events (\% present) & & $50.0 \%$ \\
\hline \multicolumn{3}{|l|}{ Psychosocial factors * } \\
\hline Withdrawn ${ }^{+}$ & $0-14$ & $4.8(2.7)$ \\
\hline Anxious/depressed ${ }^{+}$ & $0-32$ & $7.2(5.4)$ \\
\hline Passive coping reaction $\$$ & $7-28$ & $12.8(3.4)$ \\
\hline Avoidance ${ }^{\S}$ & $8-32$ & $16.4(3.0)$ \\
\hline Positive anxiety ${ }^{\ddagger}$ & $0-18$ & $9.3(4.5)$ \\
\hline Negative anxiety ${ }^{\ddagger}$ & $0-26$ & $10.7(6.1)$ \\
\hline Social inadequacy (problems with peers) ${ }^{\infty}$ & $0-30$ & $11.3(6.9)$ \\
\hline Outcome measures (dependent variables) & Scale range & Baseline mean score (SD) \\
\hline
\end{tabular}

School participation

Normal attendance (\%) $18.0 \%$

Partial absenteeism (\%) $49.1 \%$

Complete absenteeism (\%)

HRQoL - Physical functioning *

$0-100$

$20.4(9.5)$

HRQoL - Psychosocial functioning *

$0-100$

$42.4(9.6)$

* The higher the score, the more intense the pain/fatigue * The higher the score, the higher the presence of psychosocial factors (withdrawn, anxious/depressed, passive coping style, avoidance, positive and negative anxiety, social inadequacy) ${ }^{+}$Measured with the Youth Self Report (YSR $)^{27,28} \quad{ }^{\S}$ Measured with the Utrecht Coping List $(\mathrm{UCL})^{26} \quad{ }^{\ddagger}$ Measured with the Achievement Motivation Test (PMT) ${ }^{29}$

${ }^{\infty}$ Measured with the Dutch Personality Questionnaire for Youth (NPV-J) ${ }^{30} \quad ¥$ The higher the score, the better the health-related quality of life in the adolescent as reported by the parent: measured with the 50-item Child Health Questionnaire - Parent Form (CHQ-PF50) 
explanatory model for school participation. Second, HRQoL - physical functioning (PhS) was significantly associated with the severity of (pain/fatigue) complaints (Spearman's rho $=-0.265 ; \mathrm{p}=0.003$ ), indicating that a higher level of complaints was related to a lower level of physical functioning. Third, several significant bivariate associations were found for HRQoL - psychosocial functioning (PsS). The withdrawn scale of the Youth Self Report (YSR) (Pearson $r=-0.257 ; p=0.006$ ), the anxious/depressed scale of the YSR (Pearson $r=-0.302 ; p=0.001$ ) and the passive coping reaction scale of the Utrecht Coping List (UCL) (Pearson $r=-0.364 ; p<0.000$ ) were all negatively associated with psychosocial functioning; in other words, a higher score on these factors was associated with a lower psychosocial healthrelated quality of life.

\section{Regression analyses \\ School participation}

For school participation, it appeared that the OR for age was 1.251 (1.064-1.470) with a Wald score of $7.327(p=0.007)$, while the OR for diagnosis was 2.709 (1.347$5.445)$ with a Wald score of $7.822(p=0.005))$. These findings indicate that older adolescents and adolescents with chronic fatigue have a higher chance of dropping out of school completely. The Nagelkerke $\mathrm{R}^{2}$ score of 0.151 indicates that variables in the model accounted for $15.1 \%$ of the total variance in school participation; these results are shown in table 2.

Table 2: Results of the logistic regression analysis with baseline scores and confounders of the significant associated factors (representing the pre-treatment situation) for school participation

\begin{tabular}{lccccc}
\hline Independent variable & $\begin{array}{c}\text { Baseline score } \\
\text { (SD) }\end{array}$ & $\begin{array}{c}\text { Odds ratio }- \\
\text { Exp (ß) }\end{array}$ & $\begin{array}{c}\mathbf{9 5} \% \text { confidence } \\
\text { interval }\end{array}$ & Wald & $\begin{array}{c}\text { Significance } \\
\text { level* }\end{array}$ \\
\hline Age (mean) & $16.2(2.5)$ & $\mathbf{1 . 2 5 1}$ & $1.064-1.470$ & 7.327 & $\mathbf{0 . 0 0 7}$ \\
Gender (\% girls) & $85.5 \%$ & 0.401 & $0.146-1.103$ & 3.133 & 0.077 \\
Diagnosis (\% chronic & $55.8 \% / 44.2 \%$ & $\mathbf{2 . 7 0 9}$ & $1.347-5.445$ & 7.822 & $\mathbf{0 . 0 0 5}$ \\
pain / chronic fatigue) & & & & & \\
Nagelkerke $\mathbf{R}^{2}$ & & $\mathbf{0 . 1 5 1}$ & & & \\
\hline
\end{tabular}

* The p-values below 0.05 are marked bold in the table

\section{Quality of life - physical functioning (PhS)}

After the introduction of age and gender in the first step, the next factor added to the model was pain/fatigue severity, which belongs to the ICF-block of body functions and structures. Pain/fatigue severity appeared to have a significant association with HRQoL-physical functioning (standardized $B=-0.253 ; t=-2.771(p=0.006)$ ) indicating that a higher level of pain/fatigue is related to a lower level of HRQoL- 
physical functioning. The explained variance of the model is $6.7 \%\left(R^{2}=0.067\right.$; $\left.\Delta R^{2}=0.060\right)$ with an $F$ change of $7.678(p=0.006)$.

\section{Quality of life - psychosocial functioning (PSS)}

In the first block, age and gender were added. During the second step, the three variables 'withdrawn', 'anxious/depressed' and 'passive coping reaction' were added to the model simultaneously, as they all belong to the ICF block of personal factors. Passive reaction coping style (standardized $B=-0.346 ; t=-2.007(p=0.048)$ ) contributed significantly, indicating that a higher level of a passive reaction style seemed related to a lower level of HRQoL-psychosocial functioning. The summary of this model is $R^{2}=0.182 ; \Delta R^{2}=0.152(\Delta F=4.587(p=0.005))$, indicating that the combination of factors in the model accounted for $18.2 \%$ of the total variance in psychosocial functioning. The results of the two linear regression analyses are presented in table 3.

For all regression models, co-linearity (VIF $>10)$ was not found for the independent variables.

\section{Discussion}

The primary aim of the present study was to assess factors associated with the level of school participation and quality of life in adolescents with musculoskeletal chronic pain or fatigue with impaired functioning. Our study included 172 adolescents with prolonged pain/fatigue complaints. Results indicated, first, that age and a diagnosis of fatigue (but not pain) were associated with school participation, which means that older adolescents and adolescents with chronic fatigue have a higher chance to drop out of school completely. Second, a higher level of pain/fatigue appeared to be related to a lower level of HRQoL-physical functioning. Third, a more passive coping strategy is associated with lower HRQoL-psychosocial functioning

School, and being able to participate in school, are an important topic in the adolescent's life. In our study sample, one third $(32.9 \%)$ of the adolescents were completely absent from school and almost half $(49.1 \%)$ were partially absent. From a clinical and societal point of view, this is definitely an undesirable phenomenon. The relationship between school participation on the one hand and age and fatigue on the other hand indicates that special attention should be paid during the treatment intake to older adolescents with a diagnosis of chronic fatigue. 
Table 3: Results of the linear regression analyses with baseline scores and confounders of the significant associated factors only (representing the pre-treatment situation) for HRQoL-physical functioning and HRQoL-psychosocial functioning

HRQoL - Physical functioning (PhS)

\begin{tabular}{|c|c|c|}
\hline & Standardized $ß$ & $t$ (p-value) \\
\hline \multicolumn{3}{|l|}{ Confounders } \\
\hline Age & -0.017 & $-0.188(0.851)$ \\
\hline Gender & 0.033 & $0.365(0.716)$ \\
\hline \multicolumn{3}{|l|}{ Body functions and structures } \\
\hline \multirow[t]{2}{*}{ Pain/fatigue severity } & -0.253 & $-2.771(0.006)$ \\
\hline & $\mathbf{R}^{2}$ & $\Delta \mathbf{R}^{2}$ \\
\hline \multirow[t]{3}{*}{ Result of the regression analysis } & 0.067 & 0.060 \\
\hline & \multicolumn{2}{|c|}{ HRQoL - Psychosocial functioning (PsS) } \\
\hline & Standardized $ß$ & $t$ (p-value) \\
\hline \multicolumn{3}{|l|}{ Confounders } \\
\hline Age & 0.010 & $0.088(0.930)$ \\
\hline Gender & 0.205 & $1.839(0.070)$ \\
\hline \multicolumn{3}{|l|}{ Personal factors } \\
\hline Passive coping reaction & -0.346 & $-2.007(0.048)$ \\
\hline Withdrawn & -0.029 & $-0.219(0.827)$ \\
\hline \multirow[t]{2}{*}{ Anxious/depressed } & -0.036 & $-0.207(0.837)$ \\
\hline & $\mathbf{R}^{2}$ & $\Delta \mathbf{R}^{2}$ \\
\hline Result of the regression analysis & 0.182 & 0.152 \\
\hline
\end{tabular}

* The p-values below 0.05 are marked bold in the table

In previous public research on the Dutch population, it was shown that increased school absence is related to a higher age segment, ${ }^{33}$ which corresponds to our results. Having fatigue even seems to have a larger influence on daily functioning than having pain. A possible explanation for this finding might be that adolescents with pain have more ways of compensation to ensure participation in school than their peers with fatigue. For example, adolescents with pain might use crutches or a wheelchair to circumvent limb pain or avoid carrying their schoolbooks in a backpack to circumvent lower back pain. These alternatives are not available to adolescents with fatigue, resulting in reduced school participation. Further research is needed to validate this hypothesis.

From a clinical perspective, it is expected that there are multiple factors that explain the level of school participation in adolescents with chronic pain/fatigue. Previous studies have mentioned several factors in relation to school functioning such as anxiety ${ }^{34}$ and depressive symptoms. ${ }^{20}$ Our results did not confirm the role of anxiety 
or depression in relation to school functioning. It might have been the case that our dichotomized outcome variable of school participation was not sensitive enough to identify the contribution of these factors.

Furthermore, the consequence of the presence of variables in the existing database might have been that we missed some contributing factors for school participation that had already been identified in previous studies. Pain catastrophizing, ${ }^{35}$ sleep problems, ${ }^{36}$ bullying, abuse and family conflict, ${ }^{9}$ and parent psychological flexibility ${ }^{37}$ might be suggested and studied as factors that could potentially have contributed to explaining the level of school participation. Unfortunately, these factors were not part of our database.

The adolescents included in this study had severe complaints and were substantially disabled for the performance of their daily activities and participation, as compared to their peers. ${ }^{38}$ Our results indicate that the severity of disability in adolescents before treatment is mainly expressed in physical functioning, as shown by the rather low score on parent reported $\mathrm{PhS}$ (mean=20.4 $(\mathrm{SD}=9.5)$ ) compared to the normal population (mean $\mathrm{PhS}=56.4(\mathrm{SD}=5.7)){ }^{24}$ As the population presently studied is referred to a rehabilitation clinic, this finding can be linked to the Dutch focus on movement-related impairments to pain rehabilitation. The relationship between the severity of complaints and the level of HRQoL-physical functioning was as expected.

Adolescents and their parents reported few psychosocial problems before treatment. Similar results were presented in a recent study on Dutch adults with chronic musculoskeletal pain. ${ }^{39}$ A previously published Australian study also supports our results. ${ }^{40}$ In addition, the same relationship was identified in earlier research on a cohort with self-reported chronic pain, ${ }^{4}$ which formed a representative sample of the Dutch population. ${ }^{41}$

In the regression analysis for psychosocial functioning, a passive reaction coping style was related to a lower level of HRQoL. From a clinical perspective, it may be expected that adolescents who classify themselves as having a passive coping style will join fewer social activities and retreat more into the home, where this behaviour might be visible to parents. By contrast, a lower score on HRQoLpsychosocial functioning is likely to be given by parents who have an adolescent with less visible withdrawn behaviour. As passive coping reaction was the only contributing factor identified, this means that many other as yet unknown factors or not available in the present dataset can be thought to influence the psychosocial part of HRQoL. Previous research has shown that potential contributing factors might be catastrophizing, fear-avoidance ${ }^{42}$ and anxiety. ${ }^{43}$ Unfortunately, catastrophizing and fear-avoidance were not available in our existing database. Nevertheless, a 
passive coping reaction can be addressed in treatment. This notion is supported by an earlier study, in which adolescents with a strong passive coping style before treatment seemed to show more improvement during treatment. ${ }^{38}$ Further research on this topic is warranted.

\section{Limitations}

There are a number of limitations that should be taken into account. This study has a cross-sectional design, as a result of which no causal relationships can be investigated. In addition, school participation is a very important aspect in the life of adolescents, including those with chronic pain or fatigue. In this study, school participation was categorised into three groups: normal school attendance, partial absence and complete absence from school. We were subsequently forced to dichotomise these categories for analysis, because the number of adolescents in our population who attended school fully was too low to be used as a single group in the analysis. As a result, this group was merged with the group with a partial school absence, which decreased the sensitivity of the outcome variable of school participation. For future studies, it is advised to use a continuous scale for school participation.

\section{Implications for clinical practice and recommendations for future research}

General practitioners and school physicians should pay extra attention to adolescents with prolonged fatigue complaints, as these adolescents have greater problems with school participation. Referral to rehabilitation might reduce the chances of dropping out of school further, because this treatment is aimed at optimizing participation.

Improvements to passive coping styles are likely to lead to an increase in psychosocial health-related quality of life. As a consequence, paying attention to passive coping in rehabilitation treatment is recommended.

The severity of both pain and fatigue, independent of the diagnosis, can play a significant role in an adolescent's physical functioning, as these frequently occur together. We therefore suggest that future research measure the severity of pain as well as the severity of fatigue.

\section{Conclusion}

In conclusion, older adolescents and adolescents with chronic fatigue have a higher chance of complete school absence. Adolescents with a higher level of pain/fatigue also have a lower level of HRQoL-physical functioning. Furthermore, because a passive reaction coping style seems to be related to a lower level of HRQoLpsychosocial functioning, it is important to address this aspect during treatment to improve psychosocial aspects of the adolescent's quality of life. 


\section{References}

1. Crawley, E., The epidemiology of chronic fatigue syndrome/myalgic encephalitis in children. Arch Dis Child, 2014. 99(2): p. 171-4.

2. Farmer, A., et al., Prevalence of chronic disabling fatigue in children and adolescents. $\mathrm{Br}$ J Psychiatry, 2004. 184: p. 477-81.

3. Haraldstad, K., et al., Pain in children and adolescents: prevalence, impact on daily life, and parents' perception, a school survey. Scand J Caring Sci, 2011. 25(1): p. 27-36.

4. Hunfeld, J.A., et al., Chronic pain and its impact on quality of life in adolescents and their families. J Pediatr Psychol, 2001. 26(3): p. 145-53.

5. King, S., et al., The epidemiology of chronic pain in children and adolescents revisited: a systematic review. Pain, 2011. 152(12): p. 2729-38.

6. Logan, D.E., et al., School impairment in adolescents with chronic pain. J Pain, 2008. 9(5): p. 407-16.

7. Roth-Isigkeit, A., et al., Pain among children and adolescents: restrictions in daily living and triggering factors. Pediatrics, 2005. 115(2): p. e152-62.

8. Simons, L.E., et al., The relation of social functioning to school impairment among adolescents with chronic pain. Clin J Pain, 2010. 26(1): p. 16-22.

9. Voerman, J.S., et al., Bullying, abuse and family conflict as risk factors for chronic pain among Dutch adolescents. Eur J Pain, 2015. 19(10): p. 1544-51.

10. Goossens, M.E. and J.A. Verbunt, Het meten van pijn bij kinderen en adolescenten, in Jaarboek Fysiotherapie Kinesitherapie 2012, P.N. Calders, J., Editor. 2012, Bohn Stafleu van Loghum: Houten.

11. Sleed, M., et al., The economic impact of chronic pain in adolescence: methodological considerations and a preliminary costs-of-illness study. Pain, 2005. 119(1-3): p. 183-90.

12. Groenewald, C.B., et al., The economic costs of chronic pain among a cohort of treatmentseeking adolescents in the United States. J Pain, 2014. 15(9): p. 925-33.

13. Missen, A., et al., The financial and psychological impacts on mothers of children with chronic fatigue syndrome (CFS/ME). Child Care Health Dev, 2012. 38(4): p. 505-12.

14. Gold, J.I., et al., Pediatric chronic pain and health-related quality of life. J Pediatr Nurs, 2009. 24(2): p. 141-50.

15. Cantrell, M.A. and M.M. Kelly, Health-related quality of life for chronically ill children. MCN Am J Matern Child Nurs, 2015. 40(1): p. 24-31.

16. Simon, A.E., K.S. Chan, and C.B. Forrest, Assessment of children's health-related quality of life in the United States with a multidimensional index. Pediatrics, 2008. 121(1): p. e118-26.

17. WHO, ICF, Nederlandse vertaling van de 'International classification of functioning, disability and health'. ed. W.-F.C. Centre. 2002, Houten: Bohn Stafleu van Loghum.

18. Lynch, A.M., et al., Psychosocial risks for disability in children with chronic back pain. J Pain, 2006. 7(4): p. 244-51.

19. Merlijn, V.P., et al., Factors related to the quality of life in adolescents with chronic pain. Clin J Pain, 2006. 22(3): p. 306-15.

20. Logan, D.E., L.E. Simons, and K.J. Kaczynski, School functioning in adolescents with chronic pain: the role of depressive symptoms in school impairment. J Pediatr Psychol, 2009. 34(8): p. 882-92. 
21. Crawley, E. and J.A. Sterne, Association between school absence and physical function in paediatric chronic fatigue syndrome/myalgic encephalopathy. Arch Dis Child, 2009. 94(10): p. 752-6.

22. Tsao, J.C., et al., Anxiety sensitivity and health-related quality of life in children with chronic pain. J Pain, 2007. 8(10): p. 814-23.

23. Landgraf, J.M., L. Abetz, and J.E. Ware, Child Health Questionnaire (CHQ): a user's manual. 1996, Boston, MA: The Health Institute, New England Medical Center.

24. Raat, H., et al., Reliability and validity of comprehensive health status measures in children: The Child Health Questionnaire in relation to the Health Utilities Index. J Clin Epidemiol, 2002. 55(1): p. 67-76.

25. Westendorp, T., et al., Responsiveness of the Child Health Questionnaire-Parent Form in adolescents with non-specific chronic pain or fatigue. Eur J Pain, 2014. 18(4): p. 540-7.

26. Schreurs, P.J.G., van de Willige, G., Brosschot, J.F., Tellegen, B., Graus, G.M.H., ed. Handleiding Utrechtse Coping Lijst UCL (herziene versie). 1993, Swets \& Zeitlinger: Lisse.

27. Achenbach, T.M., Integrative Guide to the CBCL/4-18, YSR, and TRF Profiles. 1991, Burlington, VT: University of Vermont, Department of Psychology.

28. Verhulst, F.C. and J. van der Ende, Six-year developmental course of internalizing and externalizing problem behaviors. J Am Acad Child Adolesc Psychiatry, 1992. 31(5): p. 924-31.

29. Hermans, H.J.M., Handleiding Prestatie Motivatie Test voor kinderen 1983 [Manual Achievement Motivation Test for children, version 1983]. 1983, Amsterdam: Swets \& Zeitlinger.

30. Luteijn, F., van Dijk, H., Barelds, D.P.H., NPV-J Junior Nederlandse Persoonlijkheids Vragenlijst. 1989: Harcourt Test Publishers.

31. Field, A., Discovering statistics using SPSS. 3rd ed. 2009, Londen: SAGE Publications Ltd.

32. Cook, R.D.W., S., Residuals and influence in regression. 1st edition ed. 1983, New York: Chapman \& Hall. 240.

33. NIPO, h.m. Rapport: Schoolverzuim in het Voorgezet Onderwijs. 2002.

34. Khan, K.A., et al., Predicting Multiple Facets of School Functioning in Pediatric Chronic Pain: Examining the Direct Impact of Anxiety. Clin J Pain, 2015. 31(10): p. 867-75.

35. Tran, S.T., et al., Distinct Influences of Anxiety and Pain Catastrophizing on Functional Outcomes in Children and Adolescents With Chronic Pain. J Pediatr Psychol, 2015. 40(8): p. 744-55.

36. Harrison, L., S. Wilson, and M.R. Munafo, Exploring the associations between sleep problems and chronic musculoskeletal pain in adolescents: a prospective cohort study. Pain Res Manag, 2014. 19(5): p. e139-45.

37. Wallace, D.P., et al., The role of parent psychological flexibility in relation to adolescent chronic pain: further instrument development. J Pain, 2015. 16(3): p. 235-46.

38. Westendorp, T., et al., Multidisciplinary Treatment for Adolescents with Chronic Pain and/ or Fatigue: Who Will Benefit? Pain Pract, 2016.

39. Koke, A.J., et al., Dutch Dataset Pain Rehabilitation in daily practice: Content, patient characteristics and reference data. Eur J Pain, 2016. 
Chapter 3

40. Nicholas, M.K., A. Asghari, and F.M. Blyth, What do the numbers mean? Normative data in chronic pain measures. Pain, 2008. 134(1-2): p. 158-73.

41. Perquin, C.W., et al., Pain in children and adolescents: a common experience. Pain, 2000. 87(1): p. 51-8.

42. Simons, L.E. and K.J. Kaczynski, The Fear Avoidance model of chronic pain: examination for pediatric application. J Pain, 2012. 13(9): p. 827-35.

43. Simons, L.E., C.B. Sieberg, and R.L. Claar, Anxiety and impairment in a large sample of children and adolescents with chronic pain. Pain Res Manag, 2012. 17(2): p. 93-7. 




\section{Chapter 4}

\section{Multidisciplinary treatment for adolescents with chronic pain/fatigue. Who will benefit?}

Tessa Westendorp, Jeanine A. Verbunt, Imelda J.M. de Groot, Sylvia C. Remerie, AnneMarie ter Steeg, Rob J.E.M. Smeets Pain Practice 2017;17(5);633-642. 


\begin{abstract}
Purpose: The aims of this study were, first, to determine the percentage of adolescents with chronic pain/fatigue successfully treated with rehabilitation treatment for chronic pain/fatigue and, second, to identify predictors for a successful rehabilitation treatment.
\end{abstract}

Method: Treatment success is scored based on a combination of pre-defined clinically relevant changes in four outcome measures: level of pain/fatigue, school absence, physical functioning, and psychosocial functioning. A forward stepwise logistic regression analysis with treatment success as dependent variable is performed to identify predictors for successful treatment.

Results: A total number of 172 adolescents (mean age $16.2(\mathrm{SD}=2.5) ; 85.5 \%$ girls) participated. Almost half (49.6\%) of the adolescents had a successful treatment. The explained variance for the complete model explaining treatment success was $49 \%(R 2=0.487)$. Patients with a higher level of pain/fatigue and a passive coping style pre-treatment improved most, and these factors could thus be indicated as predictors for successful treatment. Also gender significantly contributed to the prediction, in favour of boys.

Conclusions: Regarding the first aim, using pre-defined treatment success based on clinically relevant changes, half of the participants had a successful treatment. Concerning the second aim, adolescents with a high level of pain/fatigue and those with a high passive coping style pre-treatment have a better ability to change their functioning during treatment. Boys benefit more than girls. 


\section{Introduction}

Chronic pain and fatigue are both common complaints in childhood and adolescence. Prevalence rates vary from $4-40 \%$ for chronic pain, and $2-21 \%$ for chronic fatigue. ${ }^{1-4}$

Chronic pain and fatigue both have a considerable impact on the child's or adolescent's life, especially in important domains of functioning, such as school attendance, sports and leisure time activities. ${ }^{5,6}$ Various treatment modalities have been used for this group of patients to improve functioning, frequently involving cognitive behavioural treatment elements. ${ }^{7-10}$ In the Netherlands, adolescents with a high level of disability due to chronic musculoskeletal pain or chronic fatigue are often treated in an inpatient rehabilitation setting. Adolescents, with pain and/or fatigue as their main diagnosis, receive the same treatment, whereas they both have to deal with negative symptoms (pain or fatigue) having a negatively impact on their daily living and social participation. The main aim of this treatment is to increase the adolescents' level of activity and participation, despite pain or fatigue. ${ }^{11}$

However, it is currently unknown whether and to which extent rehabilitation treatment for adolescents with chronic pain/fatigue has the potency to result in a clinically relevant improvement in the area of activity and social participation. ${ }^{12}$

The results of a number of clinical studies using a pre-post design showed that multidisciplinary treatment resulted in an increase in physical and psychosocial functioning and a decrease in restrictions in daily life. An increase in school attendance was also reported. ${ }^{13-15}$ However, due to this treatment's design, it is uncertain whether the changes can be ascribed solely to the treatment. Furthermore, studies into this design reveal no information on the number of patients with clinically relevant improvement in functioning.

In 2009, Hechler et al. presented an alternative method that facilitates the interpretation of the individual treatment success of an inpatient pain programme for children and adolescents with chronic pain. ${ }^{16}$ This method is based on the identification of statistically and clinically relevant changes of pain-related variables and school absence, and defines overall amelioration of the effectiveness of treatment. In this study population, $55 \%(n=77)$ of the adolescents demonstrated overall amelioration. ${ }^{16}$

Defining the success of treatment at the individual level also enables the identification of predictors for successful treatment. This would allow the future selection of patients to be refined to those who are likely to benefit from treatment. Currently, no predictors for inpatient treatment success in adolescents with chronic musculoskeletal pain or fatigue are available in literature. 
A review of predictors for treatment outcome for adult patients with chronic low back pain showed consistent evidence for the finding that more pain (pain intensity) negatively affects outcome and, in addition, that a high level of satisfaction (workrelated factor) and less active coping lead to a better outcome. ${ }^{17}$ Paananen et al. (2010) identified the following predictors for the persistence of multiple pains in female adolescents with chronic musculoskeletal pain: internalising problems, short sleeping time, high physical activity level, and smoking. ${ }^{18}$ In addition, Hoftun et al. (2013) showed a positive association between parental chronic pain and chronic nonspecific pain in adolescents and young adults. ${ }^{19}$

Taking everything into consideration, our primary study aim is to identify the percentage of adolescents with chronic pain/fatigue successfully treated in a rehabilitation setting. Our second aim is to identify predictors for a successful rehabilitation treatment for adolescents with chronic musculoskeletal pain or chronic fatigue.

Based on currently available literature, we hypothesise that a higher pain/fatigue intensity pre-treatment, lower active coping and parental chronic pain are negative predictors for treatment success.

\section{Method}

\section{Design and population}

This prospective cohort study included adolescents in the age range from 1020 years who received an inpatient rehabilitation treatment for severe chronic musculoskeletal pain or chronic fatigue during the period between 2001 and 2005. All patients consulted a rehabilitation physician and were offered an inpatient treatment in case of:

a. moderate to severe disability in daily activities, leisure and sport, or social activities;

b. perceived chronic musculoskeletal pain or fatigue;

c. being absent from school for more than $20 \%$ over the last three months;

d. the presence of psychological and/or social factors associated with the persistence of the chronic pain/fatigue;

e. the patient being motivated to participate in treatment; and

f. participation of parents during the treatment. 


\section{Treatment}

The inpatient rehabilitation treatment as provided for adolescents with pain/fatigue was based on cognitive behavioural treatment principles, including elements such as modules of physical training, graded activity, cognitive behavioural therapy, relaxation, education for the adolescent combined with training/education for parents. Most of the modules are given individually, whereas the relaxation and education modules were given in groups. During treatment the weekend leaves were progressively extended to facilitate school reintegration. The outline of the treatment was comparable in all participating centres. ${ }^{20}$ Patients were treated in 5 rehabilitation centres in the Netherlands. The average duration of the treatment program was 14.6 weeks ( $\mathrm{SD}=9.5$; range 0.6-50.3).

\section{Procedure of assessment}

Patients entered the study consecutively. Before the start and directly after the end of the clinical treatment, the adolescent and one of the parents filled out a booklet with several questionnaires. The questionnaires were part of the clinical assessment and treatment procedure. In addition, the rehabilitation physician assessed demographic data, including gender, age, living situation, life events, education level and school absence by filling out a registration form before treatment. School absence was again registered by the physician at the end of treatment on a registration form. In the first week of treatment, a psychological screening assessment was performed for diagnostic purposes. The procedure of assessment was the same in all participating centres.

\section{Outcome measures}

\section{Primary outcome measure: outcome rehabilitation treatment}

The primary outcome measure is treatment success. The score for treatment success is based on a combination score of the result of four outcome measures: 1) level of pain/fatigue, 2) school absence, 3) physical functioning and 4) psychosocial functioning.

According to the method of Hechler et al. (2009), overall treatment success was defined as clinically relevant changes in at least two out of four outcome measures combined with no deterioration of the post-treatment score compared to the pretreatment score for the other measures. ${ }^{16}$ Additionally, our rationale for the definition is explained into the aim of rehabilitation treatment to increase the adolescents' level of activity and participation, despite pain or fatigue. Therefore the focus of treatment success is on these concepts of activity and participation. All outcome measures, including definitions of clinically relevant changes, are described below. 


\section{Pain/fatigue}

Outcome measure

The intensity of either pain or fatigue, depending on the type of diagnoses/ complaints, was measured before and after treatment with a Visual Analogue Scale (VAS). The patient was asked to indicate on a horizontal line of 100 millimetres the average level of pain/fatigue over the previous two weeks. The line covered the range from 'no pain at all' (0) to 'worst possible pain' (100).

\section{Clinically relevant change}

Ostelo \& de Vet (2005) identified the minimal clinically important change (MCIC) for pain on a VAS scale as $20 \mathrm{~mm}$ for chronic low back pain. ${ }^{21}$ Lee et al. (2003) showed that a reduction on a VAS scale of $30 \mathrm{~mm}$ corresponds with adequate pain control and is therefore the minimal clinically important difference (MCID). ${ }^{22}$ Pouchot et al. (2008) showed a minimal clinically important difference (MCID) for normalized fatigue numeric rating scale (NRS) score of 19.7 in rheumatoid arthritis (RA) patients. ${ }^{23}$ Furthermore Wolfe (2004) indicated that the use of a single item VAS for fatigue is sensitive to change and suitable for use in clinical care in RA patients compared to longer fatigue questionnaires. ${ }^{24}$ For the current study, we defined a decrease of $30 \mathrm{~mm}$ on the VAS scale for pain/fatigue as a clinically relevant change.

\section{School absence}

Outcome measure

Based on information of the adolescent and/or his/her parents, the physician scored the level of school absence in one of three categories: 1) normal school attendance, 2) partial absence, and 3) complete absence from school. This was done before the start of treatment and at the end of treatment.

Clinically relevant change

Each of the following improvements in school attendance was defined to be a clinically relevant change: from complete absence to partial absence, from complete absence to normal school attendance and from partial absence to normal school attendance. 


\section{Physical and psychosocial functioning}

Outcome measure

Physical and psychosocial functioning was measured by the Child Health Questionnaire - Parent Form (CHQ-PF50). The parent who filled out the questionnaires before treatment was again invited to fill out the questionnaires after treatment. For the CHQ-PF50, 'Physical' (PhS) and 'Psychosocial' (PsS) summary scores were calculated. The mean norm score in general populations is $50(\mathrm{SD} \pm 10),{ }^{25}$ which applies cross-culturally. According to the method of Landgraf et al. (1996), $\mathrm{PhS}$ and PsS summary scale scores are calculated by aggregating and transforming the 11 multi-item scale scores using a linear T-score transformation method. ${ }^{25} \mathrm{We}$ used both the PhS and PsS CHQ-PF50 summary score for data analysis in this study.

Clinically relevant change in physical functioning

Based on the method of Jacobson \& Truax, ${ }^{26}$ a cut-off score for clinically significant change was determined for the summary scale of PhS CHQ-PF50 according the following formula: $\mathrm{C}=\frac{s_{0} M_{1}+s_{1} M_{0}}{s_{0}+s_{1}}$. In this formula $\left(M_{0}\right)$ is the mean score, $\left(s_{0}\right)$ is the standard deviation of the pretest, $\left(M_{1}\right)$ is the mean score of a norm population and $\left(\mathrm{s}_{1}\right)$ is its standard deviation. The mean score for the pretest physical scale was $19.7(\mathrm{SD}=10.1)$ and the mean score of the norm population is $56.4(\mathrm{SD}=5.7),{ }^{27}$ resulting in a calculated cut-off point score of 43.2. Hence, a PhS score after treatment higher than this cut-off point was defined as a clinically relevant change.

\section{Clinically relevant change in psychosocial functioning}

The calculated cut-off point for the psychosocial scale is determined in a similar fashion to the method described for physical functioning. Based on the mean score for the pretest psychosocial scale of $42.4(\mathrm{SD}=9.6)$ and of the norm population of $53.2(\mathrm{SD}=6.4),{ }^{27}$ this results in a calculated cut-off point for the psychosocial scale of 48.9 . Hence, a PsS score after treatment higher than 48.9 was defined as a clinically relevant change.

Table 1 provides details on the four outcome measures included to define treatment success. 
Table 1: Definition of clinical relevant change for each of the four outcome variables and successful treatment

\begin{tabular}{ll}
\hline Outcome variable & Definition clinically relevant change \\
\hline Pain/fatigue & $\begin{array}{l}\text { Decrease of } 30 \mathrm{~mm} \text { on the VAS } \\
\text { Change from complete to partial absence or normal } \\
\text { school presence OR change from partial absence to } \\
\text { normal school presence (expert opinion) } \\
\text { A higher score than the calculated cut-off score (43.2) on } \\
\text { the summary scale of PhS CHQ-PF50 }\end{array}$ \\
Psychosocial summary scale (CHQ-PF50) & $\begin{array}{l}\text { A higher score than the calculated cut-off score (48.9) on } \\
\text { the summary scale of PsS CHQ-PF50 }\end{array}$ \\
Successful treatment & $\begin{array}{l}\text { A clinically relevant change on at least } 2 \text { out of } 4 \\
\text { outcome measures and no deterioration on the other } \\
\text { measures between pre- and post-treatment has to be } \\
\text { seen. }\end{array}$ \\
\hline
\end{tabular}

\section{Potential predictors or confounders}

Because of the limited availability of literature about predictors for treatment success in adolescents, consultations were held with five clinical experts (rehabilitation physicians and psychologists) with at least five years of experience in the field of rehabilitation of adolescents with chronic musculoskeletal pain or chronic fatigue. These experts identified the following potential predictors: duration of complaints, presence of life events, anxiety, and problems with peers.

In the clinical test battery, which included the questionnaire and psychological screening, the following outcome measures were available: pain or fatigue severity assessed based on a VAS, duration of complaints, family member with pain/fatigue history, Utrecht Coping List $(\mathrm{UCL})^{28}$ for coping style, Youth Self Report (YSR) ${ }^{29,30}$ for competence, emotional and behavioural problems, Achievement Motivation Test $(\mathrm{PMT})^{31}$ for personality traits regarding attitude to school, and Personality Questionnaire for Youth (NPV-J) $)^{32}$ for personality traits.

Based on the literature search, the expert opinion and availability in the database, potential predictors were identified and used to build a predictive model for clinically relevant improvement of inpatient pain rehabilitation. Besides the potential predictors, we indicated age and gender as potential confounders in the prediction model. These potential confounders can affect both treatment success and the potential predictors.

To describe a person's individual level of functioning in the rehabilitation setting, the International Classification of Functioning, Disability and Health (ICF) is often 
used. ${ }^{12}$ For the eventual prediction model, we therefore used the ICF model as a framework to assign potential predictors to a category within the ICF model and entered each ICF category separately in the analysis. The potential confounders of age and gender were first added in the analysis, before entering the following ICF blocks with potential predictors:

ICF block 'body functions and structures'

- Pain or fatigue severity pre-treatment (VAS 0-100)

- Duration of complaint pre-treatment (in months)

ICF block 'environmental factors'

- Family member with pain/fatigue history (present - not present)

ICF block 'personal factors'

- Presence of life events (presence of life events related to one's family [divorce, death, removal], to school [to repeat a class, bullying, difficulties with social relations] or other, present - not present)

- Avoidance (run its course or out of the way) as coping style (UCL - range: 8-32 points $)^{28}$

- Passive reaction (not able to do anything about the situation, mulling over the past. A higher score for passive coping reaction means a more negative sight on life-related topics) as coping style ( $U \mathrm{CL}$ - range: $7-28)^{28}$

- Internalisation (depressive, anxious, bodily complaints) (Dutch YSR - range: $0-52$ points $)^{29,30}$

- Positive anxiety (fear that brings someone in an optimal stress state, in which functioning is better than in normal circumstances) (Dutch PMT - range: 0-18). The scores for Children-PMT (PMT-K) and Adolescent-PMT (PMT) were standardised. ${ }^{31}$

- Negative anxiety (fear that leads to dysfunction) (PMT - range: 0-26). The scores for Children-PMT (PMT-K) and Adolescent-PMT (PMT) were standardised. ${ }^{31}$

- Social inadequacy representing problems with peers (Dutch NPV-J - range: $0-26$ points $)^{32}$

\section{Statistical analyses}

To gain insight into the research population, descriptive analyses were performed. To answer the first research question, the number of significant changes and clinically relevant changes of the outcome measures between pre- and post-treatment were computed.

\section{Statistical significance}

To determine whether the changes pre- and post-treatment for the 4 outcome 
measures of pain/fatigue severity, school absence, physical functioning and psychosocial functioning were statistically significant, paired sample T-tests were performed for the continuous variables that were normally distributed, and the Wilcoxon Matched-Pair Signed Rank Test was used for non-normal distributed and categorical variables. The level of significance was set at $\mathrm{p}<0.05$.

\section{Clinically relevant change}

On the basis of the above-mentioned criteria, the pre-post treatment changes for the 4 outcome measures were assessed for clinical relevance.

For each of the four outcome measures, the percentage of the study population showing a clinically relevant change was calculated separately. To define treatment success, the percentage of amelioration and deterioration of each outcome measure were computed.

\section{Prediction}

A forward stepwise logistic regression analysis was performed with treatment success as dependent variable. In the first step, the potential confounders' ages and genders were introduced in the model. In the following steps, the ICF blocks were individually entered in the model. For the regression analysis, standardised beta coefficients and their significance were tested under the null hypothesis that the coefficients differ from zero.

To check for co-linearity, variable inflation factors (VIF) were checked and had to be below $10 .{ }^{33}$ Outliers, if any, with a Cook distance above 1 were removed from the model. ${ }^{34}$

All statistical analyses were performed using SPSS (software version 20.0) (SPSS Inc., Chicago, III).

\section{Results}

\section{Population}

A total number of 172 adolescents (mean age 16.2 (SD=2.5); 85.5\% girls) participated. $90.5 \%$ of the patients were mandatory school attenders, and of these $38.9 \%$ were in high school. $86.9 \%$ lived in a two-parent family. Almost one third $(29.5 \%)$ had a family member with pain/fatigue complaints. The use of medication for chronic pain/fatigue before treatment was 35.2\%, and $28.3 \%$ used aids, mostly for walking (e.g. a wheelchair, walker, or walking stick). Table 2 presents a detailed description of the different types of diagnoses/complaints. 
Table 2: The distribution of the variety in complaints in the research population in number and percentage

\begin{tabular}{lc}
\hline Description of complaints & Number (\%) \\
\hline Nonspecific neck complaints & $13(7.6)$ \\
Nonspecific back complaints & $20(11.6)$ \\
Fibromyalgia & $8(4.7)$ \\
Complex regional pain syndrome & $22(12.8)$ \\
Chronic fatigue syndrome & $76(44.2)$ \\
Other nonspecific musculoskeletal complaints (whole body) & $33(19.2)$ \\
\hline
\end{tabular}

\section{Significant change}

Statistically significant differences $(p<0.001)$ between pre- and post-treatment were found for all four outcome variables: level of pain/fatigue, school absence, physical functioning and psychosocial functioning. Table 3 presents changes and 95\% confidence intervals for the outcome variables.

\section{Clinically relevant change and successful rehabilitation treatment}

Table 3 presents for each outcome variable the pre- and post-treatment scores and the number of participants who showed a clinically relevant improvement according to the definition. Therefore, based on our criteria, $49.6 \%$ of the participants achieved a successful treatment.

\section{Predictors for successful treatment}

A forward stepwise logistic regression analysis was performed for the dependent variable successful treatment. No co-linearity (VIF>10) was found and also no outliers could be identified. 
Table 3: Pre- and post-treatment scores for the four outcome variables when available within the study sample $(\mathrm{n}=172)$

\begin{tabular}{|c|c|c|c|c|}
\hline Outcome variable & $\begin{array}{c}\text { Pre- } \\
\text { treatment } \\
\text { score (SD) }\end{array}$ & $\begin{array}{c}\text { Post- } \\
\text { treatment } \\
\text { score (SD) }\end{array}$ & $\begin{array}{c}\text { Difference between } \\
\text { pre-/post-treatment } \\
\text { [Confidence } \\
\text { Interval] }\end{array}$ & $\begin{array}{c}\text { Number of } \\
\text { patients with a } \\
\text { clinically relevant } \\
\text { improvement (\%) }\end{array}$ \\
\hline $\begin{array}{l}\text { Pain/fatigue (on 0-100 mm } \\
\text { VAS) }\end{array}$ & $67.8(19.9)$ & $31.1(24.2)$ & $\begin{array}{c}-36.7 \\
{[-42.0 \text { to }-31.4]^{*}}\end{array}$ & 77 (61.6) \\
\hline School absence & & & & $70(54.7)$ \\
\hline normal attendance & $16.9 \%$ & $43.6 \%$ & $26.7 \% *$ & \\
\hline partial absence & $45.9 \%$ & $34.9 \%$ & $-11.0 \%$ & \\
\hline complete absence & $30.8 \%$ & $1.2 \%$ & $-29.6 \%$ & \\
\hline $\begin{array}{l}\text { Physical functioning } \\
(\mathrm{CHQ}-\mathrm{PF} 50)^{\mathrm{a}}\end{array}$ & $19.2(10.4)$ & $39.7(14.3)$ & $\begin{array}{c}20.5 \\
{[17.7 \text { to } 23.2]^{*}}\end{array}$ & $56(51.4)$ \\
\hline $\begin{array}{l}\text { Psychosocial functioning } \\
\text { (CHQ-PF50) }^{\mathrm{a}}\end{array}$ & $42.1(9.7)$ & $50.2(8.6)$ & $\begin{array}{c}8.1 \\
{[6.2 \text { to } 10.2]^{*}}\end{array}$ & $71(65.1)$ \\
\hline Successful treatment & - & - & & $68(49.6)$ \\
\hline
\end{tabular}

${ }^{*} p<0.001$ for differences between pre- and post-treatment

${ }^{\text {a }}$ The mean population scores for the physical and psychosocial functioning scale of the CHQ-PF50 are 50

The explained variance for the complete model was $49 \%\left(R^{2}=0.487\right)$, indicating that the relation between the dependent variable and independent variables is moderate. In table 4 the change in explained variance per block of variables into the analysis is presented. The level of pain/fatigue $(B(\mathrm{SE})=0.85(0.41) ; \mathrm{p}=0.037)$ and a passive coping reaction $(B(S E)=0.37(0.17) ; p=0.032)$ pre-treatment appeared to be predictors for a successful treatment. This means that the chance of a successful treatment outcome increases by 0.85 with every $\mathrm{mm}$ higher on the VAS scale for the level of pain/fatigue, and by 0.37 with every point higher on the passive coping scale. Also gender significantly contributed to the prediction ( $B(S E)=-3.99(1.62)$; $p=0.013$ ). This variable was defined beforehand as a confounder. The chance of a successful treatment outcome for boys is four times higher than for girls. A complete overview of the results is shown in table 5. 
Table 4: The explained variance, $\mathrm{R}^{2}$, change in $\mathrm{R}^{2}$ and the increase of the explained variance per added block in the forward stepwise logistic regression analysis

\begin{tabular}{|c|c|c|c|c|}
\hline $\begin{array}{l}\text { Added blocks into forward } \\
\text { stepwise logistic regression }\end{array}$ & $\begin{array}{c}\text { Explained } \\
\text { variance (\%) }\end{array}$ & Nagelkerke $\mathbf{R}^{2}$ & $\begin{array}{c}\text { Change in } \\
\text { Nagelkerke } R^{2} \\
\text { (after adding the } \\
\text { next block) }\end{array}$ & $\begin{array}{c}\text { Gradually increase } \\
\text { of explained } \\
\text { variance }(\%)\end{array}$ \\
\hline $\begin{array}{l}\text { Block confounders: } \\
\text { Age } \\
\text { Gender }\end{array}$ & $20 \%$ & 0.204 & & \\
\hline $\begin{array}{l}\text { ICF Block 'body functions and } \\
\text { structures': } \\
\text { Level of pain/fatigue } \\
\text { Duration of complaints }\end{array}$ & $35 \%$ & 0.346 & 0.142 & $69.6 \%$ \\
\hline $\begin{array}{l}\text { ICF Block 'environmental } \\
\text { factors': } \\
\text { Family pain/fatigue history }\end{array}$ & $36 \%$ & 0.362 & 0.016 & $4.6 \%$ \\
\hline $\begin{array}{l}\text { ICF Block 'personal factors': } \\
\text { Life events } \\
\text { Avoidance coping } \\
\text { Passive coping reaction } \\
\text { Internalisation } \\
\text { Positive anxiety } \\
\text { Negative anxiety } \\
\text { Peer problems }\end{array}$ & $49 \%$ & 0.487 & 0.125 & $34.5 \%$ \\
\hline
\end{tabular}

Table 5: The results of the linear regression analysis (Beta and $p$-value) $(n=172)$ with the potential predictor variable baseline scores (representing the situation pre-treatment)

\begin{tabular}{lcc}
\hline Variable & Baseline score (SD) & Beta (p-value) \\
\hline Age (mean) & $16.2(2.5)$ & $0.306(0.135)$ \\
Gender (\% girls) & 85.5 & $\mathbf{- 3 . 9 9 1 ( 0 . 0 1 3 )}$ \\
Pain/fatigue pre-treatment (VAS 0-100 in mm) & $68.7(19.6)$ & $\mathbf{0 . 8 5 1}(\mathbf{0 . 0 3 7 )}$ \\
Duration of the complaint pre-treatment (in months) & $36.0(28.2)$ & $-0.270(0.415)$ \\
Family pain/fatigue history (\% present) & $29.5 \%$ & $0.528(0.455)$ \\
Life events (\% present) & $50.0 \%$ & $-1.295(0.095)$ \\
Coping style - avoidance (\% above average) & $30.9 \%$ & $0.052(0.656)$ \\
Coping style - passive reaction (\% above average) & $36.5 \%$ & $\mathbf{0 . 3 7 2}(\mathbf{0 . 0 3 2})$ \\
Anxiety - internalisation (mean) & $18.1(8.9)$ & $-0.092(0.096)$ \\
Anxiety - positive anxiety (mean) & $9.3(4.5)$ & $-0.137(0.202)$ \\
Anxiety - negative anxiety (mean) & $14.0(6.8)$ & $-0.001(0.988)$ \\
Social inadequacy - peer problems (\% under average) & $38.0 \%$ & $-0.073(0.303))$ \\
\hline
\end{tabular}

* The p-values below 0.05 are marked bold in the table 


\section{Discussion}

This study assessed the percentage of treatment success among adolescents who underwent an inpatient rehabilitation treatment for chronic musculoskeletal pain or chronic fatigue associated with severe disability, and was aimed at gaining insight into predictors for this success.

Our results show that, following the defined description of a successful treatment, almost half of the participants $(49.5 \%)$ were successfully treated for their chronic musculoskeletal pain or chronic fatigue complaints. The level of pre-treatment pain/ fatigue and passive coping reaction predicted this treatment success. Higher levels of pain/fatigue and a passive coping style pre-treatment increased the chance for a successful treatment outcome. Furthermore, gender was found to be an important confounder, meaning that boys had a higher chance of treatment success.

In our study, the definition of a successful rehabilitation treatment is based on statistically significant as well as predefined clinically relevant changes for at least two of four outcome measures and without deterioration in any of these four measures. We believe we described our method to define treatment success thoroughly and were strict in our criteria. Despite these rather strong and strict criteria, still around $50 \%$ of the patients were treated successfully.

The finding that pre- and post-treatment outcomes differed significantly are in line with findings in other studies on multidisciplinary treatment for children and adolescents with chronic pain showing positive changes in disability, level of pain and anxiety after treatment. ${ }^{7,13,15}$ However, it was unclear whether these changes presented in those studies were also clinically relevant. The study of Hechler et al. (2009) was the first study that focused on the clinical relevance of changes during treatment by applying clearly defined rules for clinical relevance. ${ }^{16}$ Based on our adapted set of rules, we found comparable results: $50 \%$ of the patients had a successful treatment, compared to $55 \%$ in the Hechler et al. (2009) study. ${ }^{16}$ The difference in treatment success could be due to a difference in study population. The percentage of boys in the population of Hechler et al. (2009) was considerably higher $(38 \%$ versus $15 \%)$ than in our research sample. ${ }^{16}$ This might have caused a higher success rate as boys in our study had a better chance of treatment success. Furthermore, the diagnoses of the study population of Hechler et al. (2009) consisted for $63 \%$ of adolescents with headache and abdominal pain, ${ }^{16}$ whereas these complaints are not treated within the rehabilitation setting in the Netherlands and are therefore not included in our sample. Considering that we used a very strict definition for treatment success and that these patients had already been experiencing complaints during a considerable amount of time (mean: 36 months before treatment), we may conclude that a multidisciplinary rehabilitation treatment 
of adolescents with severe chronic musculoskeletal pain or fatigue is worthwhile since it positively influences the level of complaints, activity and participation for a considerable part of this population.

We identified 2 predictors for treatment success: pre-treatment level of pain/fatigue and passive coping style. In addition, gender was identified as a confounder. First, the predictive value of pre-treatment pain/fatigue can be explained by the fact that a higher level of pain/fatigue offers more possibility to improve during treatment. Our definition of clinically relevant change on the level of pain/fatigue supports this because we defined a specific amount of reduction $(30 \mathrm{~mm})$ as clinically relevant instead of a percentage of change.

Regarding the second predictor, the treatment seemed indeed to be more successful for patients with an originally passive coping reaction. Possibly because, during treatment these patients were coached to concur and/or restructure their negative thoughts about the impossibility of being physically active because of musculoskeletal pain or severe fatigue. It might be that patients with a higher tendency to cope in a passive way benefit more from this cognitive behavioural treatment.

Third, gender was identified as a confounder. The chance of boys having a successful treatment is much higher than for girls. If we look at the outcome measures of treatment success, there is a remarkable difference between boys and girls in terms of physical functioning, diverse to the other outcome measures where no differences between genders were shown. The average PhS score for boys (48.6) is five points above the cut-off point for clinically relevant change (43.2) and the average score for girls (38.2) five points below this cut-off point. This difference in physical functioning, with more boys being in the successful treatment group, might explain the higher chance of boys having treatment success. This corresponds with the idea that, during puberty, the focus for boys is more on physical activity and for girls more on social activities. ${ }^{35}$

\section{Limitations}

Our study was performed in a clinical rehabilitation setting in the Netherlands without the presence of a control group. Therefore, it is not possible to correct the results for the natural course of the severity of complaints and perceived disability. However, because of the long duration of complaints pre-treatment, the improvement is unlikely to be caused by spontaneous improvement alone. The effectiveness of multidisciplinary treatment is also confirmed based on recently published randomised controlled trial (RCT) of Hechler et al. (2014). ${ }^{36}$ Using the same definition as the study of Hechler et al. (2009), it was shown that intensive multidisciplinary pain treatment is successful in $55 \%$ of the participants versus 
$14 \%$ in the waiting-list control group. ${ }^{16}$ Future RCTs are necessary to confirm these positive effects of generalizable multidisciplinary treatment for this population. However, as long as the resources for performing RCTs are limited, clinical studies like ours using clear definitions of successful outcome are the best available alternative. Likewise, the search for predictors of treatment success can also be more developed.

A second limitation in this study is the choice for the potential predictors in the regression analyses. The choice of potential predictors was limited by the availability of the instruments within the clinical database of this cohort. Due to the size of the study sample and the questionnaires available, it was possible to include 12 potential predictors, which offered us the opportunity to test the hypothesized prediction model for treatment success. To test the validity of the model, the model has to be tested on other adolescent populations.

\section{Implications for clinical practice and recommendations for future research}

The predictors as identified might contribute to a better pre-selection of patients for rehabilitation treatment. The level of pain/fatigue and passive coping style as significant predictors for treatment success need to be taken into account in this pre-selection. With this information, the rehabilitation physician can better manage the expectations regarding treatment results.

\section{Conclusion}

Treatment will be most successful for adolescents with a high level of pain/fatigue and those with a high passive coping reaction before multidisciplinary rehabilitation. Boys will benefit more than girls. 


\section{References}

1. Farmer, A., et al., Prevalence of chronic disabling fatigue in children and adolescents. $\mathrm{Br}$ J Psychiatry, 2004. 184: p. 477-81.

2. Haraldstad, K., et al., Pain in children and adolescents: prevalence, impact on daily life, and parents' perception, a school survey. Scand J Caring Sci, 2011. 25(1): p. 27-36.

3. King, S., et al., The epidemiology of chronic pain in children and adolescents revisited: a systematic review. Pain, 2011. 152(12): p. 2729-38.

4. ter Wolbeek, M., et al., Severe fatigue in adolescents: a common phenomenon? Pediatrics, 2006. 117(6): p. e1078-86.

5. Crawley, E. and J.A. Sterne, Association between school absence and physical function in paediatric chronic fatigue syndrome/myalgic encephalopathy. Arch Dis Child, 2009. 94(10): p. 752-6.

6. Konijnenberg, A.Y., et al., Children with unexplained chronic pain: substantial impairment in everyday life. Arch Dis Child, 2005. 90(7): p. 680-6.

7. Eccleston, C., et al., Chronic pain in adolescents: evaluation of a programme of interdisciplinary cognitive behaviour therapy. Arch Dis Child, 2003. 88(10): p. 881-5.

8. Kashikar-Zuck, S., et al., Changes in pain coping, catastrophizing, and coping efficacy after cognitive-behavioral therapy in children and adolescents with juvenile fibromyalgia. J Pain, 2013. 14(5): p. 492-501.

9. Viner, R., et al., Outpatient rehabilitative treatment of chronic fatigue syndrome (CFS/ ME). Arch Dis Child, 2004. 89(7): p. 615-9.

10. Wicksell, R.K., et al., Evaluating the effectiveness of exposure and acceptance strategies to improve functioning and quality of life in longstanding pediatric pain--a randomized controlled trial. Pain, 2009. 141(3): p. 248-57.

11. Westendorp, T., et al., Responsiveness of the Child Health Questionnaire-Parent Form in adolescents with non-specific chronic pain or fatigue. Eur J Pain, 2014. 18(4): p. 540-7.

12. WHO, ICF, Nederlandse vertaling van de 'International classification of functioning, disability and health'. ed. W.-F.C. Centre. 2002, Houten: Bohn Stafleu van Loghum.

13. de Blecourt, A.C., et al., Preliminary evaluation of a multidisciplinary pain management program for children and adolescents with chronic musculoskeletal pain. Disabil Rehabil, 2008. 30(1): p. 13-20.

14. Klineberg, E., et al., Adolescent chronic fatigue syndrome and somatoform disorders: a prospective clinical study. J Paediatr Child Health, 2014. 50(10): p. 775-81.

15. Maynard, C.S., et al., Interdisciplinary behavioral rehabilitation of pediatric painassociated disability: retrospective review of an inpatient treatment protocol. J Pediatr Psychol, 2010. 35(2): p. 128-37.

16. Hechler, T., et al., Effectiveness of a 3-week multimodal inpatient pain treatment for adolescents suffering from chronic pain: statistical and clinical significance. Clin J Pain, 2009. 25(2): p. 156-66.

17. van der Hulst, M., M.M. Vollenbroek-Hutten, and M.J. Ijzerman, A systematic review of sociodemographic, physical, and psychological predictors of multidisciplinary rehabilitation-or, back school treatment outcome in patients with chronic low back pain. Spine (Phila Pa 1976), 2005. 30(7): p. 813-25.

18. Paananen, M.V., et al., Risk factors for persistence of multiple musculoskeletal pains in 
adolescence: a 2-year follow-up study. Eur J Pain, 2010. 14(10): p. 1026-32.

19. Hoftun, G.B., P.R. Romundstad, and M. Rygg, Association of parental chronic pain with chronic pain in the adolescent and young adult: family linkage data from the HUNT Study. JAMA Pediatr, 2013. 167(1): p. 61-9.

20. Dutch Expert Group for Children in Pain and Fatigue, Elements of treatment for chidren and adolescents with chronic musculoskeletal pain - consensus report. 2008, Rotterdam: Rijndam Rehabilitation.

21. Ostelo, R.W. and H.C. de Vet, Clinically important outcomes in low back pain. Best Pract Res Clin Rheumatol, 2005. 19(4): p. 593-607.

22. Lee, J.S., et al., Clinically important change in the visual analog scale after adequate pain control. Acad Emerg Med, 2003. 10(10): p. 1128-30.

23. Pouchot, J., Kherani, R.B., Brant, R., et al. Determination of the minimal clinically important difference for seven fatigue measures in rheumatoid arthritis. J Clin Epidemiol. 2008;61:705-713.

24. Wolfe, F. Fatigue assessments in rheumatoid arthritis: comparative performance of visual analog scales and longer fatigue questionnaires in 7760 patients. J Rheumatol.2004;31:1896-1902.

25. Landgraf, J.M., L. Abetz, and J.E. Ware, Child Health Questionnaire (CHQ): a user's manual. 1996, Boston, MA: The Health Institute, New England Medical Center.

26. Jacobson, N.S. and P. Truax, Clinical significance: a statistical approach to defining meaningful change in psychotherapy research. J Consult Clin Psychol, 1991. 59(1): p. 12-9.

27. Raat, H., et al., Reliability and validity of comprehensive health status measures in children: The Child Health Questionnaire in relation to the Health Utilities Index. J Clin Epidemiol, 2002. 55(1): p. 67-76.

28. Schreurs, P.J.G., van de Willige, G., Brosschot, J.F., Tellegen, B., Graus, G.M.H., ed. Handleiding Utrechtse Coping Lijst UCL (herziene versie). 1993, Swets \& Zeitlinger: Lisse.

29. Achenbach, T.M., Integrative Guide to the CBCL/4-18, YSR, and TRF Profiles. 1991, Burlington, VT: University of Vermont, Department of Psychology.

30. Verhulst, F.C. and J. van der Ende, Six-year developmental course of internalizing and externalizing problem behaviors. J Am Acad Child Adolesc Psychiatry, 1992. 31(5): p. 924-31.

31. Hermans, H.J.M., Handleiding Prestatie Motivatie Test voor kinderen 1983 [Manual Achievement Motivation Test for children, version 1983]. 1983, Amsterdam: Swets \& Zeitlinger.

32. Luteijn, F., van Dijk, H., Barelds, D.P.H., NPV-J Junior Nederlandse Persoonlijkheids Vragenlijst. 1989: Harcourt Test Publishers.

33. Kutner, M.H., Nachtsheim, C.J., Neter, J., Applied Linear Regression Models. 5th edition ed. 2004, Irwin: McGraw-Hill.

34. Cook, R.D.W., S., Residuals and influence in regression. 1st edition ed. 1983, New York: Chapman \& Hall. 240.

35. Nelis, H., Van Sark, Y., Puberbrein binnenstebuiten. 13rd ed. 2014, Utrecht: Kosmos Uitgevers. 264. 
36. Hechler, T., et al., Inpatient-based intensive interdisciplinary pain treatment for highly impaired children with severe chronic pain: randomized controlled trial of efficacy and economic effects. Pain, 2014. 155(1): p. 118-28. 



\section{Chapter 5}

\section{Social functioning in adulthood:}

Understanding long-term outcomes of adolescents with chronic pain/fatigue treated at inpatient rehabilitation programs

Tessa Westendorp, Jeanine A. Verbunt, Sylvia C. Remerie, Aleid C.E. de Blécourt, Bianca van Baalen, Rob J.E.M. Smeets European Journal of Pain 2016;20;1121-1130. 


\begin{abstract}
Background: Chronic pain and fatigue are both common complaints in childhood and adolescence and often persist over time. The aim of the study was to investigate whether chronic pain/fatigue persists during adulthood and how former patients function and participate in society as adults.
\end{abstract}

Methods: This historical cohort study used questionnaires to gather the data. Predictors for social participation in adulthood were also identified. Differences in functioning and health care use between young adults with current pain/fatigue complaints and those without were also discussed.

Results: 94 young adults responded; their mean age was 26.6 years and $91.5 \%$ were female. The average time since treatment was 10.2 years. $63.4 \%$ reported ongoing or new pain/fatigue complaints. $72.0 \%$ had a paid job; of those who worked, $22.1 \%$ reported taking sick leave in the past month. $78.7 \%$ of them reported having one or more chronic diseases.

A higher level of pain/fatigue measured pre-treatment was identified as a predictor for more impaired social participation in adulthood. Young adults with current pain/ fatigue complaints reported more healthcare utilization, lower levels of physical functioning and limitations in daily activities due to physical problems.

Conclusions: A considerable number of these young adults still have pain/fatigue complaints in adulthood. More pain/fatigue pre-treatment during adolescence predict impaired functioning in the work-educational domain in young adulthood. 


\section{Introduction}

Chronic pain and fatigue are both common in childhood and adolescence. Prevalence rates vary from $4-40 \%$ for chronic pain and $2-21 \%$ for chronic fatigue..$^{1-5}$ Both complaints often persist over time, from childhood and adolescence into adulthood. ${ }^{6,7}$

Both pain and fatigue have considerable negative impacts on a child's or adolescent's life in important domains, like school, sports and leisure. ${ }^{2,8,9}$ Pain and fatigue, often reported together, ${ }^{10}$ can negatively impact physical functioning, $\operatorname{mood}^{8}$ and quality of life ${ }^{11}$ and lead to high use of health care services. ${ }^{12}$ Chronic pain or fatigue in adolescents can also have an enormous economic impact on families ${ }^{13}$ and society (e.g. due to restricted work potential in adulthood). ${ }^{14}$

Adolescents with chronic pain or fatigue are often treated in a rehabilitation setting in which the International Classification of Functioning, Disability and Health (ICF) is used as a framework to describe an individual's functioning. ${ }^{15,16}$ Participation, one component of the ICF-model, is considered the most relevant rehabilitation outcome, and social participation refers to 'involvement in a life situation'. ${ }^{17}$

However, the literature contains limited information on adult daily functioning, social participation and health care consumption of adolescents confronted with severe chronic pain or fatigue. Results based on two 13-year-follow-up surveys indicate that pain or fatigue reported in childhood and adolescence are associated with pain or fatigue in early adulthood. ${ }^{18,19}$ Walker et al. (2010) found that youth with functional abdominal pain during adolescence that persists into adulthood may have increased risk for developing headache and chronic pain in different body parts. ${ }^{20}$ Regardless of persisting symptoms, it appears that the quality of life (HRQoL) reported by these youth six years after referral for paediatric pain is comparable to that of healthy peers. ${ }^{21}$ It is unclear whether HRQoL relates to the persistence of complaints or whether differences in functioning exist between adults with and without complaints.

The level of fatigue during adolescence has been reported as the best predictor for fatigue in young adulthood. ${ }^{22}$ Multiple pains in adolescents were associated with more internalizing and externalizing problems, short sleeping time, and smoking. ${ }^{23}$ But it is unclear whether these factors also predict social participation in adulthood.

The overall aim of this study is to increase our knowledge about the future functioning and long-term social participation in adulthood of adolescents with chronic pain or fatigue that is treated by inpatient rehabilitation. First, we will gain insight into their situations as young adults. Second we will identify pre-rehabilitation treatment predictors for social participation in later life. Third, we will discuss differences in 
health care utilization, participation and quality of life between young adults with and without chronic pain or fatigue.

\section{Methods}

Approval for this study was received from the Medical Ethical Committee of the Erasmus Medical Center (reference number: MEC-2010-317). All statistical analyses were performed using SPSS (software version 20.0; SPSS Inc., Chicago, III).

\section{Participants}

This historical cohort study included adolescents who received inpatient rehabilitation treatment for severe chronic pain or chronic fatigue in one of five rehabilitation centers in the Netherlands. They had the following International Classification of Diseases (ICD-diagnoses); nonspecific neck complaints (723.9), nonspecific back complaints (724.2), fibromyalgia (729.1), other nonspecific complaints (729.9), complex regional pain syndrome (733.7) or chronic fatigue syndrome (780.7).

The adolescents participated in one of two inception cohort studies. The National cohort study consisted of 172 adolescents (mean age 16.2 (SD=2.5); 85.5\% girls) who participated in inpatient rehabilitation treatment between 2002 and 2005. The Friesland cohort study consisted of 70 adolescents (mean age 15.1 (SD=2.6); $91.4 \%$ girls) who participated in inpatient rehabilitation treatment for chronic pain between 1992 and 2000. These patients were treated at the rehabilitation center of rehabilitation Friesland. ${ }^{24}$

The patients in both studies received inpatient treatment based on cognitive behavioral treatment principles that included elements such as graded activity, cognitive behavioral therapy, relaxation, education and involvement and counseling of the parents. During treatment, weekend leaves were progressively extended to facilitate the patients' ability to partly resume school participation. The outline of the treatment was identical in all the participating centers. No fundamental changes in the treatment approach took place during the 13-year treatment period of the two cohorts.

\section{Procedure}

To retrieve the addresses of participants in these two inception cohorts, we explored patient files in 2011. First, we phoned those former patients for whom a phone number was available. If a person could be reached, he/she was asked whether he/ she was willing to participate in the study and was asked for a current address. If a 
person could not be contacted by phone, we searched for his/her address on social media (e.g. Facebook, Hyves and Linkedln).

If a current address could be identified, the potential participant was sent an envelope with information about the study. This included an informed consent form, a return envelope and a questionnaire about his/her social level of participation, daily functioning, pain/fatigue complaints, activity level, ability to work, quality of life and health care utilization. Participants were asked to return the signed consent form and the completed questionnaire. If a potential participant did not respond within four weeks, we sent a reminder. If no response followed, no further action was taken. The time required to fill out the questionnaire was 30-40 minutes.

\section{Outcome measures}

\section{Primary outcome measure: Social participation}

The Impact on Participation and Autonomy (IPA) questionnaire ${ }^{25}$ was used to quantify limitations to participation and autonomy. It has good validity, internal consistency and reliability. ${ }^{26}$ The IPA questionnaire consists of 25 items, each with an item score ranging from 0 (very good) to 4 (very poor). An average score was calculated for every subscale; a higher score denotes more limitations to participation.

We used the IPA subscales 'social relations' and 'work and education' as primary outcome variables to represent social participation. Examples of items from the 'social relations' subscale are: 'My chances of talking to people close to me on equal terms are' and 'The respect I receive from acquaintances is'. Examples from the 'work and education' subscale are: 'My chances of getting or keeping a paid or voluntary job that I would like to do are' and 'My chances of getting the education or training I want are'.

\section{Functioning in adulthood}

To gain insight into the current situation regarding the functioning of these young adults, we collected a number of variables.

\section{Demographic variables}

We measured the following demographic variables: age, gender, education level and relationship status.

\section{Presence of complaints}

Presence of (pain or fatigue) complaints was assessed by the following question: 'Do you have any pain or fatigue complaints at this moment?'. Four answers were 
possible: no complaints, same pain/fatigue complaints as during rehabilitation treatment, other pain/fatigue complaints or other complaints (no pain/fatigue).

Presence of chronic diseases was assessed by the question: 'This is a list of chronic syndromes and diseases. Could you check whether you currently have or during the last year have had any or more of the following syndromes or diseases?' 29 possible syndromes or diseases were presented. ${ }^{27}$

Pain and fatigue severity were measured by Numeric Rating Scales (NRS) for average pain $^{28}$ and fatigue ${ }^{29}$ experienced in the last week. The higher the score, the more severe pain/fatigue. These scales were only filled out by participants who indicated that they had ongoing or new complaints of pain/fatigue.

\section{Functioning and activity level}

Activity level was measured with the Short QUestionnaire to ASsess Healthenhancing physical activity (SQUASH). ${ }^{30}$ The SQUASH is a self-report inventory that assesses physical activity at work/school, leisure time, household activities, and sports per week. It is a reliable and valid questionnaire for assessing physical activity. ${ }^{30}$

Participants rated the time spent in each activity category (in minutes per day) and scored the intensity of each activity (light, moderate or intense). In addition, participants were asked about their involvement in sport activities. The intensity of every sports activity performed was then classified based on the corresponding value of metabolic equivalent of task (MET). ${ }^{31}$ To calculate activity scores in METtimes minutes per week, we multiplied the total minutes of activity by the intensity score. The total activity score was calculated as the sum of all separate activity scores. In addition, we calculated the amount of time spent in light, moderate and heavy-loaded activities for all categories.

Health-related quality of life was measured with the RAND-36. ${ }^{32}$ This measure has eight subscales (mentioned in table S2), which vary from physical and social functioning to mental and general health. For example the RAND-36 asks questions about limitations in daily activities, judgment about feelings of depression and a subjective evaluation of general health status. Higher scores indicate a higher level of functioning or well-being. We applied all the subscales of the RAND-36 in our analysis.

Work situation was measured using the Short Form of the Health and Labour Questionnaire (SF-HLQ), which includes questions about having a paid job and the number of absence from work. ${ }^{27}$ 
Health care utilisation

Health care use in the period after rehabilitation treatment was assessed by questions about what kind of medical specialists the participants had visited and whether and what kinds of surgery they had undergone after treatment.

Health care use in the last three months was assessed by questions about medication use, the sorts of caregivers (e.g. medical specialists, psychologist, social worker, physiotherapist, occupational therapist) visited and the frequency of visits related to health problems in general and specifically to pain/fatigue complaints.

\section{Potential predictors or confounders}

To retrieve potential predictors for long-term social participation, we performed a literature search. We only found a few studies about predictors for fatigue in young adulthood, ${ }^{22}$ long-term maintenance of paediatric pain ${ }^{33}$ and the persistence of multiple musculoskeletal pain in adolescence. ${ }^{23}$ No studies about social participation were found. Based on the outcome of the literature search, combined with expert opinion, we identified the following potential predictors: time since treatment (in years), diagnosis (pain or fatigue), pain/fatigue severity pre-treatment (Visual Analogue Scale (VAS) 0-100 mm), duration of complaint pre-treatment (in months) and, family member with pain/fatigue history (present or not present).

In addition to these factors, we presumed age, gender and education level were potential confounders because their presence can affect both long-term social participation and the potential predictors mentioned above.

\section{Classification: Complaints versus no complaints}

People with and without current complaints were allocated into two groups, a 'complaints group' and a 'no complaints group'. The allocation was based on their scores on two questions about the presence of pain/fatigue or other complaints and the presence of chronic diseases. The 'no complaints group' consisted of participants who answered 'no complaints' to the question: 'Do you have any pain or fatigue complaints at this moment?'

Participants who answered 'same pain/fatigue complaints as during rehabilitation treatment' and 'pain/fatigue complaints but in other parts of my body than during rehabilitation treatment' were allocated to the 'complaints group'.

A researcher (TW) allocated the participants who answered 'no pain/fatigue complaints of which I had rehabilitation treatment, but another disease/complaint that influences my daily living' to one of the groups based on their answer to the question: 'Do you currently have or in the last year have suffered from one or more 
of the diseases on the list?' Participants who reported having chronic diseases, back disorders lasting longer than three months, migraines or chronic rheumatoid arthritis were also assigned to the 'complaints group'. People who answered 'no pain/fatigue complaints for which I had rehabilitation treatment, but another disease/complaint that influences my daily living' were allocated to the 'no complaints group'.

\section{Statistical analyses}

Independent t-tests and an $\mathrm{X}^{2}$ test were performed to test whether responders and non-responders in this study differed on the following demographic and complaint characteristics: age, gender, duration of complaint, time since treatment and VAS score for pain or fatigue pre-treatment.

We performed descriptive analyses to answer the first research question (about gaining insight into the current situation of these young adults' functioning and social participation). To study the second research question, we identified predictors for social participation and studied associations between potential predictive variables and levels of social participation. Pearson correlations were calculated for continuous variables with a normal distribution, and Spearman correlations were calculated for those with a non-normal distribution. For potential predictive variables with a dichotomous structure, differences in social participation between groups were computed with an independent t-test for normally distributed data and a Mann-Whitney $U$ test for non-normally distributed data. In addition, two linear regression analyses were performed with the subscales 'social relations' and 'work and education' of the IPA as dependent variables. Potential predictor variables (time since treatment, level of pain/fatigue pre-treatment, duration of complaints pretreatment, diagnosis and family pain/fatigue history) were introduced as independent variables in the model. In addition, gender, age and level of education were integrated in the regression analysis as potential confounders. For both regression analyses, standardised beta coefficients and their significance were tested under the null hypothesis that the coefficient differs from zero. To control for co-linearity, variable inflation factors (VIF) were checked and had to be below 10. ${ }^{34}$ Any outliers with a Cook distance above 1 were removed from the model. ${ }^{35}$

To answer the last research question about the differences between people with or without current complaints, we assigned each participant to one of two groups based on the presence of current complaints. We then analysed the differences between the groups based on the following variables: age, gender, number of complaints, duration of complaints, health care utilisation, living situation, civil status, education level, paid job, absence of work, activity level, participation and health-related quality of life. When there was a normal distribution of a continuous variable, we used an independent t-test analysis. When there was a non-normal 
distribution of the data, we used the Mann-Whitney $U$ test for unpaired observations. When there was a dichotomous variable, we used $X^{2}$ testing. Since we conducted multiple analyses, we adapted the statistical threshold (according to the Bonferroni procedure) to a p-value of $0.0019(0.05 / 26)$.

\section{Results}

\section{Response}

Of the 242 patients in both cohorts, we were able to obtain addresses for 169 potential participants and send them questionnaires. Of those, 94 people responded and 75 did not (a 55.6\% response rate). We found no significant differences between responders and non-responders on the variables age, gender, duration of complaint, time since treatment and the level of pain/fatigue.

\section{Demographic and complaints characteristics}

The mean age of the 94 responders was 26.6 years [range 19.0-37.2] and 91.5\% were female. More than half of the participants (59.6\%) lived independently. Almost half (49.4\%) were married or living together with a partner. The average time since treatment was 10.2 years [range $5.7-20.7$ ], and $63.4 \%$ of the participants had ongoing or new pain/fatigue complaints. The participants who still had complaints reported an average pain score of $4.13(\mathrm{SD}=2.63)$ and a fatigue score of 4.95 $(\mathrm{SD}=2.75)$ during the last week. Table 1 provides information on demographic and complaints characteristics for the total study sample, the National cohort and the Friesland cohort. A significant difference was found for civil status $(p<0.001)$ between the two cohorts.

\section{Functioning in adulthood}

Table 2 displays results related to the levels of activity, social participation and health-related quality of life. In addition, it presents norm values for the general Dutch population or a representative comparable population. $57.8 \%$ of our study sample reached the Dutch norm for healthy physical activity and scored 7309 (SD=4685) METS x min/week on the overall activity level of the SQUASH. Furthermore, $72.0 \%$ of the participants had a paid job and $22.1 \%$ of those workers reported taking one or more days of sick leave in the past month. The scores on the IPA subscales were 1.57 ( $\mathrm{SD}=1.14)$ for 'work and education' and 0.82 ( $\mathrm{SD}=0.56)$ for 'social relations', respectively. The RAND-36 scale scores varied from 54.8 $(\mathrm{SD}=21.3)$ to $83.7(\mathrm{SD}=31.8)$. 
Table 1: Demographic characteristics, complaints characteristics and health care utilization for the total study sample $(n=94)$, the National cohort $(n=67)$ and the Friesland cohort $(n=27)$ and the differences between the National and Friesland cohort.

\begin{tabular}{|c|c|c|c|}
\hline Variable & Outcome (SD) & $\begin{array}{l}\text { National cohort - } \\
\text { Outcome (SD) }\end{array}$ & $\begin{array}{l}\text { Friesland cohort - } \\
\text { Outcome (SD) }\end{array}$ \\
\hline \multicolumn{4}{|l|}{ Demographic } \\
\hline Mean age in years [range] & $\begin{array}{c}26.56 \\
{[19.02-37.17]}\end{array}$ & $\begin{array}{c}24.93 \\
{[19.02-31.75]}\end{array}$ & $\begin{array}{c}30.60 \\
{[27.37-37.17]}\end{array}$ \\
\hline Gender (\% female) & $91.5 \%$ & $91.0 \%$ & $92.6 \%$ \\
\hline Relationship status (\% married/cohabited) & $49.4 \%$ & $37.9 \% *$ & $77.8 \% *$ \\
\hline \multicolumn{4}{|l|}{ Complaints } \\
\hline Present complaints (\% present) & $63.4 \%$ & $71.2 \%$ & $77.8 \%$ \\
\hline Average level of pain last week (0-10) & $4.13(2.63)(n=64)$ & $4.30(2.73)(n=46)$ & $3.67(2.38)(\mathrm{n}=18)$ \\
\hline Average level of fatigue last week $(0-10)$ & $4.95(2.75)(n=60)$ & $5.11(2.67)(\mathrm{n}=45)$ & $4.47(3.02)(n=15)$ \\
\hline \multicolumn{4}{|l|}{ Health care utilization } \\
\hline $\begin{array}{l}\text { Visit medical specialist after rehabilitation } \\
\text { (\% one or more) }\end{array}$ & $77.4 \%$ & $76.1 \%$ & $80.8 \%$ \\
\hline Visit caregiver last 3 months (\% yes) & $64.5 \%$ & $62.7 \%$ & $69.2 \%$ \\
\hline $\begin{array}{l}\text { Visit caregiver last } 3 \text { months in relation to } \\
\text { pain/fatigue complaints (\% yes) }\end{array}$ & $39.8 \%$ & $43.3 \%$ & $30.8 \%$ \\
\hline $\begin{array}{l}\text { Presence chronic disease } \\
\text { (\% one or more) }\end{array}$ & $78.7 \%$ & $74.6 \%$ & $88.9 \%$ \\
\hline
\end{tabular}

* Significant differences between the cohorts $(p<0.05)$

Information on the participants' health care utilisation can be found in table 1 . More than three-quarters $(77.4 \%)$ of the participants visited one or more medical specialists in the period after their clinical rehabilitation treatment. $29.8 \%$ of the respondents had visited a caregiver during the last three months because of pain or fatigue complaints. Moreover, $78.7 \%$ of them reported having one or more chronic diseases.

\section{Predictors for social participation}

Table S1 shows the associations between the outcome measures 'social relations' and 'work and education', and the potential predictors. Association testing revealed that 'work and education' was significantly correlated with both the level of pain/ fatigue pre-treatment $(r=0.236, p=0.034)$ and education level $(F=5.885, p=0.018)$. This means that a higher level of restrictions on the 'work and education' scale has a positive relation with the level of pain/fatigue and a negative relation with the level of education. Furthermore, we found a significant gender-related difference for scores on 'work and education': males indicated fewer limitations in this 
domain of participation $(\mathrm{p}=0.001)$. In addition, IPA scores for 'social relations' were significantly associated with time since treatment $(r=-0.212, p=0.044)$. A genderrelated difference also appeared: males had a lower IPA score, referring to fewer limitations $(p=0.010)$. A diagnosis-related difference was present within the 'social relations' subscale: the higher IPA score for the adolescents diagnosed with chronic fatigue compared to chronic pain referred to more limitations $(p=0.038)$.

Table 2: Functioning in adulthood: levels of activity, participation and health-related quality of life compared to norm from the general Dutch population or a representative comparable population $(n=94)$

\begin{tabular}{lcc}
\hline Variable & Outcome & Norm values \\
\hline Activity level & & \\
\hline Activity score - SQUASH (SD) (MET x min/week) & $7309(4685)$ & $7787(3061)^{\mathrm{a}}$ \\
Sufficient to Dutch norm for healthy movement (NNGB) (\% yes) & $57.8 \%$ & \\
\hline Restrictions in participation & & \\
\hline Paid job (\% yes) & $72.0 \%$ \\
Sick leave of work in past month (\% yes) & $22.1 \%$ \\
Work and education - IPA (SD) (0-4) & $1.57(1.14)$ \\
Social relations - IPA (SD) (0-4) & $0.82(0.56)$ \\
\hline Health-related quality of life (0-100) & \\
\hline Physical functioning - RAND-36 (SD) & $74.1(24.0)$ \\
Role functioning - physical - RAND-36 (SD) & $89.5(17.8)^{\mathrm{b}}$ \\
Role functioning - emotional - RAND-36 (SD) & $56.2(42.6)$ & $82.5(32.4)^{\mathrm{b}}$ \\
Social functioning - RAND-36 (SD) & $83.7(31.8)$ & $86.8(29.6)^{\mathrm{b}}$ \\
Pain - RAND-36 (SD) & $73.7(25.0)$ & $90.7(16.5)^{\mathrm{b}}$ \\
Mental health - RAND-36 (SD) & $67.7(28.4)$ & $84.1(23.9)^{\mathrm{b}}$ \\
Vitality - RAND-36 (SD) & $73.9(17.4)$ & $78.8(17.5)^{\mathrm{b}}$ \\
General health - RAND-36 (SD) & $54.8(21.3)$ & $69.1(19.0)^{\mathrm{b}}$ \\
\hline
\end{tabular}

a Wendel-Vos et al. (2003) ${ }^{b}$ Van der Zee et al. (2012)

We performed linear regression analyses for the IPA subscales 'work and education' and 'social relations', but could not identify any co-linearity (VIF>10) or outliers (Cook distance $>1$ ). Table 3 shows the mean baseline scores of all potential predicting variables and confounders. Table 3 shows the results (Beta and p-value) of the two regression analyses with the two IPA subscales as the outcome variable. For the outcome variable 'work and education', we identified one significant predictor: the level of pain/fatigue measured pre-treatment (Beta ( $p$-value) $=0.260(0.036)$, $\mathrm{R}^{2}=0.212$ ). This means that a higher level of pain/fatigue pre-treatment during adolescence predicts a higher level of restrictions on the IPA subscale 'work and education' in adulthood. The Pearson correlations between the level of pain/fatigue 
pre-treatment and the current level of pain (average of one week) was $r=0.035$ $(p=0.802 ; n=55)$ and for the current level of fatigue (average of one week) was $r=0.120(p=0.395 ; n=52)$. For the subscale 'social relations', we could not identify any significant predictors using linear regression analyses.

Table 3: Mean baseline scores (pre-treatment) of all potential predicting variables and confounders related to social participation in adulthood (Beta and $p$-value) $(n=94)$

\begin{tabular}{lccc}
\hline Variable & $\begin{array}{c}\text { Baseline score } \\
(\text { SD) }\end{array}$ & $\begin{array}{c}\text { Work \& Education - } \\
\text { Beta (p-value) }\end{array}$ & $\begin{array}{c}\text { Social Relations - } \\
\text { Beta (p-value) }\end{array}$ \\
\hline Mean age in years & $16.35(2.57)$ & $0.173(0.157)$ & $0.084(0.514)$ \\
Gender (\% girls) & $91.5 \%$ & $0.219(0.064)$ & $0.193(0.119)$ \\
Time (years) since treatment & $10.22(3.39)$ & $0.057(0.660)$ & $-0.156(0.253)$ \\
Diagnoses (number pain/fatigue) & $64 / 30$ & $-0.037(0.779)$ & $0.044(0.748)$ \\
Pain/fatigue pre-treatment (VAS 0-100) & $64.59(21.37)$ & $\mathbf{0 . 2 6 0}(\mathbf{0 . 0 3 6})$ & $0.054(0.678)$ \\
$\begin{array}{l}\text { Duration of the complaint pre-treatment } \\
\text { (in months) }\end{array}$ & $29.83(23.74)$ & $-0.085(0.476)$ & $-0.047(0.707)$ \\
Family pain/fatigue history (\% present) & $34.4 \%$ & $0.143(0.215)$ & $-0.058(0.632)$ \\
Education level (3 levels) & & $-0.115(0.314)$ & $-0.111(0.354)$ \\
$\quad$ Low & $17.2 \%$ & & \\
$\quad$ Middle & $52.7 \%$ & & \\
\hline
\end{tabular}

The $\mathrm{p}$-values below 0.05 are marked bold in the table

\section{Differences between people with and without current complaints}

The study sample was grouped into participants with $(n=59)$ and without $(n=34)$ current complaints. One participant did not answer the question about current pain or fatigue complaints and was therefore not allocated into one of the groups. In the 'no complaint' group 65\% did not report any chronic disease. The other allocated participants $(n=12)$ of this group reported various chronic diseases; from a broken toe to sinusitis. Table S2 shows the differences between the groups.

It appeared that young adults with current complaints visited health care professionals more often $(p<0.001)$. Also, in relation to pain/fatigue complaints $(p<0.001)$, they had lower levels of physical functioning $(p=0.001)$ and more limitation in daily activities due to physical problems $(p=0.001)$ than young adults without complaints. 


\section{Discussion and conclusions}

This study was performed to investigate the functioning and long-term social participation in adulthood of adolescents who need healthcare for severe pain and fatigue. We found that a considerable number of those young adults still have complaints and a level of functioning lower than the Dutch norms. ${ }^{32}$ In addition, the level of pain/fatigue pre-treatment during adolescence is a predictor for longterm social participation in young adulthood. Young adults with current pain/fatigue complaints appeared to use more health care and reported lower levels of physical functioning and limited role functioning due to physical problems than their peers without complaints.

Two-thirds of the adolescents' complaints of pain/fatigue persisted into adulthood. These findings are in line with previous findings. Brattberg (2004) found that 59\% of the women and $39 \%$ of the men surveyed reported pain 13 years after follow-up $(n=335) .{ }^{19}$ Bell et al. (2001) mentioned that $62.9 \%$ considered themselves to be well but not cured, chronically ill or more ill than at the first measurement $(n=35) .{ }^{18}$ Since reducing or curing pain/fatigue is not the main goal of multidisciplinary treatment, the existence of remaining complaints is unsurprising. These findings illustrate again that pain/fatigue persists and crosses borders between different life stages.

Our study population rated their HRQoL as moderate to good. Compared to the normal Dutch population of 25-34 years, ${ }^{32}$ the participants' scores on all subscales of the RAND-36 were somewhat lower than average. These findings are not in line with results of Knook et al. (2012) who found that after six years, the HRQoL of adolescents referred for chronic pain (assessed by the SF-36) equalled that of healthy peers. ${ }^{21}$ However, that study population had different diagnoses than ours: for $54 \%$ adolescents with abdominal pain and headache were included and the population was younger (13-24 years versus 19-37 years), which could explain this discrepancy in findings.

Young adults in our study reported higher levels of healthcare utilization: they reported more visits to medical specialists after rehabilitation and visited more caregivers over the last three months than the general Dutch population. ${ }^{36}$ It is unclear whether these young adults were continuing to seek for a cure for their pain/fatigue or needed medical care for other problems related to pain/fatigue.

The young adults in our study who had paid jobs also took more sick leave than the general Dutch population $(22.1 \%$ versus $4.0 \%){ }^{36}$ The presence of current complaints does not seem to be the differentiating factor, since the participants on sick leave are equally divided across both groups. This makes the cause of the high percentage of sick leave usage unclear. 
We conclude that, despite the high number of present complaints, the frequent use of health care, and a high level of sick leave, overall the participants have a moderate to good HRQoL. However, it is lower than the normal Dutch population.

The pre-treatment level of pain/fatigue appeared to be a significant predictor for the IPA subscale 'work and education'. A higher level of pain/fatigue pre-treatment during adolescence predicts a higher level of restrictions on participation in both educational and work-related activities during adulthood. It is unclear what underlying mechanism is responsible for the negative influences on long-term participation.

Different factors such as psychiatric co-morbidity, fear and catastrophising could play a mediating or catalysing role. For example catastrophising; catastrophising thoughts are a predictor for pain episodes ${ }^{37}$ in the fear-avoidance model developed by Vlaeyen et al. (2000). It is also known that catastrophising by children can contribute to increased pain and disability after a six-month follow-up period ${ }^{38}$ and that the level of catastrophising might influence perceived restrictions to social participation..$^{39}$ Unfortunately, this study did not measure psychiatric co-morbidity, fear and the level of catastrophising, so further research is warranted.

Another explanation could be that having to deal with severe complaints in an early phase of life interferes with a person's educational track and therefore has a negative effect on a person's educational possibilities and work later in life. In addition, having to deal with severe health complaints during adolescence can change one's perspective on the importance of different future life goals. Adolescents who are confronted with severe pain/fatigue may value striving for success in educational and work-related activities differently than their healthy peers. Whether this is indeed true is currently unknown.

Another potential predictor for long-term functioning/social participation is the result achieved directly after multidisciplinary treatment. Unfortunately, we do not have data about treatment success for all the participants. Although treatment outcomes could be identified for participants in the National cohort (based on the method of Hechler et al. $\left.(2009)^{40}\right)$, this could not be done for participants in the Friesland cohort. For future research, it may be interesting to explain the relationship between the success of rehabilitation treatment and social participation during adulthood.

The results showed that young adults with persistent complaints had a lower level of physical functioning, a lower level of social participation and more problems with work and other daily activities related to health problems than did those who did not report any complaints. ${ }^{32}$ On the other hand, surprisingly, we found no substantial differences related to mental and emotional functioning. The differences 
between our study sample and healthy individuals found on the RAND-36, can be specifically attributed to the young adults with persistent complaints. In addition, the young adults with persistent complaints used more health care and visited more health care professional in general than people withpain/fatigue complaints. It is unclear whether this is related to differences in health care behavior (the decision to visit a physician) or to a difference in actual complaints.

\section{Limitations}

The response rate in our study was $55.6 \%$, which we believe to be quite acceptable for a study with a ten-year follow-up. It is quite complex to attempt to contact people after ten years when they are in a life stage during which a considerable number of people change their addresses. In our opinion, our method of retrieving addresses and mailing questionnaires to the 169 potential participants was the optimal way to get information from young adults who received rehabilitation treatment for chronic pain/fatigue during adolescence. In addition, since we found no indication of information bias, this sample appears to be an adequate representation of the original population. Although other long-term follow-up studies had response rates around $75 \%,{ }^{18,19}$ either their study sample was half our size $(n=46)^{18}$ or it was possible to do a telephone interview with people who did not respond to the written questionnaire. ${ }^{19}$ Even though our sample size was double the size of Bell et al.'s (2001), we realise that it is rather small $(n=94)$ and could be seen as a study limitation.

Data were collected from two inception cohorts using different outcome measures.18 The information on potential predictors available in both datasets was therefore only limited compared to the actual available information. In addition, since data were collected between 1992 and 2005, questionnaires for catastrophizing and fear in adolescents were unavailable and thus not included in our original data set. Recent research ${ }^{41}$ shows that catastrophizing and fear as potential predictors might play a role in social participation in adulthood for persons with chronic pain. It seems important to include this variable on baseline in future studies.

During their periods of rehabilitation treatment, each patient received a main diagnosis: chronic pain or chronic fatigue. According to the main diagnosis, we used this level of pain or fatigue in our analyses. Therefore we could not use pain and fatigue as two potential predictors in the models.

Nevertheless, we do have information about the severity of pain and fatigue being suffered by the young adults who reported current complaints. However, another limitation is that no severity scores are available for the participants who reported having no current complaints, since we assumed that young adults without 
complaints would rate zero for the current levels of pain and fatigue.

\section{Implications for clinical practice and recommendations for future research}

Based on the current findings, extra attention should be paid to adolescents with a high level of pain/fatigue pre-treatment in the follow-up after treatment. They have a higher risk of future restrictions to social participation. Future research is recommended about the underlying mechanism by which the level of pain/fatigue influences later functioning and social participation. In current rehabilitation treatment, lowering pain/fatigue is not the main goal.

Results also indicate that providing extra long-term follow-up care might help adolescents with pain/fatigue complaints during their transition into adulthood, with a potential reduction of costs of future health care utilisation.

In summary, many young adults still have pain or fatigue complaints in adulthood and the level of pain/fatigue pre-treatment during adolescence is a predictor for long-term social participation in young adulthood. 


\section{Supplement}

Table S1: Associations and corresponding p-values between the outcome measures 'work and education' and 'social relations', and the potential predictors in the linear regression analyses

\begin{tabular}{|c|c|c|}
\hline Variable & $\begin{array}{l}\text { Work and Education - } \\
\text { correlation (p-value) }\end{array}$ & $\begin{array}{c}\text { Social relations - correlation } \\
(p-\text {-value })\end{array}$ \\
\hline Mean age & $0.181(0.086)$ & $0.077(0.468)$ \\
\hline Time since treatment & $-0.111(0.295)$ & $-0.212(0.044)$ \\
\hline Pain/fatigue pre treatment & $0.236(0.034)$ & $0.132(0.241)$ \\
\hline Duration of the complaint pre treatment & $-0.023(0.829)$ & $0.104(0.333)$ \\
\hline
\end{tabular}

A higher score on the outcome measures denote more limitations in participation. The p-values below 0.05 are marked bold in the table.

Table S2: Differences between the groups with and without present chronic pain/fatigue complaints

\begin{tabular}{|c|c|c|c|}
\hline Variable & $\begin{array}{c}\text { Outcome } \\
\text { (SD) current } \\
\text { complaints }(n=59)\end{array}$ & $\begin{array}{c}\text { Outcome }(\mathrm{SD}) \\
\text { - no complaints } \\
(\mathrm{n}=34)\end{array}$ & 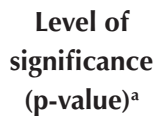 \\
\hline \multicolumn{4}{|l|}{ Demographic } \\
\hline Mean age in years [range] & $26.8[20.4-37.2]$ & $26.2[19.0-33.7]$ & 0.340 \\
\hline Gender (\% female) & $96.6 \%$ & $85.3 \%$ & 0.046 \\
\hline Civil status (\% married/cohabited) & $55.2 \%$ & $41.2 \%$ & 0.195 \\
\hline Education level (3 levels) & & & 0.162 \\
\hline Low & $19.0 \%$ & $14.7 \%$ & \\
\hline Middle & $58.6 \%$ & $44.1 \%$ & \\
\hline High & $22.4 \%$ & $41.2 \%$ & \\
\hline Family history with pain/fatigue (\% yes) & $39.3 \%$ & $27.3 \%$ & 0.251 \\
\hline \multicolumn{4}{|l|}{ Complaints } \\
\hline $\begin{array}{l}\text { Number of complaints } \\
\text { (\% more than } 1 \text { complaint) }\end{array}$ & $30.5 \%$ & $17.6 \%$ & 0.172 \\
\hline $\begin{array}{l}\text { Duration of complaints pre-treatment } \\
\text { (\% more than } 1 \text { year) }\end{array}$ & $74.1 \%$ & $70.6 \%$ & 0.712 \\
\hline $\begin{array}{l}\text { Presence of chronic diseases } \\
(\% \text { one or more) }\end{array}$ & $88.1 \%$ & $64.7 \%$ & 0.007 \\
\hline Diagnosis & & & 0.988 \\
\hline Chronic pain & $67.8 \%$ & $67.6 \%$ & \\
\hline Chronic fatigue & $32.2 \%$ & $32.4 \%$ & \\
\hline
\end{tabular}

a The statistical threshold (p-value) is 0.0019 according the Bonferroni procedure for multiple analyses. The p-values below this threshold are marked bold in the table. 
Table S2 continued: Differences between the groups with and without present chronic pain/ fatigue complaints

\begin{tabular}{|c|c|c|c|}
\hline \multicolumn{4}{|l|}{ Health care utilisation } \\
\hline $\begin{array}{l}\text { Visit specialist after rehabilitation } \\
\text { (\% one or more) }\end{array}$ & $86.2 \%$ & $61.8 \%$ & 0.007 \\
\hline $\begin{array}{l}\text { Visit health care professional in the last } 3 \\
\text { months (\% one or more) }\end{array}$ & $77.6 \%$ & $41.2 \%$ & 0.000 \\
\hline $\begin{array}{l}\text { Visit health care professional in the last } \\
3 \text { months in relation to pain/fatigue } \\
\text { complaints (\% one or more) }\end{array}$ & $60.3 \%$ & $5.9 \%$ & 0.000 \\
\hline Medication use (\% yes) & $56.9 \%$ & $26.5 \%$ & 0.005 \\
\hline \multicolumn{4}{|l|}{ Activity and participation level } \\
\hline Activity level (MET x min/week) & $6590(3937)$ & $8281(5515)$ & 0.250 \\
\hline Paid job (\% yes) & $62.1 \%$ & $91.2 \%$ & 0.002 \\
\hline $\begin{array}{l}\text { Absence of work in the past month (\% yes) } \\
\text { of those with paid job }\end{array}$ & $21.6 \%(n=37)$ & $22.6 \%(n=31)$ & 0.924 \\
\hline IPA - Work and education (0-4) & $2.01(1.07)$ & $0.79(0.73)$ & 0.003 \\
\hline IPA - Social relations $(0-4)$ & $1.00(0.54)$ & $0.50(0.44)$ & 0.637 \\
\hline \multicolumn{4}{|l|}{ Health-related quality of life } \\
\hline RAND-36 - physical functioning & $63.7(23.0)$ & $91.3(13.3)$ & 0.001 \\
\hline RAND-36 - role functioning physical & $38.8(40.1)$ & $84.6(29.5)$ & 0.001 \\
\hline RAND-36 - role functioning emotional & $83.6(32.2)$ & $83.3(32.0)$ & 0.952 \\
\hline RAND-36 - social functioning & $65.0(24.9)$ & $87.9(17.5)$ & 0.154 \\
\hline RAND-36 - bodily pain & $56.0(25.5)$ & $87.0(21.7)$ & 0.101 \\
\hline RAND-36 - mental health & $71.8(18.3)$ & $77.4(15.7)$ & 0.165 \\
\hline RAND-36 - vitality & $46.9(19.7)$ & $67.7(17.4)$ & 0.110 \\
\hline RAND-36 - general health & $47.6(21.8)$ & $69.9(22.7)$ & 0.596 \\
\hline
\end{tabular}

a The statistical threshold ( $p$-value) is 0.0019 according the Bonferroni procedure for multiple analyses. The p-values below this threshold are marked bold in the table. 


\section{References}

1. Farmer, A., et al., Prevalence of chronic disabling fatigue in children and adolescents. $\mathrm{Br}$ J Psychiatry, 2004. 184: p. 477-81.

2. Haraldstad, K., et al., Pain in children and adolescents: prevalence, impact on daily life, and parents' perception, a school survey. Scand J Caring Sci, 2011. 25(1): p. 27-36.

3. King, S., et al., The epidemiology of chronic pain in children and adolescents revisited: a systematic review. Pain, 2011. 152(12): p. 2729-38.

4. Perquin, C.W., et al., Pain in children and adolescents: a common experience. Pain, 2000. 87(1): p. 51-8.

5. ter Wolbeek, M., et al., Severe fatigue in adolescents: a common phenomenon? Pediatrics, 2006. 117(6): p. e1078-86.

6. Perquin, C.W., et al., The natural course of chronic benign pain in childhood and adolescence: a two-year population-based follow-up study. Eur J Pain, 2003. 7(6): p. 551-9.

7. ter Wolbeek, M., et al., Predictors of persistent and new-onset fatigue in adolescent girls. Pediatrics, 2008. 121(3): p. e449-57.

8. Crawley, E. and J.A. Sterne, Association between school absence and physical function in paediatric chronic fatigue syndrome/myalgic encephalopathy. Arch Dis Child, 2009. 94(10): p. 752-6.

9. Konijnenberg, A.Y., et al., Children with unexplained chronic pain: substantial impairment in everyday life. Arch Dis Child, 2005. 90(7): p. 680-6.

10. Köke, A.J.A., Implementatie en uitbreiding Nederlandse Dataset Pijnrevalidatie. 2012.

11. Hunfeld, J.A., et al., Chronic pain and its impact on quality of life in adolescents and their families. J Pediatr Psychol, 2001. 26(3): p. 145-53.

12. Perquin, C.W., et al., Insights in the use of health care services in chronic benign pain in childhood and adolescence. Pain, 2001. 94(2): p. 205-13.

13. Missen, A., et al., The financial and psychological impacts on mothers of children with chronic fatigue syndrome (CFS/ME). Child Care Health Dev, 2012. 38(4): p. 505-12.

14. Sleed, M., et al., The economic impact of chronic pain in adolescence: methodological considerations and a preliminary costs-of-illness study. Pain, 2005. 119(1-3): p. 183-90.

15. WHO, ICF, Nederlandse vertaling van de 'International classification of functioning, disability and health'. ed. W.-F.C. Centre. 2002, Houten: Bohn Stafleu van Loghum.

16. ASHA. International Classification of Functioning, Disability, and Health (ICF). 19972015 [cited 2015 October 6th]; Available from: http://www.asha.org/slp/icf.

17. Piskur, B., et al., Participation and social participation: are they distinct concepts? Clin Rehabil, 2014. 28(3): p. 211-20.

18. Bell, D.S., K. Jordan, and M. Robinson, Thirteen-year follow-up of children and adolescents with chronic fatigue syndrome. Pediatrics, 2001. 107(5): p. 994-8.

19. Brattberg, G., Do pain problems in young school children persist into early adulthood? A 13-year follow-up. Eur J Pain, 2004. 8(3): p. 187-99.

20. Walker, L.S., et al., Functional abdominal pain in childhood and adolescence increases risk for chronic pain in adulthood. Pain, 2010. 150(3): p. 568-72.

21. Knook, L.M., et al., Quality of life and academic functioning 6 years after paediatric referral for chronic pain. Acta Paediatr, 2012. 101(9): p. 957-63. 
22. ter Wolbeek, M., et al., Fatigue, depressive symptoms, and anxiety from adolescence up to young adulthood: a longitudinal study. Brain Behav Immun, 2011. 25(6): p. 1249-55.

23. Paananen, M.V., et al., Risk factors for persistence of multiple musculoskeletal pains in adolescence: a 2-year follow-up study. Eur J Pain, 2010. 14(10): p. 1026-32.

24. de Blecourt, A.C., et al., Preliminary evaluation of a multidisciplinary pain management program for children and adolescents with chronic musculoskeletal pain. Disabil Rehabil, 2008. 30(1): p. 13-20.

25. Cardol, M., et al., The development of a handicap assessment questionnaire: the Impact on Participation and Autonomy (IPA). Clin Rehabil, 1999. 13(5): p. 411-9.

26. Cardol, M., et al., Psychometric properties of the Impact on Participation and Autonomy Questionnaire. Arch Phys Med Rehabil, 2001. 82(2): p. 210-6.

27. Hakkaart-van Roijen, L., and C. Bouwmans, Manual Short Form-Health Labour and Questionnaire (SF-HLQ). 2007.

28. Bolton, J.E., Accuracy of recall of usual pain intensity in back pain patients. Pain, 1999. 83(3): p. 533-9.

29. Lee, N.H. and C.G. Son, Fatigue severity of patients with idiopathic chronic fatigue compared to healthy subjects. J Tradit Chin Med, 2012. 32(3): p. 355-7.

30. Wendel-Vos, G.C., et al., Reproducibility and relative validity of the short questionnaire to assess health-enhancing physical activity. J Clin Epidemiol, 2003. 56(12): p. 1163-9.

31. Ainsworth, B.E., et al., Compendium of physical activities: an update of activity codes and MET intensities. Med Sci Sports Exerc, 2000. 32(9 Suppl): p. S498-504.

32. van der Zee, K.I., Sanderman, R. , Het meten van de algemene gezondheidstoestand met de RAND-36, een handleiding. 2012, UMCG / Rijksuniversiteit Groningen, Research Institute SHARE.

33. Miro, J., A. Huguet, and R. Nieto, Predictive factors of chronic pediatric pain and disability: a Delphi poll. J Pain, 2007. 8(10): p. 774-92.

34. Kutner, M.H., Nachtsheim, C.J., Neter, J., Applied Linear Regression Models. 5th edition ed. 2004, Irwin: McGraw-Hill.

35. Cook, R.D.W., S., Residuals and influence in regression. 1st edition ed. 1983, New York: Chapman \& Hall. 240.

36. CBS. Sick leave percentage and health care utilization. [Website] 2012 [cited 2014 June 23th]; Available from: http://www.cbs.nl/infoservice.

37. Vlaeyen, J.W. and S.J. Linton, Fear-avoidance and its consequences in chronic musculoskeletal pain: a state of the art. Pain, 2000. 85(3): p. 317-32.

38. Simons, L.E. and K.J. Kaczynski, The Fear Avoidance model of chronic pain: examination for pediatric application. J Pain, 2012. 13(9): p. 827-35.

39. Vervoort, T., et al., Catastrophic thinking about pain is independently associated with pain severity, disability, and somatic complaints in school children and children with chronic pain. J Pediatr Psychol, 2006. 31(7): p. 674-83.

40. Hechler, T., Dobe, M., Kosfelder, J., Damschen, U., Hubner, B., Blankenburg, M., Sauer, C., Zernikow, B. (2009). Effectiveness of a 3-week multimodal inpatient pain treatment for adolescents suffering from chronic pain: statistical and clinical significance. Clin J Pain 25, 156-166. 
Long-term participation after chronic pain/fatigue

41. den Hollander, M., et al., Fear reduction in patients with chronic pain: a learning theory perspective. Expert Rev Neurother, 2010. 10(11): p. 1733-45. 



\section{Chapter 6}

\section{General Discussion}


In adolescence chronic pain and fatigue are common complaints ${ }^{1-5}$ and can persist over time during childhood and adolescence..$^{6-9}$ Both chronic pain and fatigue have major negative consequences for daily life. ${ }^{10-12}$ Although it is known that chronic pain and fatigue affect social participation and health-related quality of life (HRQoL) of adolescents, ${ }^{13,14}$ it is still not clear whether other factors, besides pain and fatigue, specifically influence social participation and HRQoL. Increased knowledge about these factors might lead to the possibility to positively change these factors, resulting in a positive effect on social participation and HRQoL in adolescence, but also further on in life when these adolescents turn into young adults.

Therefore, the aim of this thesis was to increase knowledge on social participation and health-related quality of life in adolescents with chronic musculoskeletal pain or chronic fatigue in relation to complaints, personal and environmental factors. In addition, predictive factors of successful rehabilitation treatment and long-term functioning in adulthood of persons who have received rehabilitation treatment during their adolescence were studied (cohort). In order to study predictive factors for successful treatment, more knowledge was necessary regarding the responsiveness of the Child Health Questionnaire (CHQ), an HRQoL instrument used within the cohort study.

Studies of this thesis indicate that:

- The CHQ 50-item parent form (CHQ-PF50) appeared to be satisfactorily responsive for assessing change in the physical component ( $\mathrm{PhS}$ ) and moderately responsive for the psychosocial component (PsS). Overall, the CHQ-PF50 seems able to measure relevant change in a clinical rehabilitation treatment setting.

- Before the start of treatment several significant associations between potential influencing factors and outcomes on the level of participation and quality of life have been found; first, older adolescents and adolescents diagnosed with chronic fatigue were more often absent from school. Secondly, higher selfreported levels of pain/fatigue were associated with lower HRQoL-physical functioning and thirdly, a passive coping style was associated with lower HRQoL-psychosocial functioning.

- Treatment success was based on a combination of predefined clinically relevant changes in four outcome measures: level of pain/fatigue, school absence, HRQoL-physical functioning and HRQoL-psychosocial functioning. According to this strict definition around half of the participants had a successful treatment. Besides, the results show that boys had more benefit from treatment than girls. Additionally, adolescents with a higher level of pain/fatigue and those with more passive coping at the start of treatment appeared to improve their functioning more during treatment. 
- A considerable number (63.4\%) of young adults, who received an inpatient rehabilitation treatment during adolescence, reported to experience pain/ fatigue complaints 10 years later. Furthermore, it appeared that a higher level of pain/fatigue pre-treatment predicted impaired social participation in the workeducational domain in young adulthood.

In this discussion section, interpretations of the main findings are presented and discussed in relation to current scientific evidence. Furthermore, methodological considerations are discussed and implications for clinical practise and recommendations for future research are provided. Finally, overall conclusions will be drawn.

\section{Interpretation of main findings}

Scientific studies ought to represent the situation of the population under study. It is therefore important to check whether our results can be generalized to the population of adolescents with pain/fatigue in general. For this reason, we will first focus on three questions:

- Is the population as included in the studies comparable to populations presented in international studies?

- Is the treatment provided in these studies comparable to treatments provided as presented in the literature?

- Is the former treatment comparable to the treatment nowadays?

\section{Population}

\section{Is the population as included in the studies in this thesis comparable to populations presented in international studies?}

In the studies presented in this thesis, adolescents from Dutch rehabilitation centers participated. The patients in this Dutch National cohort, who all received an inpatient rehabilitation treatment for chronic musculoskeletal pain or chronic fatigue, were on average 16.2 years old and only $14.5 \%$ were male. This unbalanced gender distribution, seems comparable with findings in other international studies on chronic pain and fatigue in adolescents, ranging from $20.0 \%$ to $26.8 \% .{ }^{15-18}$ Also in adult rehabilitation in the Netherlands only $29 \%$ of all patients with chronic musculoskeletal pain and/or fatigue referred to rehabilitation treatment, appeared to be male. ${ }^{19}$ This uneven gender distribution is also in accordance with the percentage of adolescents having pain in the general Dutch adolescent population. More girls than boys experience recurrent or continuous pain/fatigue for a longer period in time. ${ }^{1,4,5}$ 
Furthermore, participants in the studies of this thesis reported severe pain or fatigue complaints (VAS mean $=68.7$ ) and the mean duration of their complaints was 36 months. For the study on long-term functioning (chapter 5), the Friesland cohort has been added to the National Cohort study population to increase the number of participants. Both study populations did not differ in terms of age, gender, duration of complaints and level of pain/fatigue pre-treatment. ${ }^{20}$ When compared to patient populations undergoing inpatient treatment in studies from other countries, our study population seems quite comparable. For example, the study sample of Hechler et al. (2009) reported a mean level of general complaints of 6.7 measured on a NRS and a mean duration of complaints of 42 months. ${ }^{21}$ Our study does however differ regarding the diagnoses included for treatment. Within our study, only diagnoses associated with musculoskeletal chronic complaints and chronic fatigue were included. Several other studies from abroad also included young people with chronic headache and abdominal pain. ${ }^{18,21}$ This difference in diagnoses that were eligible for inclusion seems related to the health care system. In the Netherlands, rehabilitation medicine specifically focuses on the musculoskeletal system related problems, resulting in moderate to severe disability (activities and participation). In other countries, patients with musculoskeletal pain complaints but also pain evolving from other systems like the abdomen or head, are mostly treated in pain clinics. For this reason, our population only represents adolescents with chronic pain or fatigue related to the musculoskeletal system.

With regard to social participation: a remarkable high level of school absence (82\%) before the start of treatment was found and even one third (32.9\%) of the adolescents was completely absent from school. This reflects a high level of disability and was one of the reasons for referring these adolescents for intensive clinical rehabilitation treatment. This percentage of school absence is comparable with findings in other studies $\left(73 \%{ }^{21}\right.$ and $\left.88 \%{ }^{18}\right)$, reflecting again that our population resembles those in other international studies.

At the start of treatment there was a considerable difference between physical and psychosocial quality of life reflected in scores of the CHQ-PF50 physical functioning (mean $\mathrm{PhS}=19.2$; range 0-100) and psychosocial functioning (mean PsS $=42.1$; range 0-100). In the study of Klineberg et al. (2014) scores on physical and psychosocial quality of life also differed but to a lesser extent. Scores were based on the judgement of the adolescents mother, and the population consisted of adolescents with chronic fatigue syndrome and somatoform disorders. ${ }^{17}$ In the studies of Dodson et al. (2008 and 2010) in which HRQoL was assessed with the $\mathrm{CHQ}$ parent form for adolescents with congenital urological disorders, the differences between the PhS and PsS were substantially smaller (PhS = 50.7; PsS = $51.1,{ }^{22}$ and $\mathrm{PhS}=44.5 ; \mathrm{PsS}=50.3^{23}$ ). Results of another study showed that adult 
patients with pain have a lower perceived HRQoL compared with patients with migraine and cancer pain. ${ }^{24} \mathrm{HRQ}$ oL was measured with the SF-36 and specifically the subscales role limitations physical and bodily pain demonstrated a noteworthy lower score. Also adults referred to pain rehabilitation report lower scores on physical functioning (SF-36 subscales physical functioning and role limitations physical) than on psychosocial functioning (SF-36 subscales mental health and vitality). ${ }^{19}$ Therefore, these outcomes might indicate that moving with pain seems more complex in case pain is related to the musculoskeletal system itself, probably resulting in more physical problems compared to persons who suffer from another chronic disease (e.g. urological problems, migraine or cancer).

To conclude, based on the comparison with other populations, it seems that our population is quite comparable to populations presented in international publications in this research field.

\section{Rehabilitation treatment}

\section{Is the treatment as provided in the studies in this thesis comparable with other treatments as presented in the literature?}

The inclusion criteria for the studies as presented reflect the criteria for clinical rehabilitation treatment in the Netherlands (having severe chronic pain or fatigue; moderate to severe disability in daily activities; school absence over $20 \%$ in the past 3 months; the presence of psychosocial factors associated with persistence of chronic pain/fatigue; motivated adolescents and parents regarding behavioural change as part of treatment $\left.{ }^{25}\right)$, and are very consistent with those reported in the study of Hechler et al. (2009). ${ }^{21}$ The study of Hechler et al. (2009) is, as our study in chapter 4, a cohort study with an interpretation of treatment success based on the evaluation of individual progress during treatment. ${ }^{21}$

Our inclusion criteria are also consistent with other studies performed in other Western countries in which children with chronic pain were treated with intensive interdisciplinary treatment, regarding age (between 10 and 18 years), duration of complaints (>3 months), presence of pain related disability and support of the parents regarding treatment. ${ }^{26-29}$

The inpatient rehabilitation treatment as provided in the rehabilitation centers that participated, was based on cognitive behavioural treatment principles, and included a variety of treatment approaches such as cognitive behavioural therapy, graded activity, relaxation and education. Furthermore, training and education for the parents with and without attendance of the adolescent, were part of the treatment. Other treatment programs provided across the Western world to identical populations are mostly based on cognitive behavioural treatment principles. ${ }^{15,21,26-28}$ 
In all treatment programs for severely disabled adolescents, multiple disciplines were involved. In most studies at least physicians, physical therapists, occupational therapists and psychologists were involved. ${ }^{26-28}$ Except in the study of Hechler et al. (2009) where besides the paediatricians, only nurses and psychologists were involved. ${ }^{21}$ In the study of Banez et al. (2014) no disciplines are mentioned, but only the treatment modalities as used. In all programs parents were involved and family therapy was given. ${ }^{15}$ Exercises to do at home during treatment were given in all programs as an important part of treatment, except in the study of Banez et al. (2014) where no homework was given during treatment, although an individualized home exercise program was developed to be followed after discharge. ${ }^{15}$ In more recent studies, it appears that treatment consisted of short intensive trajectories ( 3 weeks inpatient treatment). $15,16,27,28$ The average duration of treatment of our cohort was 14.6 weeks.

In our population almost half of the patients (49.6\%) achieved a successful treatment (chapter 4), regardless their long duration and high intensity of complaints, disability in daily life and prolonged school absence. In the study by Hechler et al. (2009), identical methodology to define a successful treatment has been used. A comparable percentage of $55 \%$ of the population appeared to have reached a clinically relevant change. ${ }^{21}$ In a recent systematic review, results of a number of intensive interdisciplinary treatments for children with a variety of chronic pain diagnoses were compared. ${ }^{30}$ In this study, the following separate outcome domains were analysed; pain intensity, disability, school functioning, anxiety and depressive symptoms. The measure for successful treatment used in those studies differed from ours. Nevertheless, the results as indicated regarding pain intensity at short-term follow-up being large and significantly effective, ${ }^{30}$ are similar to our pre-post treatment pain/fatigue intensity change (reduction of 36.7 on a VAS). Due to heterogeneity of the measurements used in the included studies, pooling of the results for school functioning and anxiety could not be performed. ${ }^{30}$

Summarizing, the content and disciplines involved in inpatient clinical treatment used in the studies of the thesis seem to be comparable to interventions studied in international publications in this field. The duration of our treatment was however longer.

\section{Is the former treatment comparable to the treatment nowadays?}

In the meetings of the Dutch Rehabilitation Expert Group of Children and Adolescents in Pain and Fatigue innovations in treatment are regularly discussed. Experts report that over time, treatment procedures and content have been adapted resulting in a shorter treatment duration in the Dutch rehabilitation centers nowadays compared to 12-17 years ago. Developments in the field of adolescent pain, such as new 
scientific research, influences from pain clinics abroad and the currently available outpatient treatment in the Netherlands seem to have contributed to this.

In recent years, the introduction of new treatment programs for adolescents with chronic pain became available. For example, Acceptance and Commitment Therapy (ACT) for adolescents is currently used in one centre in the Netherlands. ACT was developed and is called the third wave cognitive behavioural therapy ${ }^{31}$ and elements of ACT have been introduced in several programs for adolescents worldwide. According to the underlying theoretical model, ACT emphasizes the necessity of pain acceptance in order to improve functioning. Therefore, the treatment objective of ACT is to improve functioning by increasing psychological flexibility. The latter is defined as the ability to act effectively in accordance to personal values in the presence. ${ }^{32}$ Previous research seems to indicate the effectiveness of an ACTorientated intervention in adolescents with longstanding idiopathic pain. ${ }^{33} \mathrm{~A}$ recent clinical pilot study with an ACT-based interdisciplinary outpatient intervention in adolescents with disabling chronic pain confirmed these findings. Adolescents reported clinically relevant changes varying from $21-63 \%$ and from $54-76 \%$ as rated by their parents. ${ }^{34}$ In the adult pain rehabilitation, the integration of ACT principles in the treatment program is already more common. From the literature on adult patients with chronic musculoskeletal pain, a meta-analysis showed that ACT-based interventions may be good alternatives for treating chronic pain, but are not superior to traditional cognitive behavioral treatments. ${ }^{35}$

Another development is graded exposure, which is currently provided as treatment for adolescents in four centers in the Netherlands. Graded exposure is a treatment approach that is based on the Fear-Avoidance Model and also involves exposure to actions and activities. ${ }^{36}$ Graded exposure specifically addresses fear and anxiety as a main influencing factor for disability. Those patients where anxiety plays an important role in eliciting behavior (avoidance) in relation to pain, are most likely to progress when treated with graded exposure. ${ }^{37}$ Anxiety was not a specific focus in the treatments reported in this thesis (chapter 3 and 4). The cohort started in 2002, in a time in which our knowledge on pain related fear and its treatment was still underdeveloped. Currently, the added value of graded exposure for adolescents with chronic pain is studied in the Dutch 2B Active study. ${ }^{38}$

These new approaches, ACT and graded exposure, might even contribute to an enhanced effect of treatment reflecting a higher level of physical and psychosocial functioning post-treatment or a restriction of treatment duration needed in nowadays treatments compared to the results presented in this thesis.

Summarizing, we can conclude that on the whole the results and content of treatment, based on a cognitive behavioural approach, can be generalized to the 
adolescent rehabilitation population. Since no treatment elements were jet included like ACT and graded exposure. These new treatment elements might eventually contribute to a shorter treatment duration as needed.

\section{Interpretation of associations as identified}

In this paragraph, we will focus on the most important overarching outcomes of the studies in this thesis.

\section{Main findings}

In figure 1 the main findings of this thesis are summarized schematically. Before treatment older age and being diagnosed with chronic fatigue were significantly associated with more school absence. Also, a higher level of pain/fatigue and a higher level of passive coping were significantly associated with lower quality of life at the start of treatment. Furthermore, being a boy, having a higher level of pain/fatigue and higher levels of passive coping before the start of treatment were significantly associated with a higher probability for a successful multidisciplinary clinical rehabilitation treatment. Besides, a higher level of pain/fatigue before treatment in adulthood was related to a lower long-term social participation in adolescence.

In this thesis, the International Classification for Functioning, Disability and Health (ICF-model) (see top of figure 1) has been used as the theoretical framework. The model shows the variables measured in our studies for the specific health condition chronic musculoskeletal pain or chronic fatigue in adolescents and helps us to identify factors that might be addressed during treatment in order to change them and by this improve outcome at the level of activities and participation. 


\section{Health condition}

Chronic Musculoskeletal Pain or Chronic Fatigue and structures

Pain/fatigue; duration of complaint
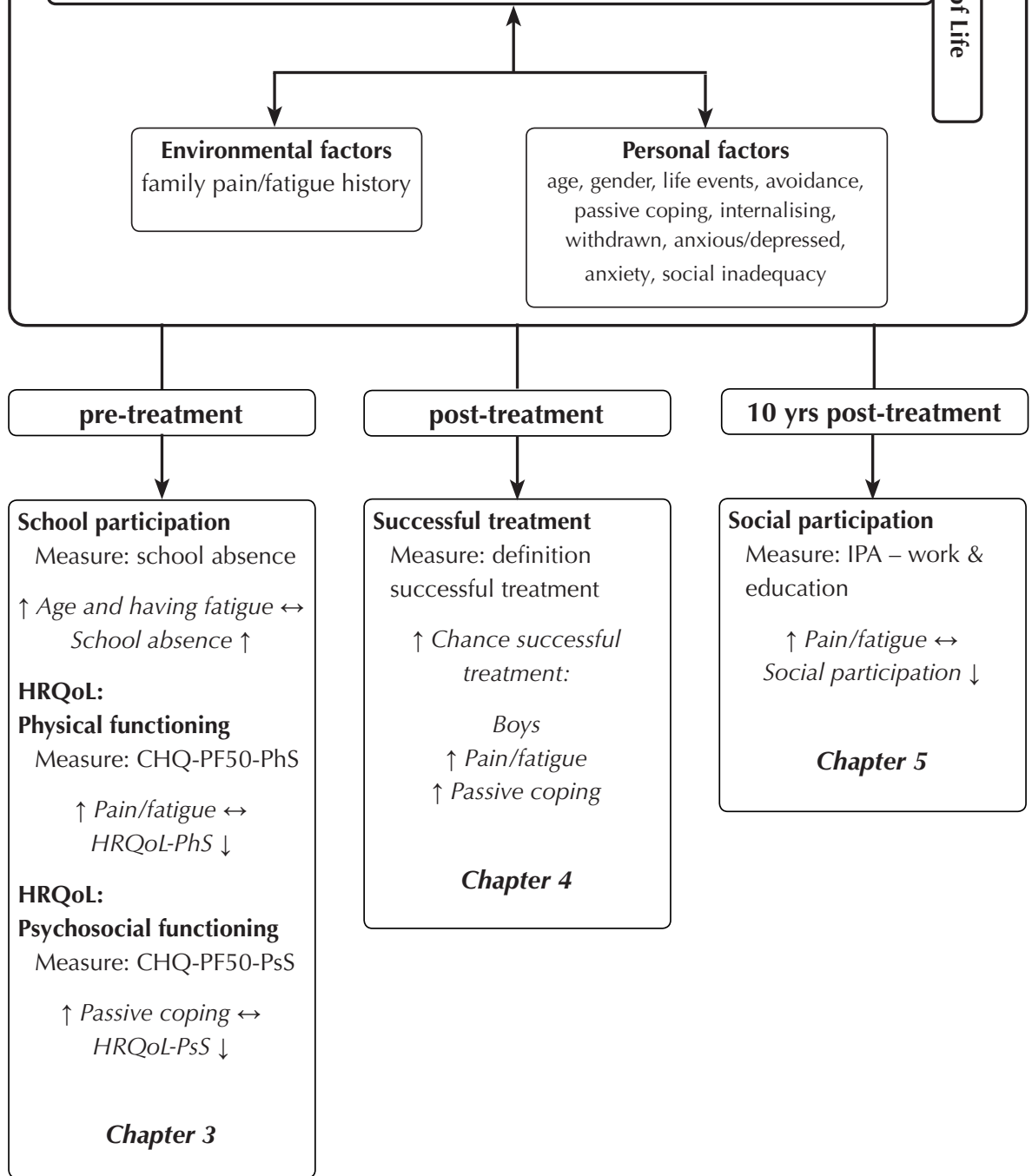

Figure 1: Main findings of this thesis 


\section{Factors identified in more than one of our studies}

Associations as identified in our studies were already discussed in the previous chapters. In this general discussion, we therefore specifically focus on two factors (level of pain/fatigue and passive coping) that were significantly associated with the outcome variables on more than one moment in time.

At short-term (post-treatment), a higher level of pain/fatigue pre-treatment appeared to be a predictor of successful treatment, but a higher level of pain/fatigue was also a predictor of lower level of participation on the long-term (10 years after treatment). Since a reduction in the level of pain/fatigue was one of the four components for labelling the treatment as being successful (chapter 4), it seems logical that a higher level of pain/fatigue at the start of treatment predicted short-term successful treatment. As the average baseline severity of pain/fatigue was 68.7 on a 0-100 VAS (chapter 3), this left rather room for improvement during treatment, making it easier to fulfill the criteria for successful treatment. Furthermore, despite the fact that pain/ fatigue reduction was not one of the aims of the provided rehabilitation treatment, decrease in pain/fatigue was however often achieved (mean change pain/fatigue pre-post-treatment 36.7 on a VAS), which can be regarded as clinically relevant ${ }^{39}$ (chapter 4).

But how can we explain a negative predictive role of higher pain/fatigue as an indicator for a lower level of participation 10 years after the end of treatment? Before giving possible explanations for this contradictory finding, we have to consider some facts.

First, for the long-term functioning study (chapter 5) the Friesland cohort was added to increase the number of participants. We could not identify the short-term results of the patients from the Friesland cohort. Therefore, we do not know for example whether all participants having a good short-term treatment result, had indeed a lower score on the long-term.

And second, two different outcome definitions and measures were used. On shortterm: the composed definition of successful treatment whereas on long-term (when the adolescents turned in young adults) social participation, measured with the Impact on Participation and Autonomy (IPA) questionnaire were used.

A potential explanation for the findings regarding the contradicting influence of the level of pain/fatigue on the short-term after treatment and long-term participation might be that adolescents with severe complaints are more prone to develop these complaints again. ${ }^{40}$ The predisposing factors that were already present during adolescence may not have been eliminated by treatment or natural course of life and might lead to a recurrence of complaints or complaints in another body region, 
which could have resulted in lower social participation in adult life. The influence of these predisposing factors cannot be analysed at the individual patient level, because data on these factors was not available.

A second explanation might be that when adolescents become adults they shift to another life phase and are confronted with new activities (e.g. living on their own, work). However, as coping with the performance of these activities was not specifically part of treatment, their pain coping strategies might not be sufficient due to restricted abilities in generalization. This might result in performing these activities less or not at all and finally in lower social participation.

The last explanation is in line with the previous, whereas new activities belonging to a different stage in life might change the total workload of the former patients. To cope with this higher total workload young adults might choose to adjust on purpose their physical performance to a lower level. This might be a learned strategy as it was taught during rehabilitation treatment. The latter is supported by the results of a qualitative survey conducted with participants of the Friesland cohort $(n=14)$. Participants stated that they, instead of participating for the full 100\% in their work, for example they consciously decide to work part-time. ${ }^{41}$

Since the baseline level of pain/fatigue showed associations with HRQoL-physical functioning, successful treatment and social participation in three different time frames (pre-treatment, post-treatment and 10 years after treatment), this indicates that further monitoring adolescents with a high level of pain/fatigue at pre-treatment, especially on the long-term, seems to be favoured. Unfortunately, due to different types of measurement for each construct over time no linear relations between the pre-treatment level of pain/fatigue and the outcome measures at the different moments in time could be calculated.

The results showed that a passive coping style was associated with a lower level of HRQoL psychosocial functioning pre-treatment and it also appeared to be a predictor for successful treatment. Passive coping seems therefore relevant to address during treatment and was indeed addressed during the treatment in the studies of this thesis. By learning to cope with their complaints, it is hypothesized that adolescents change their coping style, which might have had a positive effect on treatment.

However, in this cohort no data was collected regarding changes in coping style pre-, during and post-treatment. So unfortunately, we do not know whether this factor indeed changed at all, or whether it acted as a mediator between a variable pre-treatment and a successful treatment.

It is remarkable that passive coping is the only psychosocial factor that was 
significantly associated with the outcome measures. Other studies have shown that pain catastrophizing predicted pain, functional disability and HRQoL, ${ }^{42}$ depression was related to disability, ${ }^{43}$ anxiety predicted functional disability and $\mathrm{HRQOL}{ }^{42}$ and anxiety was linearly associated to pain related functional disability. ${ }^{44}$ Unfortunately, we were not able to measure these psychological factors because at the start of our National cohort studies, no psychometric sound measurement instruments were available to measure these variables in adolescents with pain/fatigue. For future studies, it is recommended to include at least pain catastrophizing, depression and anxiety. Based on the underlying theory of the newly developed treatments it is also advisable to measure for example fear beliefs and acceptance as they are regarded as mediators and might be also predictive factors.

\section{Methological considerations}

In this paragraph we will discuss the data and how this data was collected. Also the primary outcome measures will be reflected upon.

\section{Study design and clinical data collection}

The study presented in chapter 3 used a cross-sectional design and from these results no causal relations can be made. Though it is the most common research design used to explore potential relationships, the associations found have to be interpreted with caution. In the cohort studies (chapters 2 and 4), differences before and after treatment were studied. In chapter 5 , the pre-treatment data was used to predict current social participation.

Data collection of the National cohort and the Friesland cohort was performed in a clinical setting. The datasets, being mainly based on data collection in clinical practice, were however not complete. Therefore, before the start of the data analysis, in order to restrict the number of missing values, basic characteristics such as the date of birth and duration of complaints, when missing, were retrieved from the rehabilitation center databases. Furthermore, the number of missing data was higher at the end of treatment assessments. It is more difficult to integrate the collection of data in practice routines in case adolescents do not have any regular visits in the rehabilitation center anymore. This resulted in more missing values and hence lower number of participants for the statistical analyses of the CHQ-PF50 responsiveness (chapter 2) and to determine successful treatment (chapter 4). However, as no significant differences were found regarding baseline characteristics between persons with missing data and complete data, indicating that these missings were at random, we assume that the participants with complete datasets in these analyses still reflect the whole population and the incompleteness 
of data might not have impacted the results significantly.

Our study was performed in a clinical rehabilitation setting in the Netherlands without the presence of a control group. Therefore, it is not possible to correct the results for the natural course of the severity of complaints and perceived disability. However, because of the long duration of complaints pre-treatment, the improvement is unlikely to be caused by spontaneous improvement alone. The effectiveness of multidisciplinary treatment is also confirmed based on recently published randomised controlled trial (RCT) of Hechler et al. (2014). ${ }^{16}$ Using the same definition as the study of Hechler et al. (2009), ${ }^{21}$ it was shown that intensive multidisciplinary pain treatment is successful in 55\% of the participants versus $14 \%$ in the waiting-list control group. ${ }^{16}$ Future RCTs are necessary to confirm these positive effects of generalizable multidisciplinary treatment for this population. However, as long as the resources for performing RCTs are limited, clinical studies like ours using clear definitions of successful outcome are the best available alternative. Likewise, the search for predictors of treatment success can also be more developed.

The study presented in chapter 4 did not include a control group. Therefore, results do not provide the possibility to correct for the natural course of complaints and perceived disability that would have occurred in a situation without treatment or with an intervention based on attention alone. Nevertheless, as long as the resources for performing RCTs are limited, these studies based on clinical data collection using reproducible and clear definitions are the best available alternative, and provide an indication of the effect of treatment.

A recent report supports this and appeals for context-based practise and research, whereas this remains a continuous process of learning and improving together. ${ }^{45}$ Therefore, it is of utmost importance to continue working with national dataset collection, where agreements have been made by the members of the Dutch Expert Group for Children in Pain and Fatigue. Obviously, a decision based on results of RCTs is always to be preferred.

\section{Measurements for the primary outcome variables}

In this thesis, the main outcome variables are social participation and health-related quality of life. These main outcome variables as presented in the various studies are comparable regarding the concepts of participation and health-related quality of life, but different regarding the used measurement instruments. Therefore the comparison on the level of scores of these instruments has to be interpreted with caution. All studies included in this thesis incorporate both outcome measures or an outcome measure (definition) related to one of these two main outcomes. For the 
studies performed in chapter 2, 3 and 4 the dataset was already present, therefore the use of specific measurements could not be influenced. The Dutch Rehabilitation Expert Group of Children and Adolescents in Pain and Fatigue decided before the start of data collection of the national cohort study which measurement instruments were used. This automatically implied that only those main outcome variables (e.g. school absence and the physical and psychosocial domains of the CHQ) and potentially associated or prognostic factors included in the original dataset were available for the studies in these chapters.

\section{School participation}

In chapter 3 and 4 social participation was measured with the child and parent(s) reported amount of absence of school. Due to the database design of the National cohort it was not possible to distinguish more than three categories of school participation, 1. normal school attendance, 2. partial absence and 3. complete absence of school. This is a fairly global classification. For the statistical analyses in chapter 3, due to the number of participants in each category, these categories had to be dichotomised, further restricting responsiveness of the instrument. To define successful treatment (chapter 4), the school participation measure with three categories was used. For future studies it is preferable to use a measure for school participation with more answer categories (e.g. six categories ${ }^{46,47}$ ) or even more preferable a continuous scale with the percentage school absence as outcome.

Moreover, to gain more insight in school functioning it seems to be recommended to use also other measures, preferably those that are international comparable. Different international school systems probably make this difficult. Nevertheless, other measures assessing variables, besides school attendance are available and are already being used, e.g. academic performance by the adolescent, parents and teacher, perceived pain interference, aids provided due to pain, and global school functioning (parents judgement). ${ }^{46,47}$ In addition, it is preferred to gain insight in the number of doubling a class and possibilities for the student for follow-up education or work (school competences).

We realise that the concept of social participation is broader than school participation alone. Unfortunately, due to the database design of the National cohort, it was not possible to add other measurement instruments for social participation in the studies described in chapter 3 and 4. For future research and clinical practice it is advised to choose measurement instruments that cover a wider range for the social participation construct. As far as we know there are still no measurement instruments available for measuring the whole construct of participation in children and adolescents. Development of a measurement instrument is therefore highly recommended. 
To conclude, school absenteeism is an important measure for school dysfunctioning. Future research is necessary to gain insight into valid and reliable measuring all aspects of school participation. Moreover, also a measurement instrument for the social participation construct has to be developed.

\section{Assessment of successful treatment}

Our definition of treatment success was based on a combination of predefined clinically relevant changes in four outcome measures: level of pain/fatigue, school absence, HRQoL-physical functioning and HRQoL-psychosocial functioning. This methodology of clinical relevance was based on the method used in the study of Hechler et al. (2009) and our choices regarding each domain are thoroughly described in chapter $4 .^{21}$ For the four domains together and each domain itself the psychometric characteristics of the measurements as chosen have to be taken into account. Therefore, the results have to be interpreted with care. On the other hand, it is the question whether we have not been too strict regarding our decision whether the treatment was successful or not based on a composite of four measures, whereas these measures might have been of different relevance for each individual patient. Besides, the patients were minimally impaired for HRQoL-psychosocial functioning. Despite this rather strict definition half of the participants $(49.6 \%)$ had a successful treatment.

A patient also has his own treatment goals which sometimes can even differ considerably from the four domains we have used. As just described, successful treatment depends also on the achieved personal goals set by the patient and his parents. Therefore in future research and clinical practice we prefer to include the Canadian Occupational Performance Measure (COPM) as measurement instrument for defining successful treatment. ${ }^{46}$ In addition, the established PedIMMPACT criteria might be taken into account to define successful treatment, including treatment satisfaction, sleep and some economic factors. ${ }^{49}$

\section{Child Health Questionnaire and other measurements for quality of life}

In this thesis one of the main measurement instruments was the Child Health Questionnaire (CHQ). In chapter 2 the responsiveness of the CHQ parent form was examined. We did however not study the content validity of the questionnaire. For future research this could be of added value, especially in relation to choices of measurement instruments for HRQoL. The associations with the summary scales of the $\mathrm{CHQ}$, physical functioning and psychosocial functioning were subject of chapter 3. The summary subscales of the CHQ were two domains out of four within the definition of successful treatment (chapter 4). 
The adolescents in the National cohort filled out the 50-item child version of the CHQ (CHQ-CF50). Although this data was available, we decided not to use this since the CHQ-50 child version has not been tested for validity and reliability. In addition, no PhS and PsS summary scales are available for any CHQ-child version. Besides, the differences between the adolescents and parents on similar subscales were small and not significant. Therefore, in all three studies we used the parent form to perform the statistical analyses.

Unfortunately, to date this is still the case. There have been some studies since the start of the National cohort in which the CHQ was used as measurement, but not in adolescents with chronic pain or fatigue as participants.

Two alternative measurements for quality of life are currently available: the PedsQL ${ }^{50,51}$ and the Dutch Quality of Life questionnaire for Adolescents with Chronic Pain (QLA-CP). ${ }^{52,53}$ For our population, the child self-report version in the age group 13-18 years could be used. This Dutch version of the PedsQL has adequate psychometric properties. ${ }^{50}$ The QLA-CP, a 44 item questionnaire, shows excellent internal consistency and suitable construct validity compared with COOP/WONCA charts. ${ }^{53}$ However, further validation and comparison across centres is needed. ${ }^{52}$ For future research these measurement instruments might be considered as additional measures for HRQoL. Furthermore, it would have been favoured to collect data on the activity level, so this domain of the ICF model would also have been represented.

\section{Implications for clinical practice}

Implications for clinical practice can be derived in accordance with the results of this thesis and can also be generalized to adolescents with chronic pain or fatigue in the Dutch clinical rehabilitation treatment setting and other Western countries.

First, based on the results of chapter 2, the Child Health Questionnaire parent form can be used in clinical practice to measure changes in quality of life. It appeared adequately sensitive for change on the physical scale and moderately sensitive for the psychosocial scale during treatment.

Second, based on the results of chapter 3, in relation to school participation, general practitioners and school physicians should pay extra attention to adolescents with prolonged fatigue complaints, as these adolescents seem to have more problems with school attendance. Earlier referral or referral anyway to treatment might enhance the chance of re-integrating the adolescent in school.

Third, based on the results of chapter 3, a high pain or fatigue score pre-treatment should trigger health care professionals for a further exploration of underlying 
mechanisms. It is important to find out the reason why the adolescent reports a high score since it can be associated with long-term restrictions in quality of life.

Fourth, based on the results of chapter 5, for young adults having received clinical rehabilitation during adolescence for chronic pain or fatigue, the long-term prognosis seems quite well. These young adults are doing well on the level of activities, participation and quality of life, although a large proportion (still) has complaints (fortunately however most of the time with a restricted NRS score) and they make regularly use of the Dutch healthcare system. In addition, they have more work absenteeism than their healthy peers. Since these young adults have more work absenteeism, it is recommended to pay extra attention to future work abilities during treatment in adolescence. A possibility could be to refer these adolescents in an early phase to a comparable program as the outpatient transition treatment program 'At work', which supports work participation amongst young adults with chronic physical disabilities, ${ }^{54}$ but the effectiveness still has to be proven.

Fifth, there seems to be a certain level of vulnerability among adolescents who have chronic pain. ${ }^{55}$ From a clinical perspective, it is recommendable to invite these adolescents for follow-up care in the phase of transition into adulthood for example when they are going to live on their own or when they start working. To offer these young adults a 'refresher course' on those moments might help to prevent a recurrence of disability and participation problems at an early stage in (young) adulthood.

And finally sixth, it is highly relevant for the patient, important for the quality of healthcare and research in clinical practice to map the different domains of the ICF-model and the outcome measures for treatment in future cohort studies in this population. We advise to measure a minimal dataset in every patient admitted to rehabilitation programs. In the population we studied this would consist of several demographic characteristics, the level of complaints, personal goals, activity and participation level, health-related quality of life and psychosocial factors, like catastrophizing (for adolescent and parent), coping and system factors, e.g. protective behaviour.

\section{Recommendations for future research}

In this paragraph recommendations for future research are given. It is important to gain more insight into factors that can influence participation, quality of life and treatment success for adolescents with chronic musculoskeletal pain and chronic fatigue. Those factors that can be influenced during treatment are of special interest. 
A potential influencing factor is fear. The fear-avoidance model is translated to a child version, ${ }^{56}$ which also takes the system into account. Since the adult fearavoidance model $^{36}$ has made a significant contribution to understanding painrelated disability in adult patients with chronic pain, it is recommended for further research to use the child version of the fear-avoidance model. In particular, further research on the influence of the system of the adolescent seems to be of added value. Once evidence of the underlying mechanism has been found, treatment can be accordingly changed. A focussed treatment might then lead to an improvement on the treatment outcome measures in patients.

From the design and results of this thesis it is recommended for future research to both measure pain and fatigue separately instead of assessing it as the severity of the main complaint. This is important because both problems (pain and fatigue) together may even have a bigger impact on daily life. And it is known that pain and fatigue often occur together. ${ }^{19}$

To identify changes after treatment, assessment according the PedIMMPACT criteria, ${ }^{49}$ has added value above the set as used in our study. These criteria for clinical trials are supported around the world and contain the wide range of measurements to assess factors we need to know for an adolescent in pain. It is recommended to further design the national database for adolescents with chronic pain or fatigue, according the PedIMMPACT criteria and similar to the Dutch Dataset Painrehabilitation for adults. ${ }^{19}$ This database is necessary to monitor patients over time, to compare rehabilitation treatment in different centers, and to continuously improve the quality of treatment. In design and implementation of a national database the Dutch Rehabilitation Expert Group for Children and Adolescents in Pain and Fatigue should continue to play an important role in the evaluation of treatment.

\section{General conclusions}

The main conclusions of this thesis are summarized below:

- The parent version of the Child Health Questionnaire is able to measure relevant change in a clinical rehabilitation treatment setting, and therefore can be implemented in clinical practice.

- On the short-term, adolescents with a high level of pain/fatigue pre-treatment seem to have a good treatment result, but on the long-term they are prone to restrictions in functioning. Therefore, attention in research and clinical practice on the long-term is needed for this specific subgroup. 
- Passive coping seems relevant to address during treatment, since it is significantly associated with HRQoL-psychosocial functioning and is a predictor for successful treatment.

- Inpatient interdisciplinary treatment for adolescents with chronic pain or fatigue is successful for about half of the participants, even when using rather strict criteria.

- Despite the fact that on the long-term the young adults are quite active and participating, with a reasonable quality of life, a large proportion still has complaints. In addition, they have more work absenteeism than their healthy peers. 


\section{References}

1. Dommisse-van Berkel, A.A.M., Van der Looij-Jansen, P.M., de Waart, F.G., Voerman, J.S., van Elderen, L.J., Passchier, J., de Graaf, L.E., Remerie, S., de Klerk, C., Signalering en doorverwijzing van adolescenten met chronische pijn door de jeugdgezondheidszorg: een pilot studie. Tijdschrift voor Jeugdgezondheidszorg, 2012. 44(3): p. 4.

2. Farmer, A., et al., Prevalence of chronic disabling fatigue in children and adolescents. $\mathrm{Br}$ J Psychiatry, 2004. 184: p. 477-81.

3. King, S., et al., The epidemiology of chronic pain in children and adolescents revisited: a systematic review. Pain, 2011. 152(12): p. 2729-38.

4. Perquin, C.W., et al., Pain in children and adolescents: a common experience. Pain, 2000. 87(1): p. 51-8.

5. ter Wolbeek, M., et al., Severe fatigue in adolescents: a common phenomenon? Pediatrics, 2006. 117(6): p. e1078-86.

6. Bell, D.S., K. Jordan, and M. Robinson, Thirteen-year follow-up of children and adolescents with chronic fatigue syndrome. Pediatrics, 2001. 107(5): p. 994-8.

7. Brattberg, G., Do pain problems in young school children persist into early adulthood? A 13-year follow-up. Eur J Pain, 2004. 8(3): p. 187-99.

8. Perquin, C.W., et al., The natural course of chronic benign pain in childhood and adolescence: a two-year population-based follow-up study. Eur J Pain, 2003. 7(6): p. 551-9.

9. ter Wolbeek, M., et al., Predictors of persistent and new-onset fatigue in adolescent girls. Pediatrics, 2008. 121(3): p. e449-57.

10. Crawley, E. and J.A. Sterne, Association between school absence and physical function in paediatric chronic fatigue syndrome/myalgic encephalopathy. Arch Dis Child, 2009. 94(10): p. 752-6.

11. Haraldstad, K., et al., Pain in children and adolescents: prevalence, impact on daily life, and parents' perception, a school survey. Scand J Caring Sci, 2011. 25(1): p. 27-36.

12. Konijnenberg, A.Y., et al., Children with unexplained chronic pain: substantial impairment in everyday life. Arch Dis Child, 2005. 90(7): p. 680-6.

13. Hunfeld, J.A., et al., Chronic pain and its impact on quality of life in adolescents and their families. J Pediatr Psychol, 2001. 26(3): p. 145-53.

14. Perquin, C.W., et al., Insights in the use of health care services in chronic benign pain in childhood and adolescence. Pain, 2001. 94(2): p. 205-13.

15. Banez, G.A., et al., Chronic pain in children and adolescents: 24-42 month outcomes of an inpatient/day hospital interdisciplinary pain rehabilitation program. J Pediatr Rehabil Med, 2014. 7(3): p. 197-206.

16. Hechler, T., et al., Inpatient-based intensive interdisciplinary pain treatment for highly impaired children with severe chronic pain: randomized controlled trial of efficacy and economic effects. Pain, 2014. 155(1): p. 118-28.

17. Klineberg, E., et al., Adolescent chronic fatigue syndrome and somatoform disorders: a prospective clinical study. J Paediatr Child Health, 2014. 50(10): p. 775-81.

18. Maynard, C.S., et al., Interdisciplinary behavioral rehabilitation of pediatric painassociated disability: retrospective review of an inpatient treatment protocol. J Pediatr Psychol, 2010. 35(2): p. 128-37. 
19. Koke, A.J., et al., Dutch Dataset Pain Rehabilitation in daily practice: Content, patient characteristics and reference data. Eur J Pain, 2016.

20. de Blecourt, A.C., et al., Preliminary evaluation of a multidisciplinary pain management program for children and adolescents with chronic musculoskeletal pain. Disabil Rehabil, 2008. 30(1): p. 13-20.

21. Hechler, T., et al., Effectiveness of a 3-week multimodal inpatient pain treatment for adolescents suffering from chronic pain: statistical and clinical significance. Clin J Pain, 2009. 25(2): p. 156-66.

22. Dodson, J.L., et al., Parent perspectives of health related quality of life for adolescents with bladder exstrophy-epispadias as measured by the child health questionnaire-parent form 50. J Urol, 2010. 184(4 Suppl): p. 1656-61.

23. Dodson, J.L., et al., Parent perspectives of health related quality of life in adolescents with chronic kidney disease due to underlying urological disorders: an assessment using the Child Health Questionnaire-Parent Form 50. J Urol, 2008. 180(4 Suppl): p. 1700-4; discussion 1704.

24. Lame, I.E., et al., Quality of life in chronic pain is more associated with beliefs about pain, than with pain intensity. Eur J Pain, 2005. 9(1): p. 15-24.

25. Dutch Expert Group for Children in Pain and Fatigue, Elements of treatment for chidren and adolescents with chronic musculoskeletal pain - consensus report. 2008, Rotterdam: Rijndam Rehabilitation.

26. Eccleston, C., et al., Chronic pain in adolescents: evaluation of a programme of interdisciplinary cognitive behaviour therapy. Arch Dis Child, 2003. 88(10): p. 881-5.

27. Logan, D.E., et al., Changes in willingness to self-manage pain among children and adolescents and their parents enrolled in an intensive interdisciplinary pediatric pain treatment program. Pain, 2012. 153(9): p. 1863-70.

28. Simons, L.E., et al., Fear of pain in the context of intensive pain rehabilitation among children and adolescents with neuropathic pain: associations with treatment response. J Pain, 2012. 13(12): p. 1151-61.

29. Weiss, K.E., et al., Acceptance of pain: associations with depression, catastrophizing, and functional disability among children and adolescents in an interdisciplinary chronic pain rehabilitation program. J Pediatr Psychol, 2013. 38(7): p. 756-65.

30. Hechler, T., et al., Systematic Review on Intensive Interdisciplinary Pain Treatment of Children With Chronic Pain. Pediatrics, 2015. 136(1): p. 115-27.

31. Hayes, S.C., Acceptance and Commitment Therapy, Relational Frame Theory, and the Third Wave of Behavioral and Cognitive Therapies - Republished Article. Behav Ther, 2016. 47(6): p. 869-885.

32. Hayes, S.C., et al., Acceptance and commitment therapy: model, processes and outcomes. Behav Res Ther, 2006. 44(1): p. 1-25.

33. Wicksell, R.K., et al., Evaluating the effectiveness of exposure and acceptance strategies to improve functioning and quality of life in longstanding pediatric pain--a randomized controlled trial. Pain, 2009. 141(3): p. 248-57.

34. Kanstrup, M., et al., A Clinical Pilot Study of Individual and Group Treatment for Adolescents with Chronic Pain and Their Parents: Effects of Acceptance and Commitment Therapy on Functioning. Children (Basel), 2016. 3(4). 
35. Veehof, M.M., et al., Acceptance- and mindfulness-based interventions for the treatment of chronic pain: a meta-analytic review. Cogn Behav Ther, 2016. 45(1): p. 5-31.

36. Vlaeyen, J.W. and S.J. Linton, Fear-avoidance and its consequences in chronic musculoskeletal pain: a state of the art. Pain, 2000. 85(3): p. 317-32.

37. den Hollander, M., et al., Fear reduction in patients with chronic pain: a learning theory perspective. Expert Rev Neurother, 2010. 10(11): p. 1733-45.

38. Dekker, C., et al., Study protocol for a multicentre randomized controlled trial on effectiveness of an outpatient multimodal rehabilitation program for adolescents with chronic musculoskeletal pain (2B Active). BMC Musculoskelet Disord, 2016. 17: p. 317.

39. Ostelo, R.W. and H.C. de Vet, Clinically important outcomes in low back pain. Best Pract Res Clin Rheumatol, 2005. 19(4): p. 593-607.

40. Van Houdenhove, B., et al., Does high 'action-proneness' make people more vulnerable to chronic fatigue syndrome? A controlled psychometric study. J Psychosom Res, 1995. 39(5): p. 633-40.

41. Achten, D., et al., Pain rehab during puberty; work in adulthood? A long-term follow-up study to explore the facilitators and barriers for work. . to be submitted.

42. Tran, S.T., et al., Distinct Influences of Anxiety and Pain Catastrophizing on Functional Outcomes in Children and Adolescents With Chronic Pain. J Pediatr Psychol, 2015. 40(8): p. 744-55.

43. Bould, H., et al., Depression in paediatric chronic fatigue syndrome. Arch Dis Child, 2013. 98(6): p. 425-8.

44. Simons, L.E., C.B. Sieberg, and R.L. Claar, Anxiety and impairment in a large sample of children and adolescents with chronic pain. Pain Res Manag, 2012. 17(2): p. 93-7.

45. RVS, Zonder context geen bewijs - Over de illusie van evidence-based practice in de zorg. 2017, Raad voor Volksgezondeheid en Samenleving (RVS): Den Haag.

46. Logan, D.E., L.E. Simons, and E.A. Carpino, Too sick for school? Parent influences on school functioning among children with chronic pain. Pain, 2012. 153(2): p. 437-43.

47. Logan, D.E., et al., School impairment in adolescents with chronic pain. J Pain, 2008. 9(5): p. 407-16.

48. Law, M., et al., Canadian Occupational Performance Measure. Third ed. 1997, Ottowa: CAOT Publications ACE.

49. McGrath, P.J., et al., Core outcome domains and measures for pediatric acute and chronic/recurrent pain clinical trials: PedIMMPACT recommendations. J Pain, 2008. 9(9): p. 771-83.

50. Engelen, V., et al., Health related quality of life of Dutch children: psychometric properties of the PedsQL in the Netherlands. BMC Pediatr, 2009. 9: p. 68.

51. Varni, J.W., M. Seid, and P.S. Kurtin, PedsQL 4.0: reliability and validity of the Pediatric Quality of Life Inventory version 4.0 generic core scales in healthy and patient populations. Med Care, 2001. 39(8): p. 800-12.

52. Eccleston, C., A.L. Jordan, and G. Crombez, The impact of chronic pain on adolescents: a review of previously used measures. J Pediatr Psychol, 2006. 31(7): p. 684-97.

53. Merlijn, V.P., et al., Shortening a quality of life questionnaire for adolescents with chronic pain and its psychometric qualities. Psychol Rep, 2002. 90(3 Pt 1): p. 753-9. 
54. Bal, M.I., et al., A vocational rehabilitation intervention for young adults with physical disabilities: participants' perception of beneficial attributes. Child Care Health Dev, 2017. 43(1): p. 114-125.

55. Merlijn, V.P., et al., Psychosocial factors associated with chronic pain in adolescents. Pain, 2003. 101(1-2): p. 33-43.

56. Simons, L.E. and K.J. Kaczynski, The Fear Avoidance model of chronic pain: examination for pediatric application. J Pain, 2012. 13(9): p. 827-35. 



\title{
Chapter 7
}

\author{
Valorisation
}




\section{Introduction}

This valorisation paragraph represents the societal value of the results of this thesis. Valorisation is transferring scientific knowledge to, for example healthcare organisations, by making knowledge available and suitable for economic and social exploitation. It is the translation of knowledge into products, services, processes or new business.

The results presented in this thesis are published in peer-reviewed journals. Several oral and poster presentations have been provided to share the results with health care professionals and to spread the clinical implications. Also articles are posted on social media and websites to share the outcomes with patients and their parents. In this chapter, the relevance for patients and their families, therapists, medical specialists and health insurance companies, will be presented, followed by examples of innovative activities.

\section{Target groups}

The results of this thesis are relevant for different groups of people, especially for adolescent patients with chronic musculoskeletal pain or chronic fatigue. In the Netherlands, some of them who have to cope with severe disability, are treated in a rehabilitation setting. Therefore, the relevance of the results is also applicable for rehabilitation therapists and physicians in rehabilitation medicine treating adolescents with chronic pain or fatigue. The results are also of interest for general practitioners, school physicians, other health care professionals and health insurance companies.

\section{Relevance for adolescents with chronic musculoskeletal pain or chronic fatigue}

Patients and their parents: you are not alone! Your complaints are quite common and might persist over time. As you know your complaints have a considerable impact on your daily and leisure activities and school functioning. Some of you will be referred for inpatient rehabilitation treatment. Twelve to 17 years ago these patients were mostly girls around the age of 16 and the complaints existed on average for three years.

What can be expected of this inpatient rehabilitation treatment? According a rather strict definition almost half (49.6\%) of these adolescents had a successful treatment. On the long-term (10 years later) the total population that received rehabilitation is quite active and participating, with a reasonable quality of life. A large proportion 
of the participants still reported to have complaints, although these were on average of a lower intensity level than at the start of treatment.

In follow-up healthcare attention should be paid to future work ability, because of the present higher level of work absenteeism compared to healthy peers. Also, we advise to offer those adolescents experiencing difficulties in the transition to adulthood a 'refresher course' in order to improve their coping in this new phase of life (e.g. identified based on screening by a questionnaire or consultation when necessary).

\section{Relevance for rehabilitation therapists and physicians}

The message for rehabilitation therapists and physicians: Start or keep on continuously monitoring to improve diagnostics and treatment based on assessment. Collecting data can help to gain insight into influencing factors and working elements of treatment and helps to adjust treatment.

In clinical practice the parent form of the Child Health Questionnaire can be used to measure changes in quality of life. It is important to know that boys, adolescents with a higher level of pain/fatigue, and patients with a higher passive coping seem to benefit more from an inpatient treatment. Therefore, it seems relevant to more specifically address passive coping during treatment.

On the long term, adults having received clinical rehabilitation during adolescence for chronic pain or fatigue, have more work absenteeism than their healthy peers. It is therefore recommended to pay extra attention to future work abilities during treatment in adolescence. Adolescents should be invited for follow-up care in the phase of transition into adulthood. A 'refresher course' when they are going to live on their own or when they start working.

\section{Relevance for other medical specialists}

To other medical specialists and health care professionals, specifically general practitioners, paediatricians, and school physicians, the message is: When the adolescent patient is older, has chronic fatigue, has higher pain/fatigue scores or a more passive coping style, it is possible that social participation and health-related quality of life are at stake. Earlier referral or referral anyway to rehabilitation for these adolescents should be considered.

In case an adolescent reports lots of pain or fatigue to a health care professional, some specific attention is needed for further exploring a possible underlying mechanism. This might be a key to the possible long-term restrictions in healthrelated quality of life, which should be prevented. 


\section{Relevance for health insurance companies}

Given the scale, complexity and impact of pain and fatigue problems, it is preferred to arrange care for adolescents with fatigue and pain in healthcare networks. Based on a stepped care approach (from a bio-psychosocial perspective) with providers in primary to third care included. The Pain Alliance in the Netherlands (PAIN) can have a facilitating role in this transition of care. This way of arranging care for adolescents with chronic pain will fit the proposed health care service in the Dutch standard of care for chronic pain.

\section{Implementation, innovative and future activities}

It is recommended to further design the National database for adolescents with chronic pain or fatigue, according the PedIMMPACT criteria and in accordance to the Dutch Dataset Painrehabilitation for adults. We advise to use a minimal dataset in every patient admitted to rehabilitation programs. As a consequence, it is possible to evaluate the treatment on the level of the individual, and also on an aggregated level. In this National database at least the following data should be collected: demographic characteristics, the level of complaints (pain as well as fatigue), personal goals, activity and participation level, health-related quality of life and psychosocial factors, like catastrophizing (for adolescent and parent), coping and system factors, e.g. protective behaviour.

It is also recommended to involve health care professionals working with adolescents with chronic pain and fatigue in formulating research questions out of clinical practice.

In this way, we can hopefully build a solid bridge between research and clinical practice in order to further improve care for adolescents with chronic pain and fatigue. 




\section{Summary}


The focus of this thesis is on adolescent patients with chronic musculoskeletal pain or chronic fatigue. Chronic pain and fatigue are both common complaints in childhood and adolescence. Prevalence rates vary from $4-40 \%$ for chronic pain and $2-21 \%$ for chronic fatigue. Both complaints can persist over time during childhood and adolescence. In chapter $\mathbf{1}$, a general introduction is provided with an overview on the prevalence of chronic musculoskeletal pain and chronic fatigue in adolescents and the impact on the adolescent's life.

Adolescence is defined as the transition in development between youth and full adulthood, which represents a period in which a person organically, but not emotionally becomes mature. Chronic pain related to the musculoskeletal system, since this type of pain is the focus of multidisciplinary rehabilitation treatment in the Netherlands, was our target group. Whereas, the pain is labelled to be chronic pain when it is present for more than six months, recurrently or continuously. Also patients with chronic fatigue who are severely disabled in activities in daily living and therefore apply for multidisciplinary rehabilitation treatment were our target group. Chronic fatigue syndrome is characterized as severe and disabling newonset fatigue that lasts for at least 6 months. Chronic pain and fatigue both have a considerable impact on the adolescent's life. Consequently, the impact of pain and fatigue on functioning can differ considerably between persons and is often not only limited to the individual person. The impact on society is enormous, for instance due to reduced or absent future workability and the financial burden of families. Adolescents with pain/fatigue are often not able to function at the same level as their peers and as a consequence, their future perspective regarding school and work career is at stake. Despite the sparsely available literature on the impact of chronic pain and fatigue in adolescents, it is recognised by clinicians as well as patients and their families that chronic pain and fatigue affect social participation and health-related quality of life (HRQoL) of an adolescent. However, it is not known what factors indeed do influence the level of participation and HRQoL of adolescents being chronically in pain or fatigued.

Using the International Classification of Functioning, Disability and Health (ICF) model as a framework and starting point, it can be hypothesized that the chronic pain/fatigue related functions, activity limitations, environmental factors, and personal factors can be influencing factors for the adolescent's social participation and HRQoL.

In the Netherlands, between 1992 and 2005, the period data was collected for the cohorts in this thesis, highly disabled adolescents due to chronic musculoskeletal pain or chronic fatigue were mostly treated in a clinical rehabilitation setting. The main aim of rehabilitation treatment is to increase the level of participation, despite 
pain and/or fatigue. This thesis contains results gained from data of two cohorts of adolescents, the National cohort and the Friesland cohort. Adolescents in both cohorts received an inpatient rehabilitation treatment for chronic musculoskeletal pain or chronic fatigue.

The main aim of this thesis was to gain more knowledge on social participation and health-related quality of life in adolescents with chronic musculoskeletal pain or chronic fatigue in relation to complaints, personal and environmental factors. In addition, successful rehabilitation treatment and long-term functioning of these adolescents in adulthood is studied.

In chapter 2 the responsiveness of the Child Health Questionnaire 50-item parent form (CHQ-PF50) in a sample of adolescents with chronic nonspecific pain and/ or fatigue was studied. The Child Health Questionnaire is a widely used instrument for measuring health-related quality of life (HRQoL) covering both the physical and psychosocial domain. Responsiveness was calculated using the parent's judgement about the result of treatment as the primary external criterion. The physical component (PhS) of the CHQ-PF50 was found to be adequately responsive and the psychosocial component (PsS) moderately responsive. Overall, the CHQ-PF50 is able to measure relevant change in a clinical rehabilitation treatment setting, and therefore can be implemented in clinical practice.

The relations between the characteristics of adolescents having prolonged pain/fatigue and the relevant outcome variables; before treatment (chapter 3), immediately after treatment (chapter 4), and on a long-term follow-up, 10 years after treatment (chapter $\mathbf{5}$ ) were described in this thesis.

The study in chapter 3 aimed to identify factors associated with school participation and HRQoL in adolescents with disabling chronic musculoskeletal pain or fatigue pre-treatment. The study presented in chapter 3 was a cross-sectional study at the start of an inpatient rehabilitation treatment. Potential associated factors were identified from literature and clinical expert opinion, and assessed with questionnaires. Regression analyses were used to identify contributing factors for school participation and HRQoL. The results showed that older adolescents and adolescents diagnosed with chronic fatigue were more often absent from school. In addition, higher self-reported levels of pain/fatigue were associated with lower HRQoL-physical functioning and a passive reaction coping style was associated with lower HRQoL-psychosocial functioning. 
In chapter 4 the percentage of adolescents with chronic pain/fatigue successfully treated with rehabilitation treatment was determined and, predictors for a successful rehabilitation treatment were identified. Treatment success was based on a combination of predefined clinically relevant changes in four outcome variables: level of pain/fatigue, school absence, HRQoL-physical functioning, and HRQoLpsychosocial functioning. According this strict definition almost half $(49.6 \%)$ of the participants had a successful treatment. With a regression analysis, with treatment success as dependent variable, predictors for successful treatment were identified. The results showed that boys had more benefit from treatment than girls. Additionally, adolescents with a higher level of pain/fatigue and those with a higher passive coping pre-treatment had a better ability to change their functioning during treatment.

Chapter 5 presents the study whether chronic pain/fatigue persisted during adulthood and how former patients function and participate in society as adults. Predictors for social participation in adulthood were also identified. This historical cohort study was performed on average 10 years after the end of rehabilitation treatment by using questionnaires to gather the data.

Of the young adults who received inpatient rehabilitation treatment during adolescence (National cohort and Friesland cohort), a considerable number (63.4\%) (still) had pain/fatigue complaints, more than 10 years later. Young adults with current pain/fatigue complaints reported more healthcare utilization, lower levels of physical functioning and limitations in daily activities due to physical problems. In addition, they had more work absenteeism than the norm population. Furthermore, it appeared that a higher level of pain/fatigue pre-treatment predicted impaired social participation in the work-educational domain in young adulthood.

Chapter 6 contains the general discussion in which the main findings of the thesis are presented. First, the aim of the thesis and a summary of the results are described. Based on the comparison with other populations, it seems that our population is quite comparable to populations presented in international publications in this research field. The results and content of treatment, based on a cognitive behavioural approach, seem to be comparable to interventions studied in international publications in this field and can be generalized to the adolescent rehabilitation population. The duration of our treatment was however longer. Since no treatment elements were jet included like ACT and graded exposure. These new treatment elements might eventually contribute to a shorter treatment duration as needed. 
In this general discussion we focus on factors identified to be associated with our main outcome variables in more than one of our studies; the level of pain/fatigue and passive coping. The finding that, on the long term, a higher level of pain/fatigue intensity at the start of treatment was related to a lower level of participation 10 years later seemed in contradiction with the finding on the short-term in which the higher level of pain/fatigue predicted a higher probability of successful treatment. One of the possible explanations might be that adolescents with severe complaints are prone to develop these complaints again. Another explanation might be that when adolescents become adults they shift to another life phase and are confronted with new activities (e.g. living on their own, work). However, as their former treatment did not include how to cope with pain/fatigue when performing these new activities and experiencing increase of pain/fatigue, their pain coping strategies might not have been sufficient. This might have resulted in performing these activities less or not at all and finally will result in a lower level of social participation. The last explanation might be that new activities belonging to a different stage in life could increase the total workload of the former patients. To cope with this higher workload, young adults might choose to adjust their physical performance to a lower level.

Passive coping seems relevant to address during treatment and was addressed during the clinical treatment as studied. However, in this cohort no data was collected regarding changes in coping style pre-, during and post-treatment. So unfortunately, we do not know whether this factor indeed changed at all, or whether it acted as a mediator between a variable pre-treatment and a successful treatment. For the future, it is recommended to use new insights and measure fear beliefs, (pain) catastrophizing, depression, anxiety and acceptance as they might be also predictive for future functioning and participation.

Methodological considerations are discussed, such as the potential impact of missing data. The number of missing data was highest at the end of treatment. However, based on the comparison between baseline characteristics of the participants with complete and missing data, the missings could be indicated to be at random. Studies, like ours based on clinical data collections using reproducible and clear definitions are however the best available at the moment. It is of utmost importance to continue working with cohort dataset collections.

In this thesis the main outcome variables were social participation and healthrelated quality of life. In two chapters social participation was measured with the child and parent(s) reported amount of absence of school. School absenteeism is an important measure for school dysfunctioning. To gain more insight in school functioning it is desirable to use also other measures, e.g. academic performance, perceived pain interference, aids provided due to pain, the number of doubling 
a class and possibilities for the student for follow-up education or work (school competences). And preferable those measures that are international comparable. Future research is necessary to gain insight into valid and reliable measuring all these aspects of school participation.

Successful treatment depends also on the achieved personal goals set by the patient and his parents. Therefore in future research and clinical practice we prefer to include patient specific measurements, such as the Canadian Occupational Performance Measure for defining successful treatment. Also the established PedIMMPACT criteria have to be taken into account in designing new cohort data sets.

In this thesis one of the main measurement instruments was the Child Health Questionnaire (CHQ). For future research the PedsQL and the Dutch Quality of Life questionnaire for Adolescents with Chronic Pain (QLA-CP) might be considered as alternative measure for HRQoL. Furthermore, it would have been of additional value to collect data on the activity level, so this domain of the ICF-model would also have been represented. Also, it is recommended to use valid and reliable measurement instruments for factors with a potential influence on treatment outcome, such as catastrophizing as one of the psychological factors and parental factors.

Other implications for clinical practice and recommendations for future research are also discussed in chapter 6 . Finally, general conclusions are presented.

In chapter 7, valorisation is described. Benefits for patients, rehabilitation physicians, therapists in rehabilitation and referrers are defined. 




\section{Samenvatting}


Chronische pijn en vermoeidheid zijn veel voorkomende klachten tijdens de kindertijd en adolescentie. De mate waarin chronische pijn voorkomt varieert van $4-40 \%$ en voor chronische vermoeidheid is dit $2-21 \%$. Beide klachten kunnen aanhouden gedurende de kindertijd en adolescentie. Een deel van de jongeren, die door deze klachten beperkt zijn in het dagelijks functioneren, kan binnen de kinderrevalidatie behandeld worden.

In Nederland is er binnen de kinderrevalidatie een werkgroep actief, die voornamelijk bestaat uit revalidatieartsen en psychologen/orthopedagogen en zich bezighoudt met het delen van kennis en ervaringen ten aanzien van kinderen en jongeren met chronische pijn en vermoeidheid (werkgroep voor chronische pijn en vermoeidheid binnen de kinderrevalidatie). Deze landelijke werkgroep besloot in 2001 om in vijf centra gegevens te verzamelen van alle jongeren die een klinische revalidatiebehandeling kregen aangeboden voor chronisch pijn of vermoeidheid, om op die manier beter zicht te krijgen op deze doelgroep. Deze verzamelde gegevens vanuit de klinische praktijk vormen het vertrekpunt om de vraagstellingen in dit proefschrift te beantwoorden. Dit proefschrift kwam tot stand in een samenwerkingsverband tussen Rijndam Revalidatie Rotterdam en de Universiteit Maastricht.

In hoofdstuk 1 van dit proefschrift wordt een algemene introductie gegeven waarin het voorkomen van chronische pijn en chronische vermoeidheid wordt toegelicht. Daarnaast wordt uitleg gegeven over de gebruikte terminologie en de impact beschreven die deze klachten kunnen hebben op het leven van de jongere.

De onderzoekspopulatie van de studies in dit proefschrift waren jongeren met chronische pijn gerelateerd aan het houdings- en bewegingsapparaat of het chronisch vermoeidheidssyndroom, die vanwege de mate van ervaren beperkingen, een behandeling kregen binnen een multidisciplinaire, klinische revalidatiesetting in de periode van 1992 tot 2005. Deze gegevens zijn verzameld binnen twee cohorten, het nationaal cohort (2001-2005) en het Friesland cohort (1992-2000). Het belangrijkste doel van deze revalidatiebehandeling was het verhogen van het niveau van participatie, ondanks de pijn en/of vermoeidheid.

Chronische pijn en vermoeidheid kunnen een aanzienlijke impact hebben op het leven van een jongere. Deze impact op het functioneren kan aanmerkelijk verschillen tussen personen onderling en is meestal niet beperkt tot het individu alleen. Jongeren met pijn/vermoeidheid zijn meestal niet in staat om op hetzelfde niveau te functioneren als hun leeftijdsgenoten. Een consequentie daarvan is dat hun toekomstperspectief met betrekking tot school en werk risico loopt en er 
uiteindelijk een verminderde mogelijkheid of onmogelijkheid tot werken ontstaat. Naast de financiële lasten voor de familie, zijn de langere termijn gevolgen voor de maatschappij daarom enorm.

Ook clinici, patiënten en hun familie zijn van mening dat chronische pijn en vermoeidheid invloed hebben op de kwaliteit van leven van een jongere. Over de gevolgen van chronische pijn en vermoeidheid bij jongeren is echter beperkte literatuur beschikbaar. Ook is niet bekend welke factoren feitelijk van invloed zijn op het niveau van deelname aan de samenleving en de kwaliteit van leven van jongeren met chronische pijn of vermoeidheid.

Om te begrijpen welke factoren sociale participatie en kwaliteit van leven van de jongere kunnen beïnvloeden en hiermee samenhangen, hebben we als kader en uitgangspunt een veel gebruikt model binnen de revalidatie gekozen. Dit is het International Classification of Functioning, Disability and Health (ICF) model, waarbij we veronderstellen dat de functies gerelateerd aan de pijn/vermoeidheid, beperkingen op het gebied van dagelijkse activiteiten, omgevingsfactoren en persoonlijke factoren van invloed zijn op de mate waarin iemand participeert in de maatschappij en zijn kwaliteit van leven.

Het doel van dit proefschrift is om meer kennis te verzamelen over sociale participatie en kwaliteit van leven van jongeren met chronische pijn of vermoeidheid in relatie tot hun klachten, persoonlijke factoren en omgevingsfactoren. Daarnaast hebben we gekeken naar het resultaat van de revalidatiebehandeling en hoe deze adolescenten op de langere termijn functioneren in de periode van volwassenheid.

In hoofdstuk 2 wordt de responsiviteit van de ouderversie van de Child Health Questionnaire, een kwaliteit van leven vragenlijst bestaande uit 50 items (CHQPF50), in een groep van jongeren met chronische pijn en/of vermoeidheid bepaald. De Child Health Questionnaire is een veel gebruikt meetinstrument voor het meten van gezondheid gerelateerde kwaliteit van leven voor zowel het fysieke als het psychosociale domein. Responsiviteit is de mate waarin dit meetinstrument de werkelijke klinisch relevante verandering kan meten. Deze responsiviteit werd bepaald door gebruik te maken van de beoordeling van de ouders over het resultaat van de behandeling als primair extern criterium. De responsiviteit van de fysieke component van de CHQ-PF50 werd voldoende bevonden. Voor het psychosociale domein was de responsiviteit matig. Met deze uitkomsten denken we dat de CHQ-PF50 de mogelijkheid heeft relevante verandering binnen een klinische revalidatiebehandeling te meten en geïmplementeerd kan worden in de klinische praktijk. 
In de volgende hoofdstukken van dit proefschrift wordt geschreven over sociale participatie en kwaliteit van leven van jongeren met chronische pijn of vermoeidheid. Er worden relaties onderzocht tussen de kenmerken van de jongeren die lange tijd pijn hebben of vermoeid zijn en relevante maten op het niveau van participatie en kwaliteit van leven op verschillende momenten in de tijd (voorafgaand aan de behandeling, direct na de behandeling en 10 jaar na de behandeling).

De onderzoekspopulatie zoals beschreven in hoofdstuk 3 en 4 bestond uit 172 jongeren van gemiddeld 16,2 jaar, waarvan $85,5 \%$ meisje was. Van deze jongeren hadden er 76 chronische vermoeidheid en de anderen chronische pijnklachten. Op een schaal van 0-100 werd een hoge mate aan klachten aangegeven, namelijk gemiddeld 68,7. Deze klachten waren gemiddeld reeds drie jaar aanwezig. Van onze groep had $82 \%$ bij aanvang van de behandeling ernstig schoolverzuim (meer dan $20 \%$ van de tijd). Ongeveer een derde van de jongeren had een familielid met soortgelijke klachten.

In hoofdstuk 3 wordt een dwarsdoorsnede studie beschreven met als doel kenmerken van jongeren met chronische pijn of vermoeidheid te identificeren die samenhangen met de mate van schoolparticipatie en kwaliteit van leven. De gegevens die gebruikt zijn in deze studie, zijn verzameld voorafgaand aan de behandeling. Om een lijst met potentiële kenmerken te identificeren, werd eerst de literatuur geraadpleegd en werd tevens de mening van klinisch experts gevraagd. Omdat voor dit onderzoek gebruik werd gemaakt van gegevens uit een reeds bestaand cohort, werden alleen die factoren onderzocht die daadwerkelijk beschikbaar waren binnen het cohort. Uit de resultaten bleek dat oudere jongeren en jongeren met de diagnose chronische vermoeidheid meer schoolverzuim hadden. Daarnaast werd gevonden dat een hoger niveau van zelf-gerapporteerde pijn/vermoeidheid gerelateerd was aan een lagere kwaliteit van leven op het fysieke domein. Ook een passieve coping stijl was gerelateerd aan een lagere kwaliteit van leven op het psychosociale domein.

In hoofdstuk 4 werd het percentage bepaald van jongeren met chronische pijn/vermoeidheid die volgens een vooraf opgestelde definitie een geslaagde revalidatiebehandeling hebben gehad. Eveneens werden voorspellers voor een geslaagde klinische revalidatiebehandeling vastgesteld.

De definitie van een geslaagde behandeling was gebaseerd op een combinatie van vooraf vastgestelde klinisch relevante verandering op vier uitkomstmaten: niveau van pijn/vermoeidheid, schoolverzuim, het fysieke en het psychosociale domein van kwaliteit van leven. Voor het niveau van pijn/vermoeidheid betekende dit een 
vermindering van deze pijn/vermoeidheid van minimaal $30 \mathrm{~mm}$ op een lijn van $100 \mathrm{~mm}$ na de behandeling. Voor schoolverzuim betekende dit dat een overgang van volledig schoolverzuim naar gedeeltelijk schoolverzuim of geen schoolverzuim en van gedeeltelijk schoolverzuim naar geen schoolverzuim, een klinisch relevante verandering was. Om een klinisch relevante verandering te bereiken op kwaliteit van leven, was het nodig om na de behandeling boven een berekend afkappunt te scoren op het fysieke domein (boven 43,2) en het psychosociale domein (boven 48,9). Wanneer minimaal twee van de vier uitkomstmaten een klinisch relevante verandering lieten zien en er op de andere twee uitkomstmaten geen achteruitgang had plaats gevonden, werd de behandeling als geslaagd gedefinieerd. Volgens deze strenge definitie bleek bijna de helft $(49,5 \%)$ van de deelnemers een geslaagde revalidatiebehandeling gehad.

Voor de tweede doelstelling van deze studie, het identificeren van voorspellers voor een geslaagde behandeling, lieten de resultaten zien dat jongens meer profijt hebben van de behandeling dan meisjes. Daarnaast hebben jongeren met een hoger niveau van pijn/vermoeidheid en een hogere passieve coping voorafgaand aan de behandeling een grotere kans op een geslaagde behandeling. Ten aanzien van het niveau van pijn/vermoeidheid en de passieve coping lijkt het er op dat deze jongeren meer mogelijkheden hebben om hun functioneren te veranderen tijdens de behandeling.

Hoofdstuk 5 beschrijft een studie onder volwassenen, die allen in hun adolescentie revalideerden in verband met chronische pijn/vermoeidheid. Het doel van de studie was om het functioneren en de participatie in de maatschappij van deze groep volwassenen te beschrijven. Een tweede doel was om te onderzoeken of voorafgaand aan de behandeling in de fase van adolescentie, voorspellers te identificeren zijn die van invloed zijn op de mate van sociale participatie tijdens volwassenheid.

Voor deze studie werden gegevens verzameld met behulp van vragenlijsten onder deelnemers van het nationaal en het Friesland cohort in de fase van volwassenheid, gemiddeld 10 jaar na de behandeling. De resultaten laten zien dat een aanzienlijk deel $(63,4 \%)$ van de jongvolwassenen die eerder een klinische revalidatiebehandeling heeft gehad, meer dan 10 jaar later (nog steeds) pijn- en/of vermoeidheidsklachten heeft, maar van een lagere intensiteit. Deze jongvolwassenen met huidige pijn- en/ of vermoeidheidsklachten rapporteren een hoger gebruik van de gezondheidszorg, een lager niveau van fysiek functioneren en meer beperkingen in dagelijkse activiteiten door fysieke problemen dan de jongvolwassenen die geen pijn- en/ of vermoeidheidsklachten hadden tijdens volwassenheid. Daarnaast is inzichtelijk 
geworden dat de groep deelnemers aan het onderzoek die betaald werk heeft $(72,0 \%)$, meer werkverzuim rapporteerde dan de normpopulatie.

Wat betreft het tweede doel van het onderzoek bleek dat een hoger niveau van pijn/vermoeidheid voorafgaand aan de behandeling in adolescentie voorspellend is voor een verminderde sociale participatie op het domein werk \& educatie tijdens volwassenheid.

Hoofdstuk 6 bevat een algemene discussie waarin de belangrijkste bevindingen van dit proefschrift worden gepresenteerd.

Eerst hebben we gekeken of onze onderzoekspopulatie vergelijkbaar is met andere studiepopulaties die beschreven worden in internationale publicaties binnen dit onderzoeksveld. Dit blijkt grotendeels overeen te komen. De inhoud van de behandeling, die gebaseerd was op een cognitief gedragsmatige aanpak, lijkt vergelijkbaar met interventies die beschreven worden in internationale publicaties. Echter, de duur van de in dit proefschrift onderzochte behandeling was langer. Destijds (periode 2001-2005) was langer en intensief behandelen meer gebruikelijk en werd er nog geen gebruik gemaakt van behandelvormen zoals Acceptance and Commitent Therapy of Exposure in vivo behandeling. Deze vormen kunnen mogelijk op termijn hun kosteneffectiviteit bewijzen.

Aan het einde van ieder beschreven onderzoek in dit proefschrift staat een discussie over de bevindingen van dat hoofdstuk en de interpretatie ervan. In deze algemene discussie beperken we ons daarom tot het bespreken van factoren die in minimaal twee van de vier onderzoeken als beïnvloedende factoren naar voren komen, namelijk het niveau van pijn/vermoeidheid en passieve coping.

Ten aanzien van de factor niveau van pijn/vermoeidheid lijkt het dat jongeren die bij aanvang van de behandeling meer klachten aangeven, beter reageren op behandeling. Tien jaar na de behandeling (lange termijn) lijkt het dat deze inmiddels jongvolwassenen met een hoog aanvangsniveau van klachten een lager niveau van participeren hebben op het domein opleiding en werk. Hiervoor wordt een aantal mogelijke verklaringen aangedragen. Een verklaring kan zijn dat de onderzoekspopulatie kwetsbaarder is voor het ontstaan van hernieuwde klachten. Een andere mogelijke verklaring is dat de deelnemers wel geleerd hebben om hiermee om te gaan in de oude situatie, maar dat zij dit niet kunnen toepassen in een nieuwe levensfase die weer andere eisen stelt (generalisatie). Een laatste mogelijkheid is dat het minder actief zijn wellicht een keuze is, om overbelasting in de nieuwe levensfase te voorkomen.

Ten aanzien van de factor passieve coping blijkt dat jongeren met een passievere 
manier van omgaan met problemen voorafgaand aan de behandeling een lager psychosociaal functioneren hebben en beter lijken te reageren op de gegeven revalidatiebehandeling. Het veranderen van coping stijl was een onderdeel van de behandeling en we denken dat dit dan ook kan hebben bijgedragen aan een geslaagde behandeling bij deze patiënten. Dit weten we echter niet zeker, aangezien de passieve coping stijl na afloop van de behandeling helaas niet was gemeten.

Ook worden in deze algemene discussie methodologische aspecten van het onderzoek besproken, zoals de mogelijke impact van missende gegevens, de methode van onderzoek en de gebruikte meetinstrumenten voor de belangrijkste uitkomstmaten.

Het aantal missende gegevens was het hoogst in de vragenlijsten die werden afgenomen aan het einde van de behandeling. Er was echter geen verschil tussen de basiskenmerken van de deelnemers aan het onderzoek met een complete set van gegevens en de deelnemers met een set met missende waarden. Dat betekent dat we deze missende gegevens als willekeurig (random) beschouwen en er dus geen sprake lijkt van selectieve uitval.

Helaas is het niet mogelijk geweest om het resultaat van een klinische revalidatiebehandeling te onderzoeken door middel van het uitvoeren van een randomized controlled trial (RCT). Studies, zoals die van ons, gebaseerd op gegevens verzameld in de klinische praktijk, gebruik makend van reproduceerbare en duidelijke definities, waren op het moment van uitvoer van het onderzoek qua methode het beste wat er beschikbaar was. Naast de uitvoeren van gerichte RCTs lijkt het van groot belang door te gaan met dit soort onderzoek dat gebaseerd is op verzameling van gegevens in een cohort.

Sociale participatie en kwaliteit van leven waren de belangrijkste uitkomstmaten in dit proefschrift. In dit hoofdstuk worden de meetinstrumenten die gebruikt zijn voor deze uitkomstmaten besproken. In twee hoofdstukken wordt sociale participatie gedefinieerd als de hoeveelheid schoolverzuim aangegeven door de jongere en ouder(s). Schoolverzuim is een belangrijke maat voor het disfunctioneren op school. Om meer inzicht te krijgen in het functioneren op school, is het wenselijk om ook andere uitkomstmaten te gebruiken. Bijvoorbeeld uitkomstmaten die gerelateerd zijn aan het cognitief functioneren op school (het presteren, het aantal doublures), het praktisch functioneren op school (ingezette hulpmiddelen, interferentie van klacht met school functioneren) en het toekomstperspectief (mogelijkheden voor vervolgopleiding of werk). De voorkeur gaat natuurlijk uit naar uitkomstmaten die internationaal vergelijkbaar zijn. Voor toekomstig onderzoek is het belangrijk om valide en betrouwbare metingen te verkrijgen voor deze aspecten van schoolparticipatie. 
Patiënten hebben tijdens hun behandeling persoonlijke doelen opgesteld. Het is mogelijk dat deze doelen niet altijd gerelateerd waren aan de uitkomstmaten die we hebben gebruikt om een geslaagde behandeling te definiëren. Terwijl het behalen van de persoonlijke doelen tijdens de behandeling hoogstwaarschijnlijk voor de persoon zelf veel meer van belang is voor het inschatten van het effect van de behandeling. Voor toekomstig onderzoek en voor de behandelsetting gaat de voorkeur dan ook uit naar het gebruik van aanvullende patiënt specifieke meetinstrumenten, zoals de Canadian Occupational Performance Measure (COPM). Door met de COPM het behalen van persoonlijke doelen te meten, zou deze uitkomstmaat toegevoegd kunnen worden aan de definitie van een geslaagde behandeling.

Naast persoonlijke doelen als nieuwe uitkomstmaat is het ook van belang om rekening te houden met de gevestigde internationale criteria (PedIMMPACT). Hierin worden verschillende uitkomstmaten benoemd om te meten en zo inzicht te verkrijgen op verschillende aspecten van de doelgroep.

In dit proefschrift is een van de belangrijkste gebruikte meetinstrumenten de vragenlijst Child Health Questionnaire (CHQ) voor het meten van kwaliteit van leven. In dit hoofdstuk worden twee mogelijk aanvullende alternatieven gegeven die wellicht in toekomstig onderzoek een rol kunnen innemen, namelijk de vragenlijsten Pediatric Quality of Life Inventory (PedsQL) en de Nederlandse versie van de Quality of Life questionnaire for Adolescents with Chronic Pain (QLA-CP).

We gaan in hoofdstuk 6 ook in op klinische implicaties naar aanleiding van de resultaten en geven verdere aanbevelingen voor toekomstig onderzoek. De volgende klinische implicaties worden gegeven: we adviseren huisartsen en schoolartsen om extra aandacht te besteden aan jongeren met chronische vermoeidheid aangezien zij vaker lijken te verzuimen van school. Ook geven de resultaten aanleiding voor zorgprofessionals om door te vragen wanneer sprake is van een hoge pijn/ vermoeidheid score voor aanvang van de behandeling. Het is op basis van de resultaten aan te bevelen om tijdens de behandeling meer aandacht te besteden aan mogelijkheden van werk in de toekomst en om een 'refresher course' aan te bieden op het moment dat deze jongeren/jongvolwassenen in een andere levensfase komen.

Voor toekomstig onderzoek is het aan te raden om de factoren in de gepresenteerde studies aan te vullen met nieuwe inzichten uit de literatuur over voorspellers van functioneren bij pijn. Zo kunnen ook angst gerelateerde overtuigingen, (pijn) catastroferen, depressie, angst en acceptatie als potentiële voorspellers worden gezien. Daarnaast lijkt onderzoek naar de invloed van het gezinssysteem van meerwaarde. Het apart meten van pijn en vermoeidheid is ook een aanbeveling 
voor toekomstig onderzoek. Tenslotte is het wenselijk om in de toekomst bij alle patiënten een minimum set van vragenlijsten af te nemen, waarin alle domeinen van het ICF-model als uitkomstmaat worden meegenomen.

Aan het einde van dit hoofdstuk worden de algemene conclusies gepresenteerd. In deze conclusies wordt gesteld dat:

- de ouderversie van de CHQ relevante verandering kan meten in een klinische revalidatiesetting, met name op het fysieke vlak;

- jongeren met een hoog niveau van pijn/vermoeidheid aan het begin van de behandeling op de korte termijn een goed behandelresultaat hebben, maar op de lange termijn minder lijken te participeren;

- passieve coping gerelateerd is aan psychosociaal functioneren en een voorspeller is voor een geslaagde behandeling;

- de aangeboden klinische revalidatiebehandeling voor bijna de helft van de patiënten geslaagd was op basis van strenge vooraf gestelde criteria;

- op de lange termijn bijna twee derde van de jongvolwassenen (nog) klachten heeft, terwijl ze redelijk goed functioneren en participeren in de maatschappij.

In hoofdstuk 7 worden de mogelijkheden van maatschappelijke valorisatie van de resultaten van de studies weergegeven. Voordelen voor de patiënten, revalidatieartsen, behandelaren in de revalidatie en verwijzers worden hierin beschreven. 



\section{Dankwoord}


Mijn promotietraject is klaar, mijn grootste project tot nu toe is volbracht, het is AF! Tijdens dit traject heb ik ontzettend veel geleerd over het doen van onderzoek en met name over het opschrijven daarvan. Ook was het nodig om mijn vaardigheden op het gebied project management aan te wenden. Gelukkig doe je promotieprojecten nooit alleen. Daarom wil ik dit onderdeel van mijn proefschrift benutten om iedereen te bedanken die op zijn/haar manier een bijdrage heeft geleverd aan dit promotietraject.

\section{Begin van mijn promotieproject}

Hoe begint een promotieproject? Bij mij in ieder geval niet met een sollicitatie. Het is begonnen met de inhoud! Voor het Ontwikkelcentrum Pijnrevalidatie heb ik samen met de behandelaren van Rijndam het behandelprogramma voor jongeren met chronische pijn en vermoeidheid geschreven. Een geweldig leerzame ervaring. Ook werd ik in die periode door AnneMarie ter Steeg betrokken bij de landelijke werkgroep voor chronische pijn en vermoeidheid binnen de kinderrevalidatie. Door deze werkzaamheden werd mijn affiniteit met het onderwerp groter.

En dan was er die dataset. Die mooie grote dataset, waarvan de gegevens verzameld waren door de behandelaren van vijf revalidatiecentra over een periode van 3 jaar. Alle vijf de centra participeerden in de landelijke werkgroep. De wens om met deze gegevens een internationale publicatie te schrijven was groot. En met een vervolg onderzoek er bij zou dit best eens een promotietraject kunnen worden.

Een logische inbedding voor een promotieproject door een medewerker van Rijndam was natuurlijk bij de afdeling Revalidatiegeneeskunde van het Erasmus MC. Na het schrijven van een subsidieaanvraag, waarvoor helaas geen financiering werd verkregen, bleek dat deze constructie op de inhoud niet haalbaar was. Daarna kwam gelukkig de 'nieuwe' vakgroep Rehabilitation Medicine van de Universiteit Maastricht in beeld. Daar was wel de benodigde affiniteit met het onderwerp chronische pijn binnen de revalidatie.

\section{Mijn promotieteam en twee andere belangrijke spelers}

Jeanine, jij bent mijn eerste promotor. Dit was niet vanaf de start zo, aangezien jij halverwege mijn promotietraject hoogleraar werd. Toch was het vanaf het begin duidelijk dat jij mijn 'dagelijks' begeleider was. Dank dat je mij de kans hebt gegeven om dit proefschrift te schrijven onder jouw begeleiding. Deze begeleiding betekende in onze samenwerking vooral Skypen. Ik heb dit bijna altijd als een prettige manier van overleggen ervaren. Op een aantal momenten was het echter wel nodig om elkaar in levende lijve te zien en te spreken, met name wanneer het om de planning en voortgang ging. Ik wil je bedanken voor het feit dat je mij 
gestimuleerd hebt om op mijn manier onderzoeker te worden en te zijn. Ik heb je manier van begeleiding enorm gewaardeerd, ook al was het soms zoeken in de loop der jaren naar welke manier werkte. Vooral heb ik genoten van al onze gesprekken die wel over de revalidatie gingen, maar niet over mijn onderzoek. Zonder jouw inhoudelijke kennis van het doen van onderzoek en jouw praktijk ervaring met de behandeling van deze jongeren was dit proefschrift niet geworden wat het nu is. Ook bedankt dat je bleef geloven dat ik in staat zou zijn om dit proefschrift goed af te ronden.

Rob, mijn andere promotor. Als hoofd van de vakgroep was het duidelijk dat jij bij mijn onderzoek betrokken zou zijn. Ik werd, zonder dat we elkaar kenden, door jou warm welkom geheten als externe PhD-student. Ik heb je betrokkenheid bij mijn promotietraject ontzettend gewaardeerd. Je hebt altijd de tijd genomen om je mening te geven over de vele versies van documenten die ik je heb toegestuurd. Ik heb genoten van onze inhoudelijke discussies, vooral als de spagaat over het verenigen van verschillende meningen daarna was opgelost. Dank voor het gesprek in Milaan, tijdens de IASP, waarin je mij liet inzien dat ik deze promotie toch echt voor mezelf moest doen, anders ging het afmaken me niet lukken. Ik waardeer het dan ook enorm dat je het geduld hebt opgebracht om tot het einde van mijn promotieproject mee te denken. Veel dank dat je mijn promotor wilde zijn.

Sylvia, mijn copromotor, mijn teamlid vanuit Rijndam. Ik heb je leren kennen op mijn eerste werkdag bij Rijndam, inmiddels 12,5 jaar geleden. Je inzet en zichtbare gedrevenheid voor het Ontwikkelcentrum Pijnrevalidatie staan me nog haarscherp voor ogen. Langzaam werd mij duidelijk waarom jij de pijnrevalidatiearts was en bent binnen Rijndam. Toen je over ging naar de kinderrevalidatie om de jongeren met chronische pijn en vermoeidheid te behandelen en mijn promotie startte, was het voor Michael Bergen duidelijk: jij moest mijn copromotor worden. Wat ben ik blij dat je deze uitdaging hebt aangenomen. Ik heb erg veel waardering voor alle input die je hebt gegeven vanuit jouw enorme schat aan praktijkervaring. Ook al sneeuwde de wetenschappelijke onderbouwing soms onder of werd het onderzoek stiekem bijna twee keer zo groot. Het laatste jaar zijn we samen behoorlijk doelgericht en intensief bezig geweest met mijn promotie. Frequent overleggen en vaak deadlines afspreken bleken succesfactoren te zijn. Zonder jouw aanjaagfunctie het laatste jaar, was dit proefschrift nog niet klaar geweest. Enorm veel dank voor alle inspanningen die je hebt verricht om een volwaardige copromotor te zijn. Ook veel dank voor het kunnen delen van belangrijke gebeurtenissen en perioden in jouw en mijn leven.

Michael, de beheerder van het onderzoekspotje van Rijndam. Met Sylvia als voorgedragen copromotor en mijn promotoren in Maastricht, durfde jij het aan 
om financiële middelen beschikbaar te stellen om mij te laten ontwikkelen als onderzoeker en verkennend onderzoek uit te voeren bij de doelgroep. Ontzettend bedankt voor het geven van de mogelijkheid om te promoveren binnen de muren van Rijndam. Inmiddels mag jij genieten van je welverdiende pensioen, waarin je je ongetwijfeld nog met heel veel revalidatie gerelateerde zaken bezig gaat houden. Nogmaals dank voor het vertrouwen.

Peter, mijn manager R\&D. Wat heb ik het met jou getroffen. Voor mij ben jij nog steeds de meest ideale leidinggevende die je je kan wensen. De zelfstandigheid, verantwoordelijkheid en flexibiliteit die jij mij geeft, maakt dat ik me de afgelopen 12,5 jaar heb kunnen ontwikkelen op allerlei gebieden, zowel binnen Rijndam als daarbuiten. En daarnaast heb je mij gefaciliteerd om mijn promotieproject te kunnen starten, uit te voeren en af te ronden. Regelmatig hebben we in deze jaren terugkerende discussies gehad over de balans tussen onderzoek en R\&D werkzaamheden en de balans tussen werk en privé. En ook al lijkt het dan vaak of ik je niet hoor, ik waardeer het enorm dat je je bezorgdheid uitspreekt. Ook jij bedankt voor het gestelde vertrouwen en alle mogelijkheden die je me hebt gegeven en nog steeds geeft.

\section{Uitvoering van het promotieproject}

\section{Multilocatie aanpak}

Een promovenda die in Amsterdam woont, in Rotterdam werkt en af en toe naar Maastricht komt omdat schijnt dat ze daar gaat promoveren. Ik heb regelmatig verbaasde blikken gekregen hierover. Het maakt voor mij dan ook niet uit waar ik werk, maar wel met wie.

Collega's van de UM, bedankt voor de altijd hartelijke ontvangst als ik weer eens kwam buurten. Dankzij jullie heb ik me altijd een onderdeel van de vakgroep gevoeld. Ik heb mooie herinneringen over gehouden aan de EFIC in Hamburg, de IASP in Milaan, de oratie van Jeanine en de ab challenge op de afdeling. Speciale dank voor Margareth voor het regelen van eigenlijk alles tijdens mijn promotietraject. Carolien en Janneke, bedankt voor de gezellige etentjes in Rotterdam om even bij te praten over onze projecten. Succes bij jullie laatste fase.

Collega's van de afdeling Revalidatiegeneeskunde van het Erasmus MC, bedankt voor jullie interesse in mijn onderzoek en de geboden mogelijkheden om hierover in discussie te gaan. Als Rijndammer en onderzoeker voel ik me verbonden met en betrokken bij de afdeling. En ik neem aan dat dit alleen maar gaat toenemen als we allemaal in het verbouwde Maasdamgebouw gaan werken.

Collega's van Rijndam, dank dat ik met jullie mag samenwerken en mag leren van jullie. Na 12,5 jaar Rijndam blijkt dat ik met aardig wat medewerkers heb gewerkt 
en projecten heb gedraaid. Via deze weg dank ik een ieder voor de interesse in mijn onderzoek en kijk ik uit de komende jaren met jullie in Rijndam.

\section{Leren}

Het doen van promotieonderzoek is één groot leertraject. Tijdens zo'n traject ontdek je waar je sterke en minder sterke punten liggen. Het schrijven in het Engels heeft me wat slapeloze nachten bezorgd. Het reageren op reviewers (pagina's lang) daarentegen bleek een sterk punt te zijn en daarmee een welkome afwisseling. Van de geboden opleidingsmogelijkheden heb ik gretig gebruik gemaakt en hierdoor is spelen met de data leuk geworden. Mijn optimisme over het halen van een gemaakte planning bleek vaak niet reëel te zijn. Het leren heeft ook geleid tot het meer en meer bekend worden met de doelgroep, ook al was dit weliswaar indirect via de ingevulde vragenlijsten van patiënten en deelnemers. Via deze weg wil ik alle deelnemers die een bijdrage hebben geleverd aan dit onderzoek door het invullen van vragenlijsten hartelijk danken.

\section{Mijn klankborden en spiegels}

Dank aan de beoordelingscommissie bestaande uit Sandra Beurskens, Mariëlle Goossens, Jan Passchier en Michiel Reneman voor de tijd die zij hebben genomen om mijn proefschrift te lezen en te beoordelen.

Naast mijn promotieteam zijn er een aantal coauteurs geweest die ik wil bedanken voor hun bijdrage aan het tot stand komen van artikelen in dit proefschrift. Allereerst AnneMarie ter Steeg en Imelda de Groot, revalidatieartsen betrokken bij het registratieonderzoek. Ook wil ik Marcel Post bedanken voor zijn bijdrage aan dit cohort onderzoek. Bedankt Bianca van Baalen en Marjolein de Craen, psychologen bekend met de behandeling van deze doelgroep. En bedankt Kiek de Blécourt voor haar bijdrage aan het lange-termijn onderzoek, met haar Friesland cohort. Helaas is Kiek vlak na het publiceren van dit artikel overleden na een lange ziekte periode.

Bedankt alle leden van de landelijke werkgroep! Zonder jullie initiatief voor het opzetten van het Nationaal cohort was dit proefschrift er niet geweest. Dank dat ik zo gastvrij werd ontvangen in de deelnemende centra om uit de dossiers ontbrekende en aanvullende gegevens te halen. Het is erg fijn om af en toe een kort kijkje in de keuken van een ander centrum te kunnen nemen. Ook dank voor alle inspirerende vergaderingen, die mij hielpen om door te gaan met het onderzoek naar deze interessante doelgroep.

En dan mijn collega's van het Innovatiecentrum en in het Maasdamgebouw. Fijn dat jullie er zijn voor een praatje, een overleg, een kopje koffie, het vieren van 
gebeurtenissen en het delen van lief en leed. Jorrit, al weer een aantal jaren mijn kamergenoot. Ik ben nog steeds blij dat we je binnen hebben gehaald bij Rijndam na je promotietraject. Door jou gaat relativeren ten aanzien van het doen van onderzoek een stuk makkelijker en is het stressniveau rondom werk in onze kamer zeer acceptabel. Dank voor je betrokkenheid tijdens de laatste jaren van mijn onderzoek, maar met name bij al die andere dingen. Carina, mijn mede co-trainer. Onze samenwerking binnen Rijndam is de laatste jaren intensiever geworden. Met name op het gebied van projectmatig werken kunnen we elkaar goed vinden en aanvullen. Ik ben erg blij met deze ontwikkelingen. Ook buiten werktijd sporten we samen, maken we plannen en dromen we over onze eigen coaching praktijken. Dank voor onze vriendschap en voor wie je bent. En blijf vooral vragen stellen! Annejette, mijn innovatie maatje. Sinds jij bij Rijndam werkt, staat innovatie bij Rijndam veel meer op de kaart. Wat is het toch leuk om met jou samen te werken en zichtbare resultaten te behalen. Dank dat je in de laatste fase van de afronding van mijn proefschrift betrokken wilt zijn en het aanspreekpunt hiervoor vanuit Rijndam. Speciale dank voor Fabienne en Dave voor het doorworstelen van mijn algemene inleiding en discussie en het geven van opbouwende feedback hierover.

Lieve vrienden en familie, vele van jullie zullen waarschijnlijk geen duidelijk beeld hebben waar ik de afgelopen jaren mee bezig ben geweest om te komen tot dit proefschrift. Toch wil ik jullie via deze weg bedanken voor alle momenten van samen zijn, vooral wanneer het niet over mijn proefschrift ging. Als deze momenten er niet waren geweest, dan was de balans zoek en was dit proefschrift er niet gekomen. Een aantal personen wil ik hier nog specifiek benoemen en bedanken.

Lieve Lau, mijn paranimf. Wat ben ik blij dat jij naast me staat tijdens mijn verdediging. Jij, die deze klus al heeft geklaard. Naast onze promotietrajecten hebben we wel meer paralellen in ons leven, wat onze band bijzonder maakt. We zijn begonnen als net afgestudeerde kamergenoten en zie ons nu: ambitieuze werkende moeders die nog meer opleidingen volgen en samengestelde gezinnen organiseren. Dank voor alles, maar vooral voor je mooie vriendschap.

Lieve Oude Wijffies, dank dat ik onderdeel ben van ons Kluppie. Dank voor alle heerlijke momenten van samen zijn. Ik kijk uit naar de vele OWK-uitjes die nog gaan komen. Dank dat jullie er voor me zijn en voor wie jullie zijn.

Mijn mannen van de WASVU! Het team dat mij een rotsvaste basis gaf. Dank voor alle herinneringen die we samen hebben gemaakt tijdens mijn promotietraject en al ver daarvoor. Het is een eer om jullie Koots te mogen zijn. Mark; speciale dank voor jou voor het verzorgen van de lay-out van mijn proefschrift. Mooi staaltje digitaal 
teamwork. Joep; zelfs in ons laatste gesprek toonde je interesse in mijn proefschrift. Hoe fijn het is om op die 'send'-knop te drukken. Wat had ik je graag mijn boekje laten zien. Ik mis je.

Lieve WASVU-dames. Wat zijn we toch een gaaf team. Dank voor al die heerlijke ontspanningsmomenten tussen alle bedrijven door. Ook al is mijn laatste speelseizoen bij jullie aangebroken en ga ik jullie ontzettend missen, ik weet: eens een WASVU-er altijd een WASVU-er.

Lieve Sybrand en Ingrid, wat fijn dat jullie met Mark in mijn leven zijn gekomen. Ik geniet van onze gesprekken aan tafel en bij de kachel over allerlei onderwerpen. Hoewel, het laatste jaar gingen deze met name over de oncologische zorg in Nederland. Ontzettend bedankt voor het beschikbaar stellen van werkplekken het afgelopen jaar tijdens de vakanties, met uitzicht op het weiland of op de bergen. Dit heeft enorm bijgedragen aan het kunnen afronden van mijn proefschrift. Ik kijk uit naar onze volgende momenten van samen zijn.

Lieve Jeroen en Marieke, bedankt voor de interesse die jullie altijd getoond hebben tijdens mijn promotieproject, maar vooral voor alle gezellige momenten met elkaar en onze kinderen. Bedankt voor wie jullie zijn. Ik noem jullie hier samen, maar eigenlijk gaat het nu vooral om Marieke. Lieve Marieke, wat fijn dat je mijn paranimf wilt zijn. Naast het feit dat je al heel lang familie bent, heb je ook bewegingswetenschappen gestudeerd, ben je gepromoveerd en heb je in de revalidatie gewerkt. Ik kan me geen betere paranimf wensen. Dank je wel voor al je inspanningen rondom mijn promotie.

Lieve heit en mem, dank dat jullie altijd voor mij en de kinderen klaar staan. Het afgelopen jaar was dit heel duidelijk in de vorm van oppassen op de woensdag, zodat ik op mijn vrije dag aan de slag kon met mijn boekje. Ik hoop dat jullie blijven komen op de woensdagen, vanaf nu is er dan weer meer kletstijd. Dank voor wie jullie zijn en hoe jullie mij hebben gevormd door jullie liefdevolle opvoeding.

Lieve Inte, Myrthe en Esper, mijn bonuskids. Jullie weten inmiddels dat er projecten zijn met verschillende duur en intensiteit. Mijn promotieproject vonden jullie toch wel aardig lang duren en vooralsnog zijn jullie volgens mij niet van plan om in de toekomst aan zo'n lang project te beginnen. Bedankt dat ik aan mijn proefschrift kon werken in jullie nabijheid. Bedankt dat jullie in mijn leven zijn gekomen en dat ik parttime voor jullie mag zorgen.

Onlosmakelijk verbonden aan mijn kinderen is Aiko. Dank dat je zo'n super vader bent voor onze kids. En vooral dank voor het feit dat we het samen zo goed kunnen regelen voor Lieke en Luuk. 
Lieve Lieke en Luuk, daar staan jullie namen dan, zoals ik had beloofd. Inmiddels weten ook jullie dat een boek schrijven veel werk is. Gelukkig heeft dit jullie tot nu toe vooral inspiratie gegeven, bijvoorbeeld voor het maken van de kaft van dit proefschrift en het schrijven van eigen boekjes. Vanaf nu ga ik weer mee zwemmen. Het is een voorrecht om jullie te zien opgroeien en ontwikkelen en jullie daarin te begeleiden. Lovuh you!

Lieve Mark, mijn man, mijn maatje in alles! Onze eerste kennismaking was tijdens het wereld kinderpijncongres in Vancouver om vervolgens zeven jaar later hernieuwd kennis te maken tijdens hetzelfde congres in Stockholm. Kinderen met pijn was dan ook onze eerste verbinding. Daarna bleek dat er nog veel meer verbindingen tussen ons waren, wat heeft geleid tot heel veel mooie, intense en bijzondere momenten de afgelopen 4,5 jaar. Zonder jou was dit proefschrift er nu zeker nog niet geweest. Een jaar geleden hebben we samen besloten dat we voor het afronden van mijn proefschrift gingen. De consequenties die dit met zich mee bracht heb jij zonder enige zichtbare moeite gedragen, daar waar ik heel wat baalmomenten heb gekend. Het is niet in woorden te vatten hoe ontzettend dankbaar ik je ben voor alles wat je voor mij en voor onze vijf kinderen hebt gedaan het afgelopen jaar in het kader van het afronden van mijn proefschrift. Het was een pittig energie slurpend jaar. Hoe fijn is het dan om te weten dat ik op jou terug kan vallen en te weten dat WIJ ONS ZIJN. Dank voor wie je bent en hoe wij samen ZIJN. Met jou durf ik zonder enige twijfel alle projecten die nog gaan komen aan, ook al zeg ik af en toe wat anders. Door het afsluiten van dit project is er ruimte voor nieuwe ontwikkelingen. Ontwikkelingen die zich voornamelijk af gaan spelen in het midden van het land. Ik heb er ontzettend veel zin in met JOU.

\section{Einde van het promotieproject}

Dit boekje is het resultaat van mijn promotieproject. Ik ben nieuwsgierig naar de ontvangst van mijn proefschrift in het werkveld. Is het een aanzet tot nieuwe onderzoeksvragen? Welke van mijn aanbevelingen kunnen daadwerkelijk geïmplementeerd worden in de praktijk? Door dit proefschrift blijf ik verbonden aan deze bijzondere doelgroep binnen de kinderrevalidatie. Ik draag hier in de toekomst dan ook graag een steentje aan bij.

Een kenmerk van een project is dat het een begin en een einde heeft. En het einde van projecten moet je vieren en dat gaan we dan ook doen! 




\section{About the author}


Tessa Westendorp was born on July, 16th 1979 in Hindeloopen, the Netherlands. She attended secondary school at the Augustinus college (VWO) in Groningen, where she graduated in 1997. The same year, she started her study in Human Movement Science at the Free University in Amsterdam. She graduated in 2002 with a specialization in rehabilitation medicine. Before and after her graduation she worked a couple of years as a project manager for Effectory (2001-2004) and for the Bone and Joint Decade (2004-2005).

Since 2005 she works at Rijndam Rehabilitation in Rotterdam, at the Research \& Development $(R \& D)$ department. In the first years a part of her job was to describe the treatment program and accessory measurements for adolescents with chronic musculoskeletal pain and chronic fatigue treated in the rehabilitation setting. Also since 2005 she became a member of the Dutch Rehabilitation Expert Group of Children and Adolescents in Pain and Fatigue (Werkgroep voor chronische pijn en vermoeidheid binnen de kinderrevalidatie) and took on the role of coordinator, which she still is.

In August 2010, she started the research described in this thesis at the department of Rehabilitation Medicine of the Maastricht University. During her part time thesis trajectory she worked also at Rijndam Rehabilitation, at the R\&D department. Currently, her focus is on innovation, project management and outcome measurement in paediatric rehabilitation. 



\section{List of publications}




\section{International (peer-reviewed) journals}

Westendorp T, Verbunt JA, de Groot IJM, Remerie SC, ter Steeg A, Smeets RJ. Multidisciplinary Treatment for Adolescents with Chronic Pain and/or Fatigue: Who Will Benefit? Pain Pract. 2017;17(5):633-642.

Westendorp T, Verbunt JA, Remerie SC, de Blécourt AC, van Baalen B, Smeets RJ. Social functioning in adulthood: Understanding long-term outcomes of adolescents with chronic pain/fatigue treated at inpatient rehabilitation programs. Eur J Pain. 2016;20(7):1121-1130.

Voerman JS, Remerie S, Westendorp T, Timman R, Busschbach JJ, Passchier J, de Klerk C. Effects of a Guided Internet-Delivered Self-Help Intervention for Adolescents With Chronic Pain. J Pain. 2015;16(11):1115-1126.

Voerman JS, Vogel I, de Waart F, Westendorp T, Timman R, Busschbach JJ, van de LooijJansen $\mathrm{P}$, de Klerk C. Bullying, abuse and family conflict as risk factors for chronic pain among Dutch adolescents. Eur J Pain. 2015;19(10):1544-1551.

Van Bragt PJ, van Ginneken BT, Westendorp T, Heijenbrok-Kal MH, Wijffels MP, Ribbers GM. Predicting outcome in a postacute stroke rehabilitation programme. Int J Rehabil Res. 2014;37(2):110-117.

Westendorp T, Verbunt JA, Remerie SC, Smeets RJ. Responsiveness of the Child Health Questionnaire-Parent Form in adolescents with non-specific chronic pain or fatigue. Eur J Pain. 2014;18(4):540-547.

Voerman JS, Remerie S, de Graaf LE, van de Looij-Jansen P, Westendorp T, van Elderen I, de Waart F, Passchier J, van Berkel AD, de Klerk C. Early signaling, referral, and treatment of adolescent chronic pain: a study protocol. BMC Pediatr. 2012;12:66.

Buffart LM, Westendorp T, van den Berg-Emons RJ, Stam HJ, Roebroeck ME. Perceived barriers to and facilitators of physical activity in young adults with childhood-onset physical disabilities. J Rehabil Med. 2009;41(11):881-885.

\section{Publications in Dutch journals}

Dommisse-van Berkel AAM, van de Looij-Jansen PM, Voerman JS, Passchier J, WestendorpT, de Graaf, LE, Remerie, S, van Elderen, I, de Klerk, CWat kan de jeugdgezondheidszorg betekenen voor adolescenten met chronische pijn? Tijdschrift voor Gezondheidswetenschappen. 2011;89:69.

Voerman JS, Remerie S, Passchier J, Westendorp T, de Graaf LE, de Klerk C. Move It Now: Een internetbehandeling voor jongeren met onverklaarde chronische pijn. Tijdschrift voor Gezondheidswetenschappen. 2011;89:90.

WestendorpT, Edelaar MJA, Slikker RM, van derWoude LHV. Effectiviteit van multidisciplinaire arbeidstraining bij chronische lage rugklachten. Tijdschrift voor Ergonomie. 2003;23(1):1118. 


\section{Poster presentations}

De Leeuw MJ, Spek B, Verschure S, Van der Ham I, Westendorp T. Daily activities in children with cerebral palsy: factors for change in self-care and mobility capabilities. 29th EACD Congress, Amsterdam, The Netherlands, 2017.

Van Oosten T, Van Vliet M, Nieuwenhuis K, Westendorp T, Van der Ham I. HIPPER: Screening and multidisciplinary treatment for children with a physical disability having continence problems during day and night. 29th EACD Congress, Amsterdam, The Netherlands, 2017.

Westendorp T, Remerie SC, Pangalila RF. 'Back to school!' A rehabilitation treatment approach for adolescents with chronic pain and/or fatigue to optimize school participation. International Study for Pediatric Pain Congress, Seattle, USA, 2015.

Westendorp T, Verbunt JA, Remerie SC, De Blecourt ACE, Van Baalen B, Smeets RJEM. Longterm participation in adulthood of persons who suffered of chronic pain and/or fatigue during their adolescence. International Study for Pediatric Pain Congress, Stockholm, Sweden, 2013.

Westendorp T, Verbunt JA, Ter Steeg A, Remerie SC, Smeets RJEM. Predictors for a successful rehabilitation treatment in adolescents with chronic pain and/or fatigue. International Study for Pediatric Pain Congress, Stockholm, Sweden, 2013.

Voerman JS, Vogel I, De Waart F, Van Busschbach J, Westendorp T, Van de Looij-Jansen P, De Klerk C. Negative life events as predictor of chronic pain among Dutch adolescents. Dutch Pain Society Congress, Ede, The Netherlands, 2013.

Westendorp T, Verbunt JA, Remerie SC, De Craen M, Smeets RJEM. Factors associated with quality of life and school absence in adolescents with nonspecifc chronic pain and/or fatigue International Association for the Study of Pain Congress, Milan, Italy, 2012.

Voerman JS, Remerie SC, Passchier J, Westendorp T, De Graaf LE, De Klerk C. Guided selfhelp via Internet for Adolescents with Chronic Pain: A study protocol. Second symposium for Pediatric Psychology, Nijmegen, The Netherlands, 2011.

Westendorp T, De Groot IJM, Remerie SC, Hilberink SR, Post MWM. Inpatient Rehabilitation Treatment of Adolescents with Chronic Nonspecific Musculoskeletal Pain and/or Chronic Fatigue: a Pre-Post Study. International Study for Pediatric Pain Congress, Acapulco, Mexico, 2010. 
$\varphi$ 